\title{
Documentos Estruturados para o Domínio de Aplicação Ensino: Modelagem, Autoria e Apresentação na WWW
}

\author{
João Benedito dos Santos Júnior
}

\section{Orientadora}

Prof ${ }^{\text {a. }}$ Drạ. Maria da Graça Campos Pimentel

\begin{abstract}
-issertação apresentada ${ }^{1}$ ao Instituto de Ciências Matemáticas e de Computação, da Universidade de São Paulo - USP, como parte dos requisitos para obtenção do título de Mestre em Ciências - Area: Ciências de Computação e Matemática Computacional.
\end{abstract}

São Carlos, agosto de 1998

\footnotetext{
${ }^{1}$ Trabalho realizado com apoio financeiro do PICDT/CAPES.
} 
"Tudo vale a pena se a alma não é pequena."

Pablo Neruda

Aos meus pais, João Benedito dos Santos e Maria de Lourdes Santos, e ao meu sobrinho, Gabriel, pelo apoio, amor e compreensão. A Elaine, por entender a minha ausência e pelo bem que a sua presença me faz. 


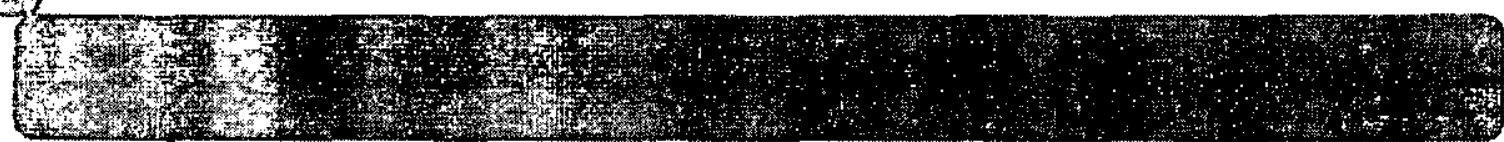

A DEUS, por me conceder saúde, por iluminar meu caminho e por me abençoar na realização de todos os meus deveres.

À Graça, pelo apoio quando da minha chegada a São Carlos, pelo incentivo constante e pela orientação.

Aos professores Edson dos Santos Moreira, Fredy João Valente, José Carlos Maldonado, Maria Cristina Ferreira de Oliveira e Maria da Graça Campos Pimentel, pela amizade e pelos ensinamentos transmitidos durante o período de créditos.

Aos professores da Universidade de Alfenas, Alexandre Martins Dias, Marly Moreira Dias e Hudson Carvalho Bianchini, pela confiança e apoio indispensáveis à minha intenção de cumprir o Programa de Mestrado, e ao Francisco Amorim Pereira pelas "dicas" que tanto me auxiliaram na adaptação a São Carlos e à USP.

Às secretárias da Pós-Graduação, Andressa, Beth, Laura e Marília, pela amizade e presteza com que sempre me atenderam, e pelo jeito humano de tratar a todos os alunos.

A todos os colegas que compartilharam comigo os momentos de alegria e de apreensão, as vitorias e derrotas do período de créditos.

Aos colegas Luís Carlos, Celso Ribeiro, Maria Helena, Renata Barros, Sandra Tutida e Veridiana Salvador, que comigo formaram equipes para desenvolver os trabalhos do período de créditos. Em especial ao Alexandre Della Nina, Luciano Esteves e Renato Haber, que se preocuparam em ser muito mais do que colegas de trabalho.

À colega Mirla, pelo auxílio quando de minha inscrição para o processo de seleção de candidatos ao Programa de Mestrado.

À CAPES, através do Programa Institucional de Capacitação de Docentes, pelo apoio financeiro concedido.

À Elaine, o meu agradecimento especial, pela sua amizade, pelo seu amor, pela sua preocupação e pelos seus sorrisos, que tornaram a minha vida mais completa durante o Programa de Mestrado. 
ÍNDICE DE FIGURAS

vi

ÍNDICE DE TABELAS.................................................................................... viii

RESUMO .................................................................................................................... ix

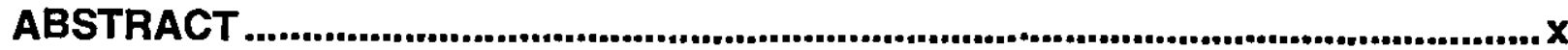

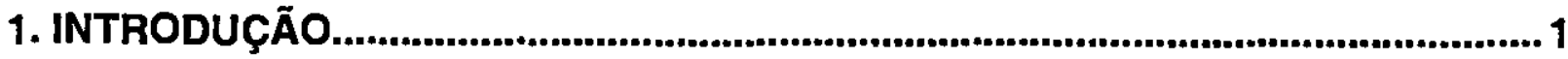

1.1. Considerações iniciais...................................................................................................... 1

1.2. Motivaç̃es ........................................................................................................

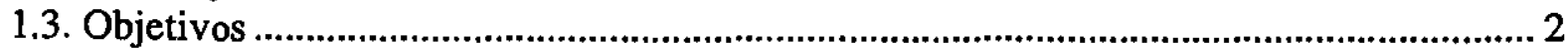

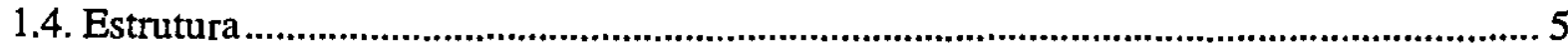

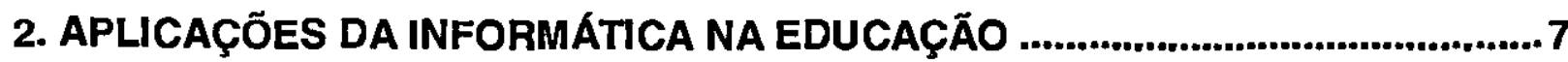

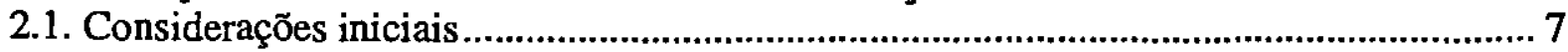

2.2. Ambientes de Aprendizagem ...................................................................................... 7

2.2.1. MAPHE: metodologia de apoio ao projeto de hipertextos educacionais ..............................

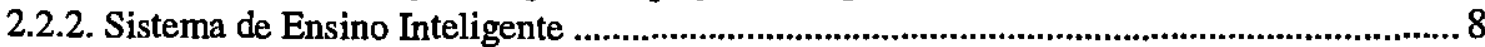

2.2.3. Desenvolvimento e avaliação de duas abordagens de ambientes de ensino........................ 9

2.2.4. SASHE: autoria de aplicações hipermídia para o ensino .................................................. 9

2.2.5. Desenvolvimento de uma ferramenta para correção automática de provas na WWW .... 10

2.2.6. Interface de navegação em hiperdocumentos para aplicaçōes educacionais.....................11

2.2.7. Projeto MatWeb: usando recursos computacionais no ensino de matemática ..................11

2.2.8. Projeto de um hiperdocumento interativo para alunos de $5^{\mathrm{a}}$. série...................................12

2.2.9. QSabe: trocando experiências sobre informática em uma rede de educadores ..................113

2.2.10. Experiência do uso da WWW para o ensino da língua portuguesa ................................. 14

2.2.11. Projeto NetAula: complementação de aulas pela Internet................................................15

2.3.Ferramentas para elaboração de cursos .................................................................. 15

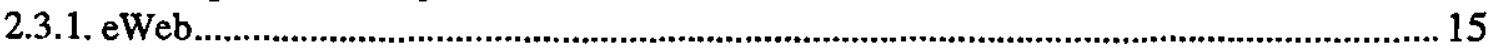

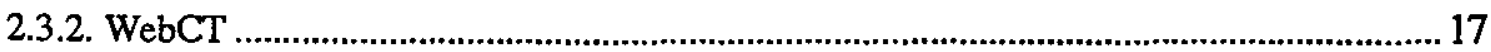

2.4.Ferramentas para autoria de questões eletrônicas......................................................... 18

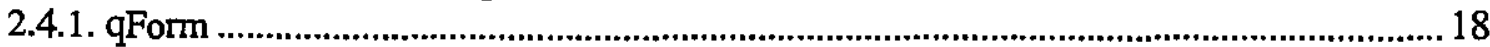

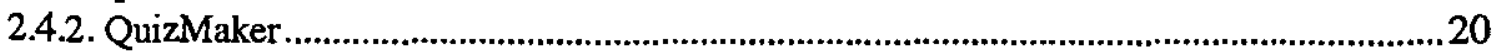

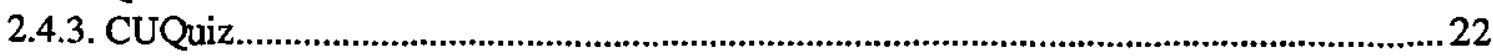

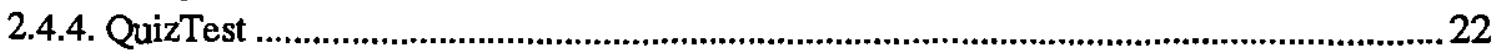

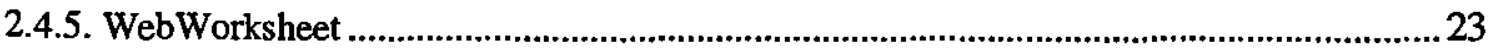

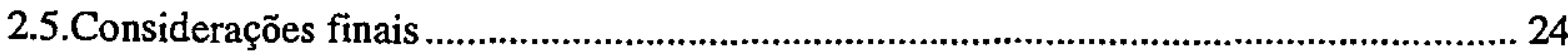

3. INTERAÇÃO USUÁRIO-HIPERTEXTO

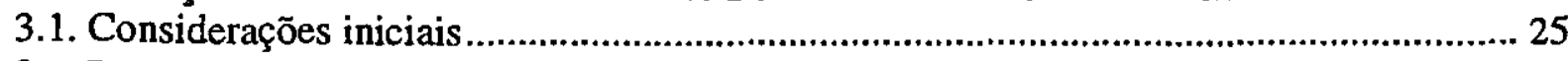

3.2. Interação usuário-computador tradicional ……...................................................... 25

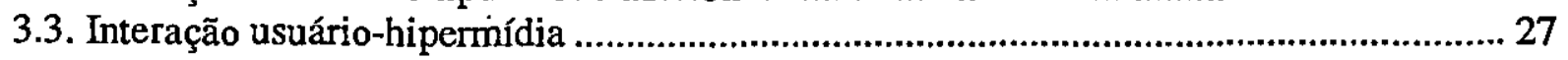

3.4. Aspectos de interação em ambientes de ensino ……................................................... 28

3.5. Problemas com a autoria de material didático para a WWW ......................................... 29

3.6. Interação do usuário no ambiente WWW: utilidade e usabilidade ................................ 30

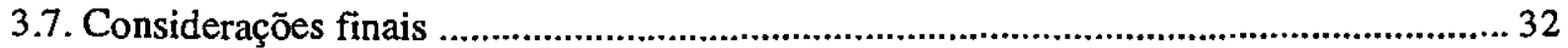


4. HIPERDOCUMENTOS HTML: MODELAGEM E INTERAÇÃO.............................33

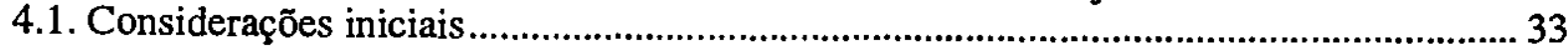

4.2. Hiperdocumentos HTML simples e estendidos ......................................................... 33

4.3. Modelagem de um sistema de informação baseado na WWW ........................................ 38

4.3.1. Análise E-R do domínio do problema ..........................................................................39

4.3.2. Análise de cenário ………...............................................................................................39

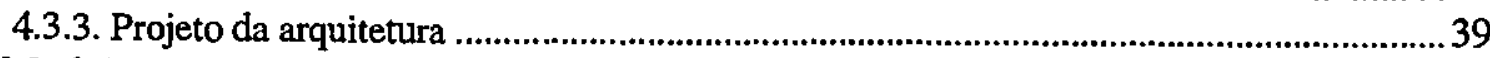

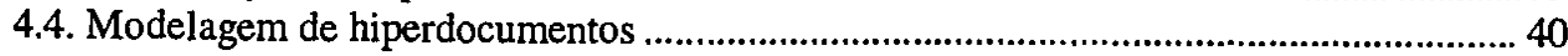

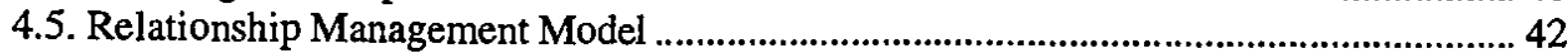

4.5.1. Relationship Management Data Model .......................................................................... 43

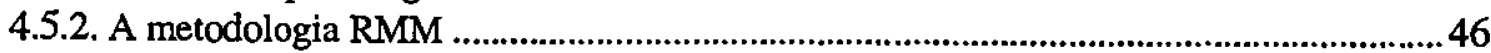

4.5.3. Projeto das entidades e relacionamentos (E-R) ……................................................4

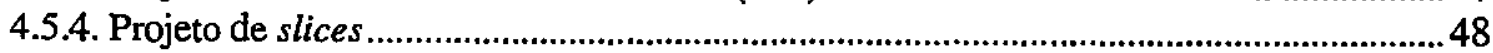

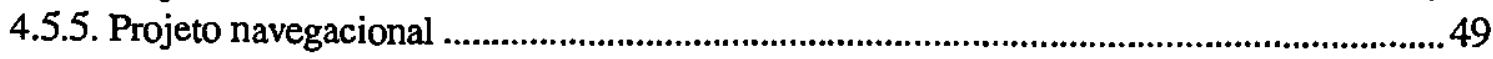

4.5.6. Projeto e construção da interface do usuário ..................................................................5

4.6. Considerações finais .............................................................................................. 51

5. FERRAMENTAS PARA AUTORIA DE MATERIAL DIDÁTICO ............................53

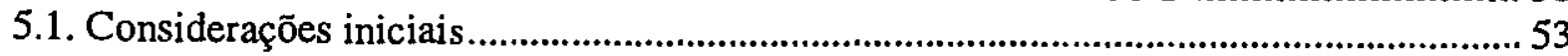

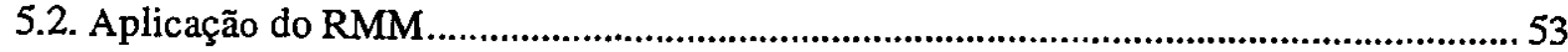

5.3. Um conjunto de ferramentas para disponibilização de material didático .......................... 57

5.4. Estrutura dos hiperdocumentos ......................................................................................... 59

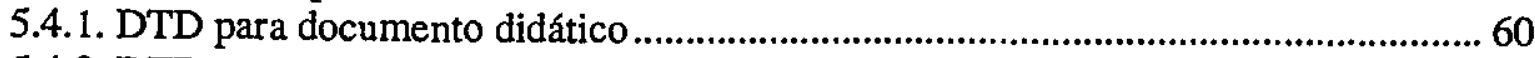

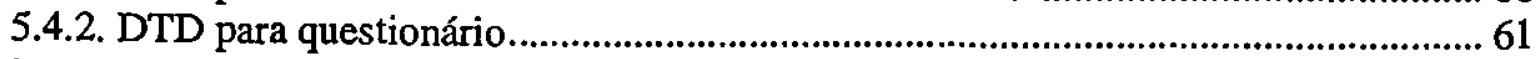

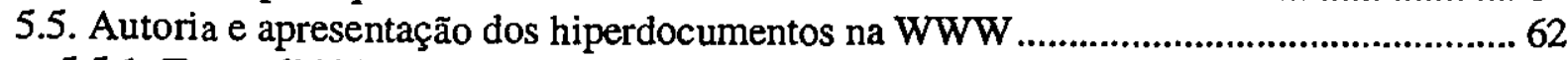

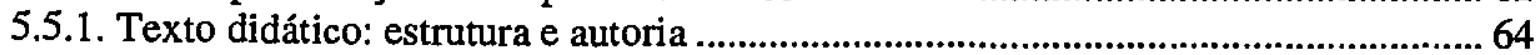

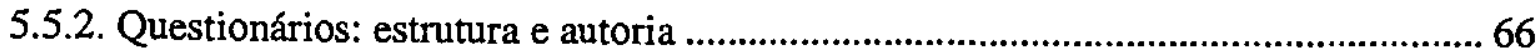

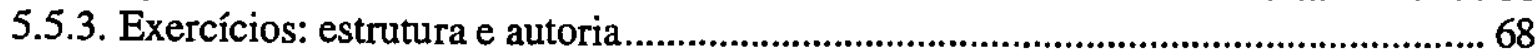

5.5.4. Mecanismo para disponibilização do material didático na WWW............................69

5.6. Ambientes de apresentação do material didático ao estudante .......................................... 71

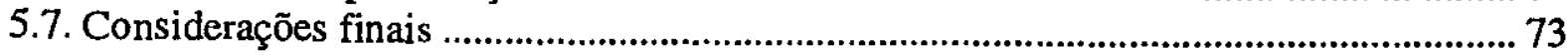

6. ANÁLISE DAS FERRAMENTAS DE AUTORIA PROPOSTAS..............................74

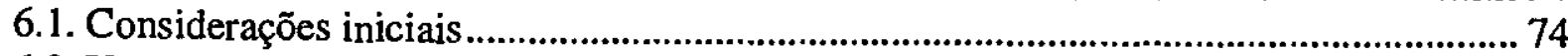

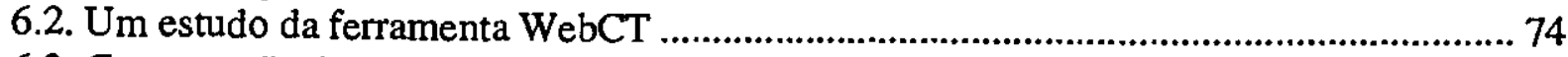

6.3. Comparação do WebCT com as ferramentas do contexto deste trabalho......................... 83

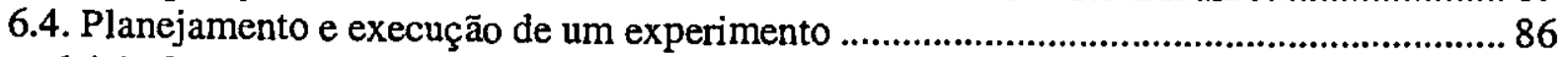

6.4.1. O material didático proposto............................................................................... 87

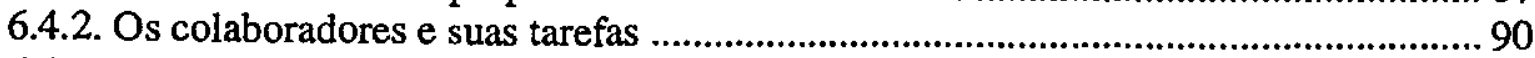

6.4.3. Apresentação e discussão dos resultados ............................................................... 92

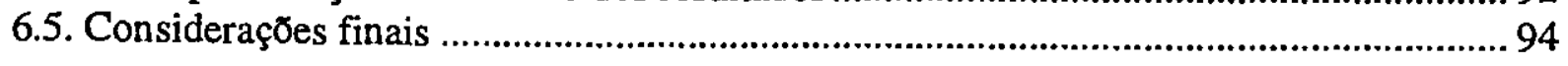

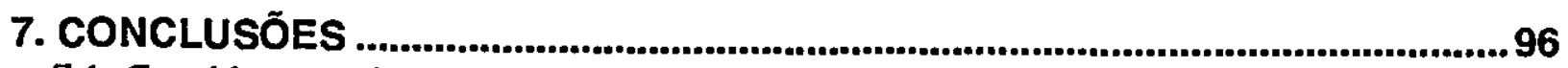

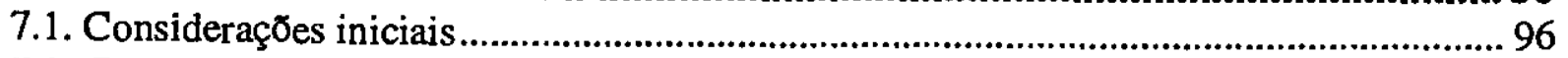

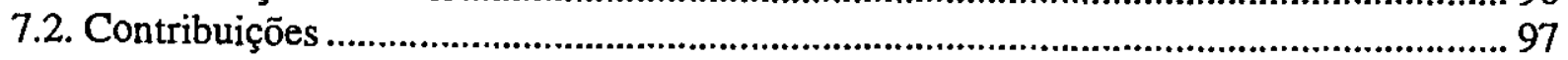

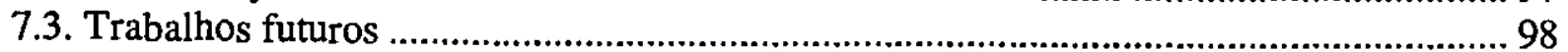

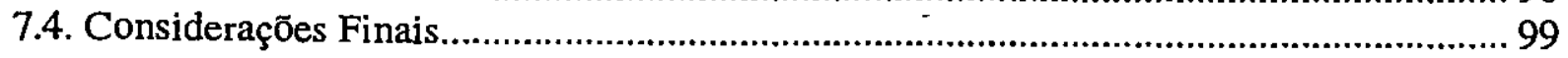

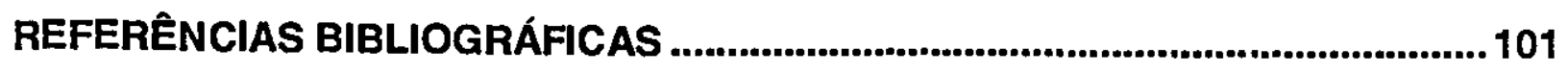




\section{ÍNDICE DE FIGURAS}

Figura 1.1 - Arquitetura básica dos componentes do ambiente WWW 3

Figura 1.2 - Arquitetura básica proposta para o domínio de aplicação Ensino 4

Figura 2.1 - Ambiente de apresentação do projeto LUAR ......................................................... 12

Figura 2.2 - Ambiente de apresentação do projeto ConVer......................................................... 14

Figura 2.3a - Módulo Fórum do eWeb .................................................................................... 16

Figura 2.3b - Módulo de criação de questões do eWeb ......................................................... 16

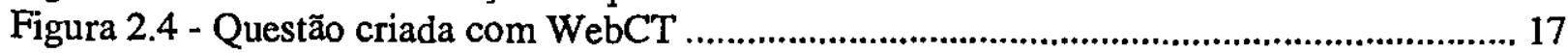

Figura 2.5 - Página de gerenciamento de cursos do WebCT ...................................................... 18

Figura 2.6 - Formato do arquivo de testes usado por qForm .................................................. 19

Figura 2.7 - Página de testes criada pela ferramenta qForm ...................................................... 20

Figura 2.8a - Documento para criação de testes do QuizMaker ............................................... 21

Figura 2.8b - Documento para apresentação de testes ............................................................. 21

Figura 2.9 - Página de testes de múltipla escolha gerada pela ferramenta CUQuiz ................. 22

Figura 2.10 - Documento para apresentação de testes criados com a ferramenta QuizTest...... 23

Figura 3.1 - Modelo de representação da memória do ser humano (Preece, 1994) ................... 26

Figura 4.1 - Exemplo de um documento HTML simples ..........................................................34

Figura 4.2 - Apresentação em um browser do documento correspondente à Figura 4.1........... 35

Figura 4.3 - Exemplo de um documento contendo applet JAVA................................................ 37

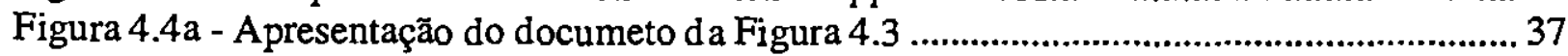

Figura 4.4b - Apresentação do documento da Figura 4.4a após interação usuário-applet ........ 37

Figura 4.5 - Primitivas de modelagem do RMDM .................................................................. 45

Figura 4.6 - Casos de uso das primitivas de acesso RMDM..................................................... 46

Figura 4.7 - Metodologia RMM e o ciclo de desenvolvimento de software .............................. 47

Figura 5.1 - Passo 1: Diagrama E-R para o domínio de aplicação Ensino ................................. 54

Figura 5.2 - Passo 1: Diagrama E-R para a entidade curso da arquitetura proposta .....................5 54

Figura 5.3a - Passo 2: Diagrama de slices para o domínio de aplicação Ensino .......................... 55

Figura 5.3b- Passo 2: Diagrama de slices para o domínio de aplicação Ensino ..........................55

Figura 5.3c - Passo 2: Diagrama de slices para o domínio de aplicação Ensino ...........................56

Figura 5.4 - Passo 3: Diagrama RMDM para o domínio de aplicação ensino ............................. 56

Figura 5.5 - Relacionamento entre as ferramentas de software propostas.................................5

Figura 5.6 - Arquitetura completa proposta para o domínio de aplicação Ensino .......................5

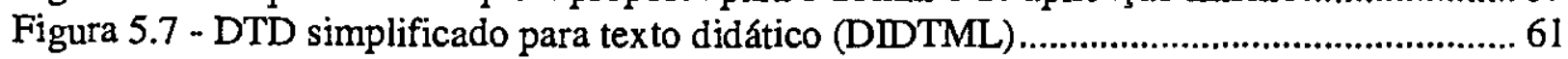

Figura 5.8 - DTD simplificado para questionário (QuestML) ..................................................6. 62

Figura 5.9a - Interface da ferramenta HyperBuilder para seleção de layout ............................... 65

Figura 5.9b - Um hiperdocumento de texto didático em ediça̧o na ferramenta HyperBuilder .. 65

Figura 5.10 - Apresentação de um hiperdocumento de texto didático estruturado......................65

Figura 5.11 - Mecanismo de inserção de questionários e exercícios no texto didático ............... 66

Figura 5.12a - Questão múttipla-escolha sendo construída com a QuestBuilder ........................67 67 
Figura 5.12b - Questão de matching sendo construída com a QuestBuilder 67

Figura 5.13a - Questão falso ou verdadeiro sendo construída com a QuestBuilder ..................... 67

Figura 5.13b - Questão dissertativa sendo construída com a QuestBuilder............................... 67

Figura 5.14 - Modo de visualização das questōes em construção ............................................. 68

Figura 5.15a - Modo de seleção de layout da ferramenta TaskBuilder .....................................6.69

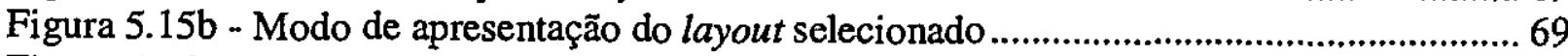

Figura 5.16a - Um teste de múltipla-escolha sendo construído na ferramenta TaskBuilder ..... 69

Figura 5.16b - Um layout completo construído ....................................................................... 69

Figura 5.17 - Mecanismo de publicação do material didático no ambiente WWW ................. 70

Figura 5.18a - Ambiente inicial do material didático apresentado ao estudante ....................... 71

Figura 5.18b - Ambiente apresentado ao estudante após acionado link da lista de tópicos....... 71

Figura 5.19 - Ambiente apresentado ao estudante após ser acionado um subitem do texto...... 72

Figura 5.20 - Exercício apresentado ao estudante................................................................ 72

Figura 5.21 - Questionário, baseados em applet JAVA, apresentado ao estudante................... 73

Figura 6.1 - WebCT - Módulo de construção da página de abertura do curso ........................... 75

Figura 6.2 - WebCT - Módu lo de gerenciamento dos arquivos que compõem o curso ............ 76

Figura 6.3 - WebCT - Módulo de definição do layout dos componentes do curso ................... 76

Figura 6.4 - WebCT - Módulo de edição dos itens e subitens do conteúdo do curso................ 77

Figura 6.5 - WebCT - Módulo de construção do layout dos itens do conteúdo do curso........... 77

Figura 6.6 - WebCT - Módulo de construção do glossário...................................................... 78

Figura 6.7 - WebCT - Módulo de construção de índices complementares ................................ 78

Figura 6.8 - WebCT - Módulo para construção de referências bibliográficas........................... 79

Figura 6.9 - WebCT - Módulo para autoria de questionários .................................................... 80

Figura 6.10 - WebCT - Módulo para inserção de objetivos de uma página do curso................ 80

Figura 6.11 - WebCT - Módulo para edição das páginas HTML geradas................................. 81

Figura 6.12 - WebCT - WebCT - Módulo para cadastramento e controle do estudante ........... 81

Figura 6.13 - WebCT - Módulo para uso do serviço de troca de mensagens ............................. 82

Figura 6.14 - WebCT - Módulo para construção de conferências e reuniões............................ 82

Figura 6.15 - Conteúdo do documento inicial do material didático......................................... 88

Figura 6.16 - Conteúdo do documento "Introdução" do material didático ................................. 88

Figura 6.17 - Conteúdo do documento "Pilhas" do material didático....................................... 89

Figura 6.18 - Conteúdo do documento "Filas" do material didático........................................ 89

Figura 6.19 - Conteúdo do documento "Lista de Exercícios" do material didático................... 90

Figura 7.1 - Arquitetura básica proposta para o domínio de aplicação ensino ..........................99 98 


\section{ÍNDICE DE TABELAS}

Tabela 4.1 - Indicação de uso do RMM.

Tabela 6.1 - Comparação das características da ferramenta HyperBuilder com o WebCT........ 85

Tabela 6.2 - Comparação das características da ferramenta QuestBuilder com o WebCT ........ 85

Tabela 6.3 - Comparação das características da ferramenta TaskBuilder com o WebCT.......... 86

Tabela 6.4 - Tempo dos alunos utilizando a ferramenta HTMLed para autoria .......................... 92

Tabela 6.5 - Tempo dos alunos utilizando as ferramenta de autoria propostas .......................... 92

Tabela 6.6 - Tempo dos professores de Computação utilizando a ferramenta HTMLed ........... 93

Tabela 6.7 - Tempo dos professores de Computação utilizando as ferramentas de autoria ....... 93

Tabela 6.8 - Tempo dos professores de Farmácia utilizando as ferramentas de autoria............. 93 
A aplicação da informática na educação tem sido alvo de investigação devido à importância da exploração do uso da tecnologia nos processos de ensino e aprendizagem. Em adição, o uso da Internet tem se expandido em aplicaçōes para o domínio ensino. Neste contexto, esta dissertação apresenta aspectos de projeto, especificação e implementação de um conjunto de ferramentas que auxiliam a autoria e disponibilização de material didático no ambiente World Wide Web (WWW). Como motivação, sistemas e aplicaçōes recentes são apresentados e o modelo de hiperdocumentos atualmente utilizado na WWW é discutido. O Relationship Management Model (RMM) é então utilizado para a modelagem do conjunto de ferramentas de autoria. Como passo seguinte da modelagem, são discutidas as vantagens do uso de SGML como uma técnica de especificação formal, e apresentadas as especificações para os documentos suportados pelas ferramentas de autoria. Após uma discussão sobre os aspectos da interação usuário-hipertexto, são apresentadas as ferramentas de autoria implementadas. Após uma discussão dos pontos fortes e fracos das ferramentas de autoria implementadas quando comparadas a um ambiente completo para autoria de material didático, são relatados os resultados de um experimento preliminar de usabilidade. Finalmente, são apresentados alguns projetos de pesquisa como continuidade do trabalho aqui reportado. 
The application of computer in education has been under investigation due the importance of exploiting such a technology in the teaching and learning processes. The wide spread use of Internet has expanded the interest in such application. In this context, this dissertation presents aspects of design, specification and implementation of a set of tools aimed at authoring and delivering didactic material in the World Wide Web environment (WWW). As motivation, recent systems and applications are presented and the model of the hyperdocuments currently used in the WWW is discussed. The Relationship Management Model (RMM) is then used to provide a design model for a set of authoring tools. As a follow up of the modeling step, the advantages of the use of SGML as a formal specification technique is discussed, and specifications for the documents supported by the authoring tools are presented. After a discussion on aspects of user-hypertext interaction, the authoring tools build are presented. After a discussion of the strengths and weakness of the tools when compared to a complete off-theshelf suit, results from a preliminary usability experiment are reported. Finally, the several research projects under development as a continuity of the this work are presented. 


\section{INTRODUÇÃO}

\subsection{Considerações iniciais}

A literatura demonstra que a aplicação da informática na educação tem sido alvo de intensas pesquisas devido à importância da utilização de ferramentas computacionais como apoio ao processo ensino-aprendizagem. $O$ uso da informática na educação constitui um novo paradigma que é justificado por inúmeros autores, que reforçam a aplicação dos computadores como agentes que contribuem para a construção do conhecimento.

Projetos que visam estimular o uso dos computadores nas escolas têm sido propostos e implementados, e experiências ao nível mundial têm demonstrado que o uso de sistemas de computação no ambiente de ensino permite o enriquecimento do material didático que é apresentado ao estudante, por exemplo (WebCT, 1996a; Greenfield, 1987).

Em termos de Brasil, algumas aplicações têm sido desenvolvidas, mas não se atingiu ainda a intensidade de uso de vários países. O uso da Internet apresenta-se como um fator importante a ser explorado (Lucena, 1997).

Neste capítulo, são apresentados os objetivos deste projeto e as motivações que conduzem à proposta de uma arquitetura de software, baseada em documentos estruturados com SGML, que apóie a construção e a disponibilização de material didático no ambiente World Wide Web (WWW).

\subsection{Motivações}

Atualmente existem duas categorias bem definidas de aplicação dos computadores no ensino. $\mathrm{O}$ aprendizado assistido por computador (Computer Aided Learning - CAL) focaliza o uso dos computadores como ferramenta para promoção do aprendizado, sendo visto como um agente que, inserido em ambientes de ensino, promove uma nova forma de transmissão de conteúdos. Por outro lado, o treinamento baseado em computador (Computer Based Training - CBT) 
focaliza o uso dos computadores como facilitadores do aprendizado de tarefas específicas em um determinado domínio de conhecimento, inclusive com o uso de simulações (Barker, 1992).

Conforme citado em (Castro, 1997) com relação à realidade brasileira, os computadores, quando empregados, o têm sido muito mais em casos isolados do que em ambientes de ensino realmente caracterizados como CBT ou CAL. De modo geral, este fato é consequiência da falta de um processo metódico, suportado por ferramentas de autoria adequadas à construção e disponibilização de material didático em todos os níveis de ensino. Outro fator limitante tem sido, naturalmente, o custo de equipamentos e software.

Neste ponto, é importante ressaltar que muitas ferramentas têm sido propostas e implementadas para apoiar a elaboração de material didático, observando-se principalmente a autoria pelo professor e a navegação do estudante no material didático apresentado. São exemplos, o ambiente SASHE (Nunes et al., 1997) e as ferramentas propostas no contexto do projeto HyDTS (Moreira et al., 1995). Em adição, projetos de amplo espectro propostos ao nível nacional como o Kidlink (Kidlink, 1996) e AulaNet (AulaNet, 1997) estão inseridos no contexto da disponibilização de material didático na WWW.

Um ambiente com características similares está em desenvolvimento no contexto do projeto HyDTS, no qual este trabalho se insere.

A grande diferença, entretanto, é o uso de documentos estruturados de acordo com padrões abertos, que promovem o reuso e o intercâmbio de informações associadas por outras ferramentas de autoria e/ou ambientes de apresentação, estendendo assim as possibilidades de provimento de material didático em ambientes de ensino.

\subsection{Objetivos}

O ambiente WWW é caracterizado, basicamente, pela publicação de hiperdocumentos simples construídos de acordo com a linguagem HTML (HyperText Markup Language) (HTML, 1992; HTML, 1997). Esses hiperdocumentos podem ser incrementados através da inserção de applets JAVA e linhas de código em JAVAScript, além de ser permitido o acesso a bases de dados 
específicas, utilizando-se para tal recursos como JDBC (Java DataBase Connectivity). A Figura 1.1 apresenta uma arquitetura genérica dos componentes mais comumente explorados na WWW. A figura ilustra que um autor tem à sua disposição ferramentas que exigem conhecimentos especializados em computação, especialmente em JAVA, JAVAScript e tecnologias afins:

- para a autoria de material, o autor deve, inicialmente, conhecer o conjunto de elementos que forma a linguagem HTML e, então, codificar documentos a partir de um editor de textos ou ambiente de desenvolvimento;

- de acordo com essa arquitetura convencional, os documentos construídos pelo autor podem se tornar complexos de acordo com a estrutura de navegação definida para esses documentos;

- caso sejam necessárias simulações e interação do usuário em tempo de apresentação dos documentos, o autor pode implementar applets JAVA e código JAVAScript e inserí-los nos documentos;

- finalmente, o autor deve conhecer mecanismos de transferência de arquivos para disponibilizar o material em um servidor de documentos HTML, fomecidos de acordo como o protocolo HTTP (HyperText Transfer Protocol) (HTTP, 1992), para posterior apresentação ao usuário final.

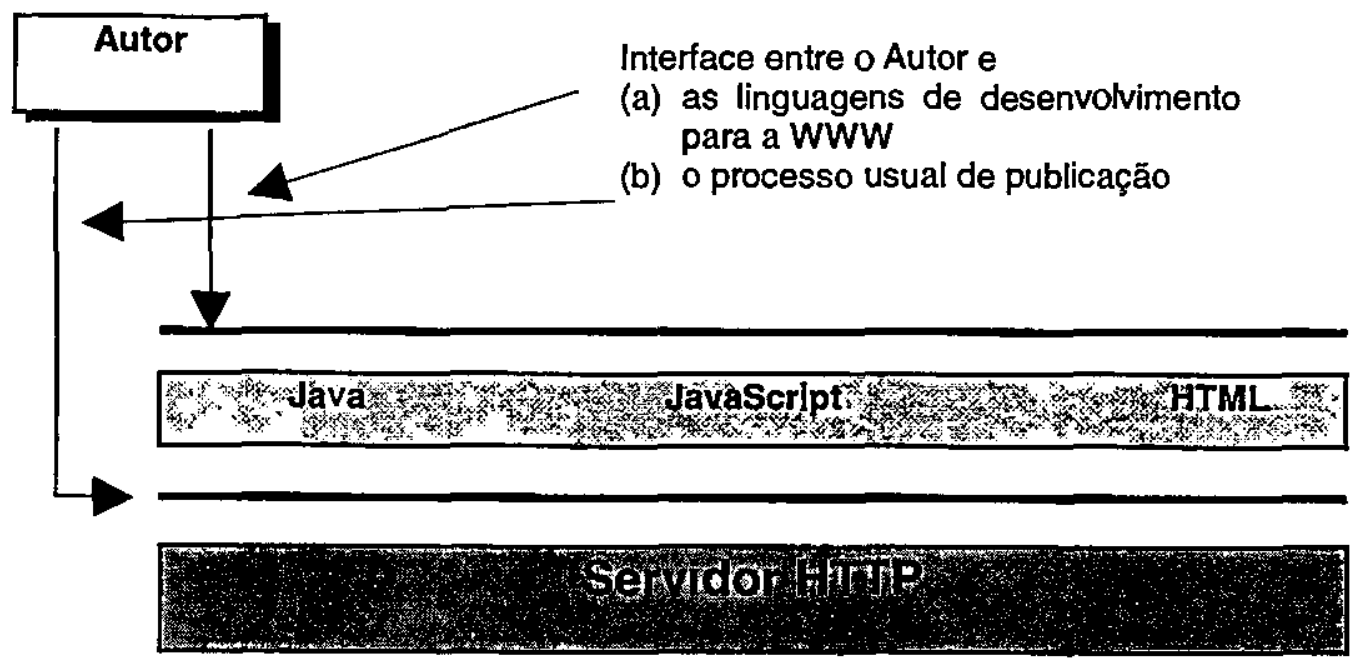

Flgura 1.1 - Arquitetura básica dos componentes do ambiente WWW

Observa-se, então, que utilizando os componentes usuais de desenvolvimento, o autor está exposto às complexidades que tais componentes exigem. 
O trabalho aqui reportado propõe a implementação de ferramentas que isolem o autor dos detalhes de criação de hiperdocumentos com o uso das linguagens de desenvolvimento para a WWW. Assim, se fazem necessárias a modelagem e implementação de ferramentas para a elaboração e disponibilização do material didático na WWW. Essas ferramentas correspondem a uma nova camada de software inserida na arquitetura convencional e se baseiam na especificação de documentos estruturados proposta por Pimentel et al. (Pimentel et al, 1998), conforme ilustra a Figura 1.2.

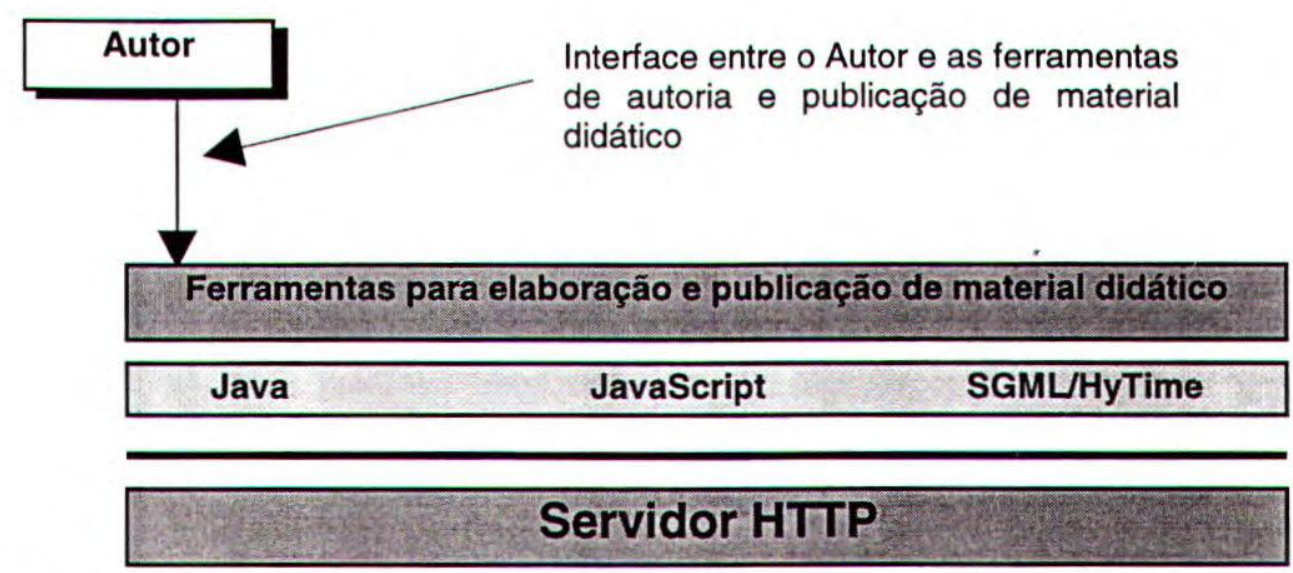

Figura 1.2 - Arquitetura básica proposta para o domínio de aplicação Ensino

No contexto da arquitetura proposta, as ferramentas oferecidas ao autor devem possuir as seguintes funcionalidades:

- definição de estruturas de hiperdocumentos baseadas em um índice de tópicos do material didático, usando SGML para usufruir das vantagens do padrão para documentos estruturados abertos;

- geração automática de roteiros de navegação em relação ao índice de tópicos;

- construção e disponibilização de questionários de avaliação, no qual poderão ser inseridas questões descritivas, de múltipla escolha, falso e verdadeiro e questões de relacionamento de opções (matching);

- construção de exercícios contendo imagens, textos e testes de múltipla escolha, os quais podem ser inseridos no material didático;

- provimento de mecanismos para publicação de hiperdocumentos de textos didáticos, questionários e exercícios em um servidor HTTP (HyperText Transfer Protocol), de maneira transparente ao autor. 
Ainda no contexto da arquitetura proposta, ferramentas para uso pelo estudante também se fazem necessárias, tendo as seguintes funcionalidades:

- um ambiente para apresentação dos hiperdocumentos didáticos através do uso de programas de apresentação (browsers) de uso disseminado;

- um ambiente para apresentação de questionários que permita a interação do usuário para o fornecimento de respostas, e o posterior envio destas para uma base de dados a ser utilizada pelo professor através de ferramental específico;

- um ambiente para visualização dos exercícios criados como complemento ao texto didático.

$\mathrm{Na}$ elaboração de material didático, deve-se observar a importância da definição de hiperdocumentos estruturados como um agente facilitador da navegação pelo estudante, buscando uma ređução dos problemas inerentes à tecnologia de hipertextos: sobrecarga cognitiva e desorientação (Conklin, 1987).

O ponto mais importante, que difere esta proposta de outras da literatura, é o uso de hiperdocumentos didáticos estruturados como facilitadores do processo de elaboração de material didático, por exemplo em termos do armazenamento e recuperação dos hiperdocumentos em bases de dados. Neste contexto, a especificação dos hiperdocumentos didáticos através de SGML (Standard Generalized Markup Language) (ISO, 1986), adotado neste trabalho, não só permite o armazenamento, recuperação e apresentação eficientes, mas também a possibilidade de reuso e intercâmbio dos hiperdocumentos com outras ferramentas de autoria e ambientes de apresentação.

\subsection{Estrutura}

Esta dissertação está organizada de forma a apresentar o contexto teórico no qual o trabalho está inserido, bem como a implementação da arquitetura de software proposta. No Capítulo 2 são apresentadas algumas iniciativas relevantes de aplicação da informática em ambientes de ensino, inclusive as que utilizam o ambiente WWW como suporte à disponibilização de material didático e ao processo de avaliação do aprendizado. 
Uma visão geral de conceitos relativos à interação usuário-hipertexto é apresentada no Capítulo 3 , onde são abordados também os aspectos da modelagem de interfaces centradas no usuário e orientadas às tarefas que o mesmo deve realizar, e sua relevância na autoria e apresentação de material didático.

No Capítulo 4 são discutidos aspectos da modelagem e utilização de hiperdocumentos, especialmente aqueles formatados em conformidade com a linguagem HTML para o ambiente World Wide Web. Em adição, são apresentados os aspectos gerais para a construção de sistemas de informação baseados no ambiente WWW e também uma visão geral da metodologia RMM (Relationship Management Model).

No Capítulo 5 é apresentada a modelagem do domínio de aplicação ensino através do RMM, bem como a estrutura dos documentos didáticos modelada em conformidade com o padrão SGML. Em seguida, as ferramentas para autoria e publicação de material didático implementadas são discutidas, ressaltando-se a funcionalidade de cada uma delas dentro do contexto de aplicação no qual este projeto se insere.

Uma discussão das facilidades das ferramentas implementadas em relação a outras existentes é apresentada no Capítulo 6. Em adição, o planejamento e a execução de um experimento preliminar de uso das ferramentas para autoria e publicação de material didático são relatados, bem como a discussão dos resultados obtidos.

No Capítulo 7 são observadas as contribuições deste trabalho e considerações sobre os trabalhos futuros. 


\subsection{Considerações iniciais}

Conforme citado, por exemplo em (Schneider, 1995), muitas iniciativas têm sido efetuadas no sentido de explorar o uso de recursos computacionais em ambientes de ensino, inclusive com o desenvolvimento de ferramentas para autoria e disponibilização de material didático no ambiente WWW. Neste capítulo, são apresentadas algumas dessas iniciativas, ao nível de Brasil e exterior, consideradas relevantes por explorarem os aspectos multidisciplinares acolhidos pelo ambiente distribuído da WWW, que permitem o seu uso para os mais diversos propósitos em termos do provimento de informações cujo domínio de aplicação seja o ensino.

Na Seção 2.2 são apresentadas algumas iniciativas brasileiras que exploram a WWW para disponibilização de material didático. Na Seção 2.3 são apresentadas algumas ferramentas acessadas através de documentos HTML e que se destinam à elaboração e disponibilização de cursos na WWW. Na Seção 2.4 são apresentadas ferramentas que utilizam a WWW como suporte à autoria e disponibilização de questionários.

\subsection{Ambientes de Aprendizagem}

Nesta seção são relatados alguns dos trabalhos brasileiros que se primam pela implementação de ambientes computacionais para apoio ao processo ensino-aprendizagem. Estes trabalhos, abrangem metodologias de desenvolvimento, ferramentas para autoria e apresentação de material didático, e aplicações específicas.

\subsubsection{MAPHE: metodologia de apoio ao projeto de hipertextos educacionais}

Gomes Pimentel propõe uma metodologia para o projeto de hiperdocumentos educacionais baseada em quatro etapas: planejamento, modelagem, implementação e testes (Pimentel, 1997). A etapa de modelagem é apresentada em termos da construção de quatro modelos:

- modelo orientado a conceitos, que é usado para estruturar o conteúdo a ser abordado no hipertexto; 
- modelo de páginas, onde representam-se as páginas do hiperdocumento e os possíveis caminhos entre elas;

- modelo de padrões, usado para definir a interface com o usuário;

- ferramentas navegacionais, onde são planejados os mecanismos que auxiliarão os leitores em sua localização e navegação.

Além da divisão das etapas e modelos, é apresentado o esquema de notação gráfica para modelagem. Não foram relatados experimentos de aplicação da metodologia, porém comentou-se a implementação futura de uma ferramenta CASE que facilitará a conversão de hiperdocumentos de plataformas específicas, tais como ToolBook, para a plataforma WWW.

A metodologia MAPHE é relevante no sentido do fornecimento de um framework específico para hiperdocumentos didáticos, considerando, por exemplo aspectos específicos da navegação pelo estudante em ambientes de ensino. Entretanto, é necessário que se aplique, efetivamente, a metodologia MAPHE na modelagem de hiperdocumentos educacionais para que se observe se os modelos propostos são realmente eficazes.

\subsubsection{Sistema de Ensino Inteligente}

O Sistema de Ensino Inteligente, SEI, proposto por Tadesco et al., é apresentado como uma arquitetura composta por agentes, tais como controlador, tutor e comunicador, permitindo a disponibilização de material didático para um determinado domínio de aplicação, bem como a conseqüente navegação pelo estudante no ambiente WWW (Tadesco et al., 1997). É caracterizado como sendo um Sistema Tutor Inteligente, STI, por permitir apresentar a tutoria ao estudante e permitir que este construa o conhecimento através de regras de interação com o conteúdo do material didático.

De modo geral, os STIs são implementados em plataformas específicas, rodando em modo isolado. A grande contribuição do trabalho proposto por Tadesco é o uso da linguagem JAVA na implementação do SEI, permitindo o uso do tutor inteligente nas mais diversas plataformas que suportam o ambiente da WWW. 
De modo geral, o uso da linguagem JAVA como ferramenta para implementação do SEI é relevante por estender a aplicabilidade do STI. No entanto, é válido observar que um framework deve ser especificado para o domínio de aplicação ensino, no qual deve-se delinear aspectos de modelagem e as formas de extensão do STI em relação aos recursos providos pelo ambiente da WWW.

\subsubsection{Desenvolvimento e avaliação de duas abordagens de ambientes de ensino}

Silveira apresenta duas versões do ambiente Eletrotutor, que se destina ao ensino da Eletrodinâmica. Neste contexto, é discutida uma versão original stand-alone e, em seguida, uma aplicação utilizando como suporte a WWW (Silveira et al., 1997). A princípio, manteve-se o mesmo conteúdo didático nas duas versões. Foram realizados experimentos com 149 alunos que, divididos em três grupos, utilizaram uma das versōes do sistema tutor ou tiveram aulas convencionais com um professor. Em seguida, aplicou-se uma prova com 10 (dez) questões sobre $o$ assunto.

Para avaliação dos resultados foram aplicados métodos estatísticos. Como resultado, observou-se que tanto a média dos alunos que utilizaram a versão stand-alone do tutor quanto a média dos alunos que utilizaram a versão WWW do tutor foram inferiores àquelas dos alunos que participaram de aulas convencionais com um professor.

O trabalho apresentado por Silveira et al. é relevante, não diretamente pelas implementações, mas, sobretudo pelo uso de uma metodologia na realização de um experimento formal, dada a importância da realização de experimentos quando se propõe ferramentas para ambientes de ensino. Evidentemente, o resultado obtido confirma a teoria de que os materiais didáticos apresentados através do computador devem ser utilizados como ferramenta de apoio ao processo de ensino-aprendizagem, não se admitindo a substituição por completo do professor e/ou tutor.

\subsubsection{SASHE: autoria de aplicações hipermídia para o ensino}

O SASHE, proposto por Nunes et al., é apresentado como um ambiente de autoria e navegação em hiperdocumentos para aplicações em ensino (Nunes et al., 1997). De modo geral, são apresentados os recursos hipermídia estendidos do modelo MCA para hiperdocumentos de 
ensino. O modelo MCA é um modelo conceitual de dados hipermídia que tem como principal característica o tratamento de nós de hiperdocumentos que podem estar recursivamente aninhados (Soares et al., 1994). Nunes et al. propõem a construção de roteiros flexíveis que permitem ao autor definir estratégias e sequiências de aprendizado que o estudante deve observar quando do processo de navegação pelos hiperdocumentos. O protótipo da ferramenta SASHE já foi experimentado por alguns usuários-autores, de cujas observações estão sendo extraídas propostas de modificação e extensão.

Atualmente, módulos estão sendo pesquisados e agregados ao SASHE, tais como a possibilidade de inserção de materiais didáticos do ambiente WWW como um contexto na hiperbase SASHE.

Observa-se que o SASHE é um ambiente local para aplicação no ensino e, apesar de ter sua relevância em relação aos seus propósitos, a ausência de mecanismos de distribuição da hiperbase restringe o seu uso. Em adição, o uso de uma estrutura proprietária para os hiperdocumentos dificulta o intercâmbio destes com outras ferramentas de autoria e ambientes de apresentação. Esses problemas têm sido investigados por diversas pesquisas, por exemplo em (Rodrigues \& Soares, 1998).

\subsubsection{Desenvolvimento de uma ferramenta para correção automática de provas na WWW}

Scapin apresenta a WebCourse como uma ferramenta para facilitar a criação de provas a serem disponibilizadas no ambiente WWW, provendo, ainda, a correção automática das mesmas (Scapin \& Garcia Neto, 1997). De modo geral, é utilizado o recurso de formulários da linguagem HTML combinado ao processamento CGI (Common Gateway Interface) (CGI, 1997), produzindo a interface de autoria fornecida ao professor.

Neste contexto, um documento HTML é apresentado ao autor como interface de autoria. A ferramenta provê suporte à autoria de questões de múltipla-escolha, verdadeiro ou falso, resposta livre e preenchimento de lacunas. Em adição, é permitido ao autor a indicação das respostas das questões que serão apresentadas ao estudante. No módulo do estudante é apresentada uma opção para correção automática das respostas fornecidas. O mecanismo de correção da prova gera um 
arquivo HTML que é disponibilizado ao professor para registro de todas as provas realizadas pelos alunos.

Observa-se que, para usar a ferramenta WebCourse, o autor necessita de uma conexão on-line com um WebServer, uma vez que a autoria é feita através de uma interface apresentada ao autor através de documentos HTML. Neste ponto, é relevante observar que a ausência do modo standalone para a ferramenta WebCourse condiciona as operações de autoria ao ambiente da WWW. Em adição, a estrutura proprietária do conteúdo HTML gerado não permite o reuso e o intercâmbio com outras ferramentas e/ou ambientes de apresentação.

\subsubsection{Interface de navegação em hlperdocumentos para aplicações educacionais}

Borges \& Lima apresentam um modelo para desenvolvimento de interfaces para navegação em hiperdocumentos desenvolvidos para a área educacional (Borges \& Lima, 1997). Neste contexto, é proposta a autoria nos seguintes sentidos:

- o acesso dirigido pelo tutor, onde existe uma rigidez na sequiência de navegação nos hiperdocumentos;

- o acesso orientado pelo tutor, no qual o tutor apenas indica uma sequiência de navegação, mas não impõe rigidez;

- o acesso livre, que permite ao aluno navegar por qualquer parte da estrutura de hiperdocumentos.

É apresentada, ainda, uma implementação de um conjunto de hiperdocumentos HTML, organizados em frames, e que permitiram a avaliação dos tipos de acesso. No entanto, não são relatados experimentos e resultados da avaliação.

No trabalho proposto por Borges \& Lima deve-se ressaltar o framework de navegação construído, e que se apresenta como uma investigação importante no sentido da definiçăo de atributos para os acessos permitidos ao estudante através da interface do usuário. 


\subsubsection{Projeto MatWeb: usando recursos computacionais no ensino de matemática}

Cláudio et al. apresentam o projeto MatWeb como sendo um conjunto de documentos HTML e exercícios interativos sobre cálculo e matemática, bem como tutoriais e atalhos para serviços que podem ser executados via Internet, tais como FTP e Telnet (Cláudio et al., 1997).

A ferramenta MatWeb é.uma contribuição relevante no sentido da disponibilização de material didático no ambiente WWW. No entanto, esta contribuição se restringe apenas à construção do material didático com uso de HTML e ao provimento de serviços de FTP e Telnet para estabelecimento da comunicação entre professores e alunos. Nota-se a ausência de um framework que sistematize o processo e o caracterize como uma proposta para autoria e disponibilização de material didático de matemática na WWW.

\subsubsection{Projeto de um hiperdocumento interativo para alunos de $5^{a}$. Série}

Cattani apresenta a implementação de um hiperdocumento interativo para ensino da representação de noções de espaço, buscando ilustrar questões básicas que dizem respeito à representação bidimensional do espaço no qual o ser humano está inserido (Cattani, 1997), conforme ilustra a Figura 2.1. O trabalho está inserido no contexto do projeto LUAR - Levar a Universidade à Aprendizagem Remota (Tarouco, 1997).

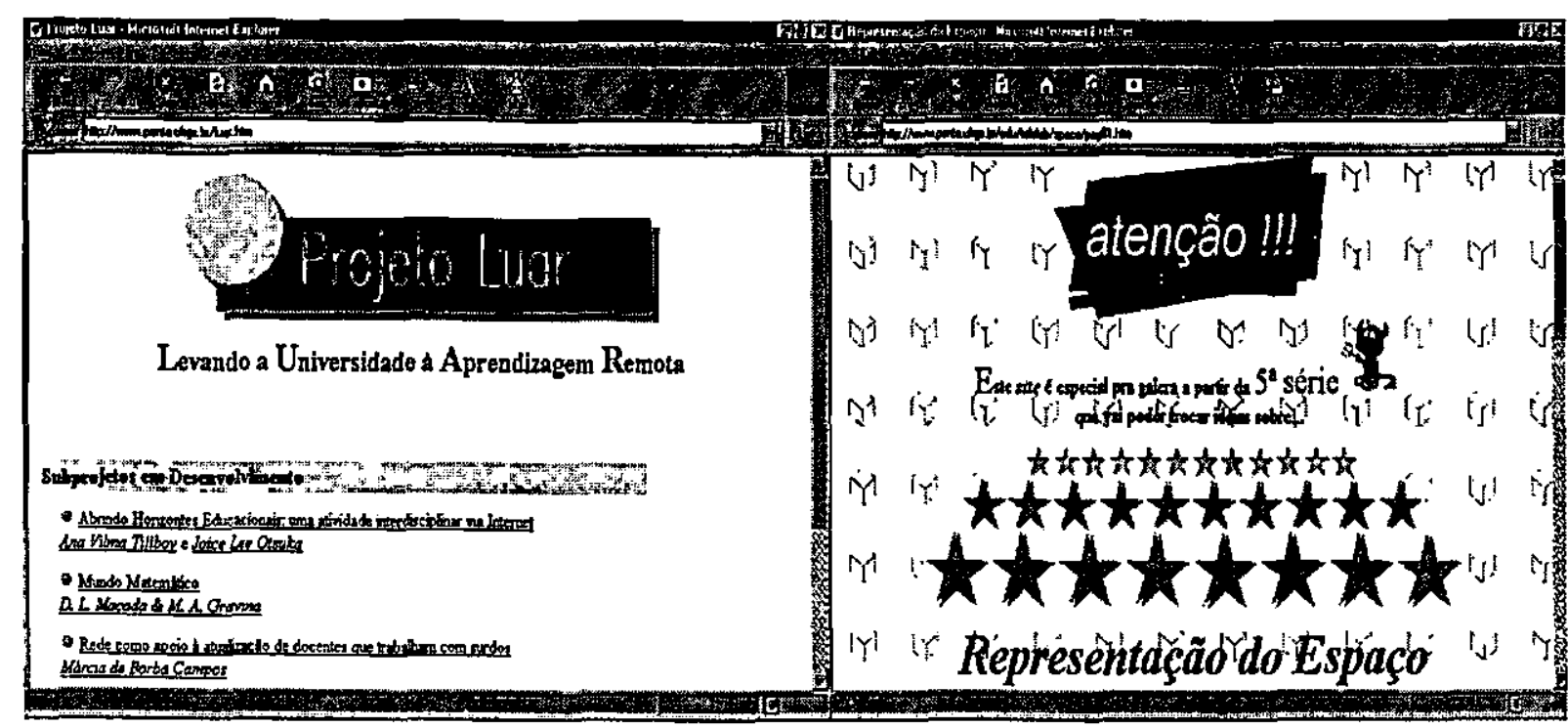

Figura 2.1 - Ambiente de apresentação do projeto LUAR 
O hiperdocumento possui uma estrutura baseada em frames, onde o aluno é convidado a selecionar uma das opções providas, além de ícones que representam cada etapa do ensino. A navegação no hiperdocumento é baseada na experimentação por parte do estudante, permitindo ao aluno a reflexão sobre o conhecimento em formação. Um ponto importante é que o modelo de navegação do hiperdocumento é fechado e somente no documento de abertura são fornecidos links para endereços de projetos relacionados.

Uma contribuição relevante do trabalho de Cattani é a implementação de um ambiente experimental que reforça o uso da WWW como suporte à construção do conhecimento, porém a estrutura proprietário dos documentos didáticos dificulta o reuso e o intercâmbio com outras ferramentas e/ou ambientes de apresentação.

\subsubsection{Projeto Qsabe: trocando experiências sobre informática em uma rede de educadores}

O projeto Qsabe, proposto por Menezes et al., é apresentado como um serviço de perguntas e respostas que atue como canalizador do perfil de especialistas das mais diversas áreas do conhecimento e permita a distribuição de mensagens de forma inteligente (Menezes et al., 1997).

O projeto QSabe é um ambiente inteligente para a cooperação de informações suportado por uma rede de computadores, constituindo-se num ambiente groupware, funcionando como uma alternativa às listas de discussão e ao mecanismo FAQ (Frequently Asked Questions) presente na Internet. De modo geral, o QSabe é um serviço fornecido via Internet, utilizando componentes de uso disseminado, tais como os browsers, e os servidores HTTP para WWW e SMTP para correio eletrônico.

A contribuição do projeto QSabe reside na construção de uma base de dados composta por informaçōes sobre um determinado domínio do conhecimento humano, permitindo o acesso por usuários devidamente autenticados. Esta proposta é relevante como suporte ao trabalho cooperativo entre professores ou mesmo entre professores e alunos, apesar de que o mecanismo de construção da base dados, e o armazenamento e recuperação de informaçð̃es não representam 
um contribuição importante em termos de tecnologia. Novamente, o uso de estruturas proprietárias impede o intercâmbio com outros projetos da mesma linha de pesquisa.

\subsubsection{Experiência do uso da WWW para o ensino da língua portuguesa}

Lima et al. apresentam o projeto ConVer, que é um conjunto de documentos HTML destinado à tutoria com o objetivo de reconhecer e gerar flexões dos verbos da língua portuguesa (Lima et al., 1997). De modo geral, a interface é formada por formulários e links que servem ao propósito da entrada de dados. Como resposta aos estudantes, é apresentada, em um documento HTML, uma listagem da conjugação do verbo especificado na entrada de dados.
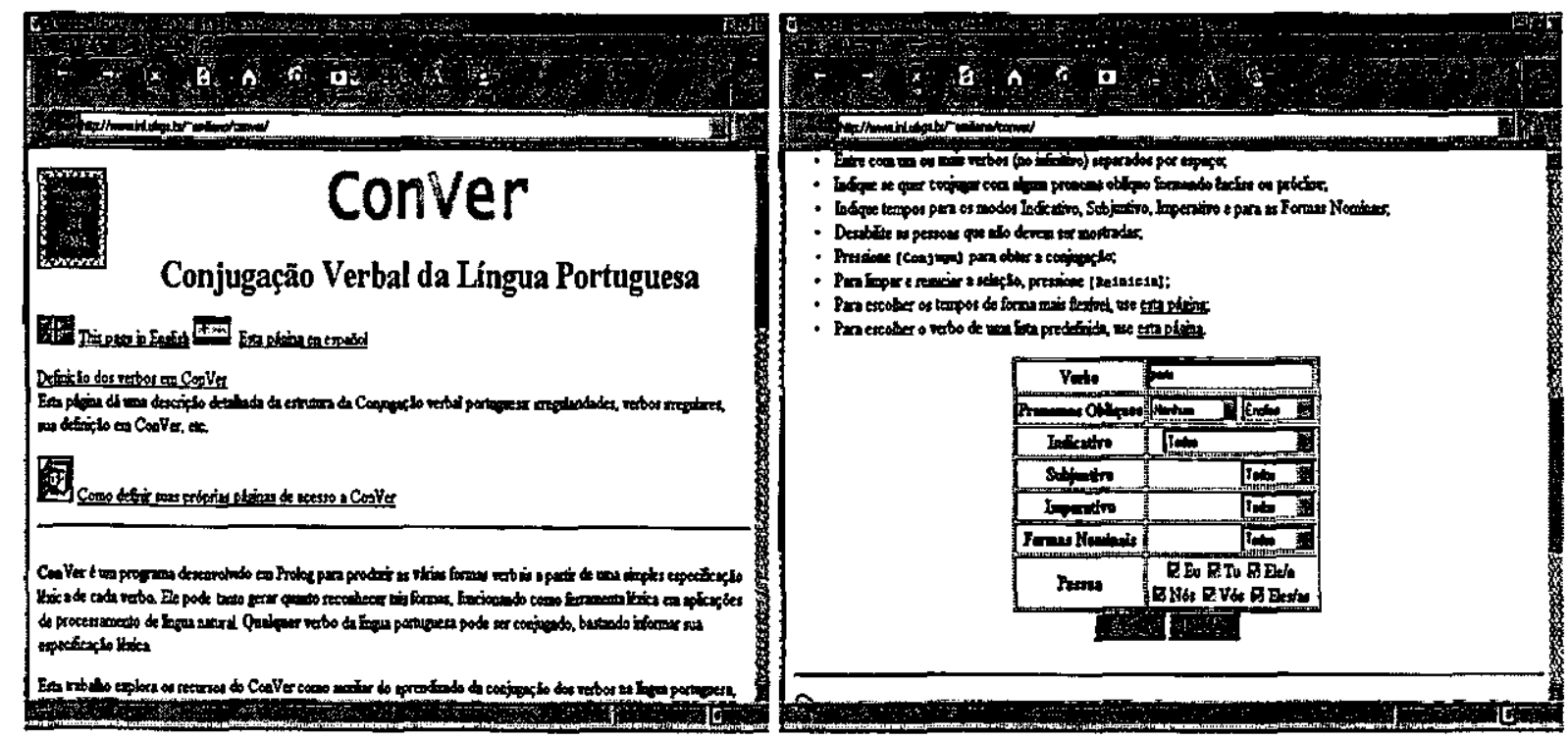

Figura 2.2 - Ambiente de apresentação do projeto ConVer

No projeto ConVer não é apresentado um framewok que dê suporte a novas implementações ou mesmo ao reuso da estrutura da interface implementada. A relevância do projeto ConVer reside somente na implementação da interação do usuário com a interface, no sistema pergunta e resposta, facilitando o aprendizado através da obtenção de informações classificadas e que colaboram para a formação do conhecimento. Apesar da relevância da implementação, é necessária a realização de experimentos reais para comprovação da eficácia da interface proposta. 


\subsubsection{Projeto NetAula: complementação de aulas pela Internet}

Morelli apresenta o projeto NetAula, que objetiva o complemento das aulas presenciais em classe, através da disponibilização de conteúdos via documentos HTML, para alunos dos cursos de Geografia, Biologia e Engenharia da Universidade do Vale do Paraíba - UNIVAP (Morelli, 1997).

De modo geral, existe uma estrutura hierárquica de documentos, indexadas por disciplina. Para cada disciplina são apresentados o plano de ensino, objetivos, ementa básica, seqüência da ementa em unidades, a programação do curso e o sistema de avaliação.

Assim como a ferramenta MatWeb, o projeto NetAula é uma conţribuição relevante no sentido de experimentar o ambiente WWW para disponibilização de material didático, porém não apresenta um framework que sistematize o processo e o caracterize como uma proposta para autoria e disponibilização de material didático na WWW. Também são necessários experimentos que apresentem resultados do uso dos documentos didáticos no ambiente de ensino a que se destinam.

\subsection{Ferramentas para elaboração de cursos}

Nesta seção são apresentadas algumas ferramentas ao nível mundial destinadas à autoria e apresentação de materiais didáticos que compõem cursos na WWW, tais como eWeb e WebCT. É relevante observar que as ferramentas citadas permitem a elaboração on-line de material didático através de páginas HTML disponibilizadas na WWW, não sendo possível a execução stand-alone das mesmas.

\subsection{1 eWeb}

A ferramenta eWeb, desenvolvida em 1996 por Young Zhao, da Michigan State University, Estados Unidos, é um aplicativo baseado num servidor de WWW, oferecendo um conjunto de ferramentas multifuncionais para a criação de cursos, propiciando aos autores adotar, desenvolver e gerenciar materiais multimídia, a fim de conduzir projetos de aprendizagem colaborativa e observar, monitorar e informar o desempenho dos estudantes (eWeb, 1996). De modo geral, a ferramenta eWeb possui seis módulos: 
- Fórum: ferramenta de comunicação que possibilita a livre troca de informaçộes entre professores e alunos;

- Quadro de Avisos: ao contrário do Fórum, o Quadro de Avisos tem por função o envio de mensagens curtas e pré-definidas em relação a assuntos catalogados. As mensagens enviadas podem ser selecionadas por autor, data de envio ou título;

- Sala de Discussão Virtual: enquanto o Fórum e o Quadro de Avisos provêem comunicação assíncrona, a Sala de Discussão possibilita comunicação síncrona. Os participantes podem iniciar discussōes e convidar outros participantes para discutir temas variados em tempo real;

- Construtor de Testes/Exercícios: esse módulo permite aos instrutores criar e administrar testes e exercícios na Web, provendo questões de múltipla escolha, verdadeiro ou falso e preenchimento de lacunas;

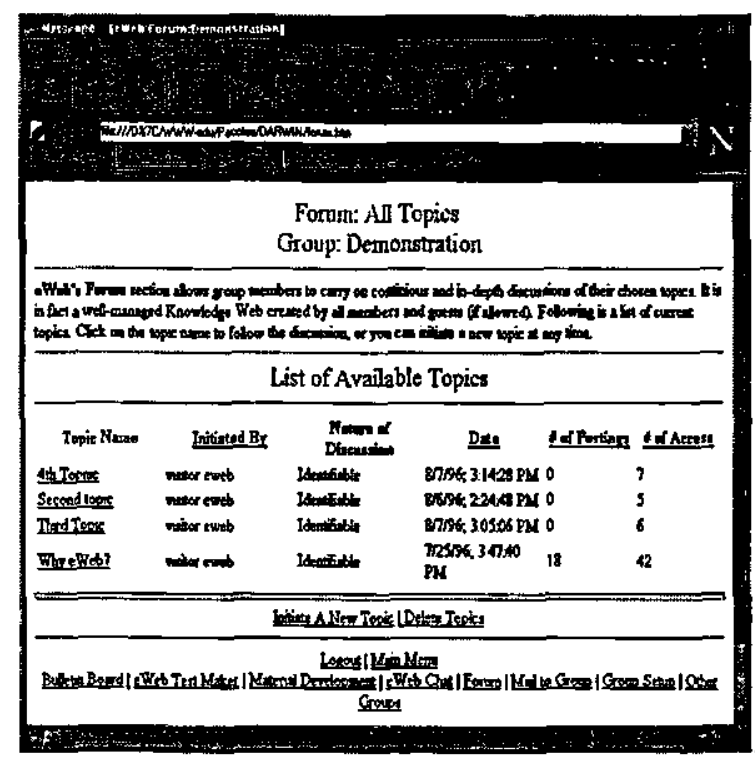

(a)

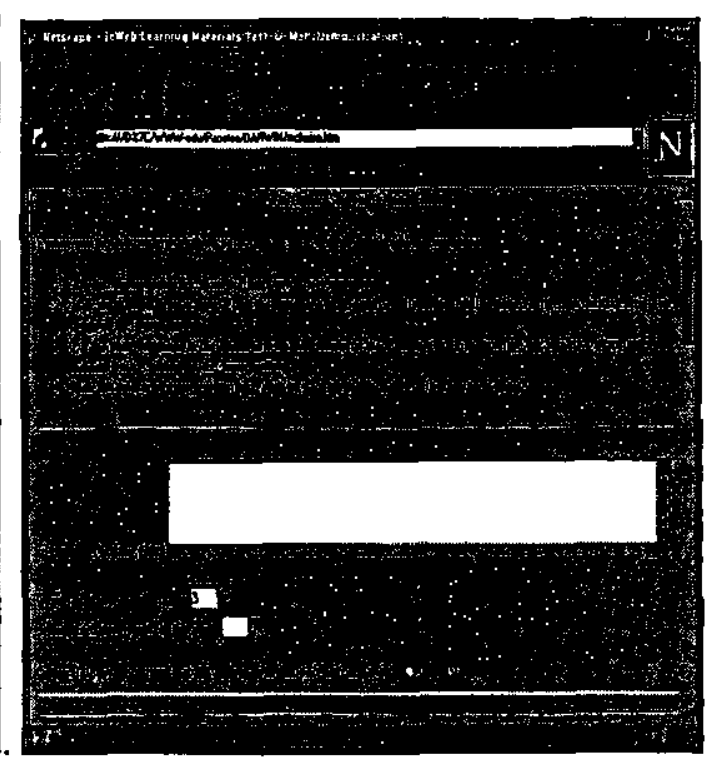

(b)

Figura 2.3 - (a) Módulo Fórum do eWeb (b) Módulo de criação de questões do eWeb

- Kit de Desenvolvimento de Material: criado para possibilitar aos professores o desenvolvimento e gerenciamento de material didático. $O$ kit provê uma interface para a criação ou uso de materiais multimídia existentes;

- Criador de Homepages: possibilita aos professores criar e gerenciar cursos na Web apenas preenchendo formulários HTML através de um browser. 
O conjunto de ferramentas eWeb provê a maioria dos recursos necessários à autoria de materiais didáticos para o ambiente da WWW. No entanto, tais recursos se destinam mais fortemente à manipulação de objetos multimídia, não sendo apresentados recursos mais aprimorados para o gerenciamento da estrutura dos hiperdocumentos didáticos. Em adição, os documentos gerados utilizam uma estrutura proprietária, dificultando o intercâmbio dos documentos com outras ferramentas e/ou ambientes de apresentação.

\subsubsection{WebcT}

O WebCT, um pacote criado por Murraw W. Goldberg, da University of British Columbia, Canadá, em 1996, consiste em uma ferramenta que facilita a criação de sofisticados ambientes educacionais baseados na WWW (WebCT, 1996b).

A ferramenta WebCT é inteiramente baseada na WWW, tanto para o estudante como para o professor. A ferramenta WebCT é apresentada ao autor como um documento HTML principal, provendo links para conteúdo dos cursos, características e ferramentas. Há uma barra de navegação que facilita o acesso aos tópicos dos cursos. De modo geral, o estudante tem à sua disposição o correio eletrônico e ambientes de navegação pelo material didático.

Para o autor, são fornecidas ferramentas para verificação do progresso do aluno, verificação do curso, elaboração de testes, gerenciamento de estudantes e geração de layout de apresentação dos hiperdocumentos. A Figura 2.4 apresenta uma questão criada com WebCT e a Figura 2.5 apresenta mecanismos de controle de cursos.

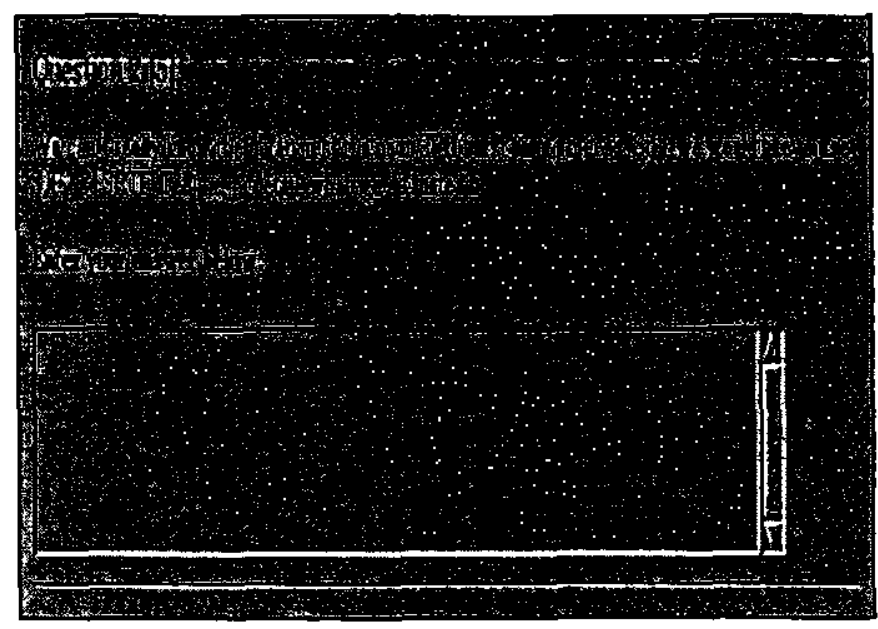

Figura 2.4 - Questão criada com WebCT 


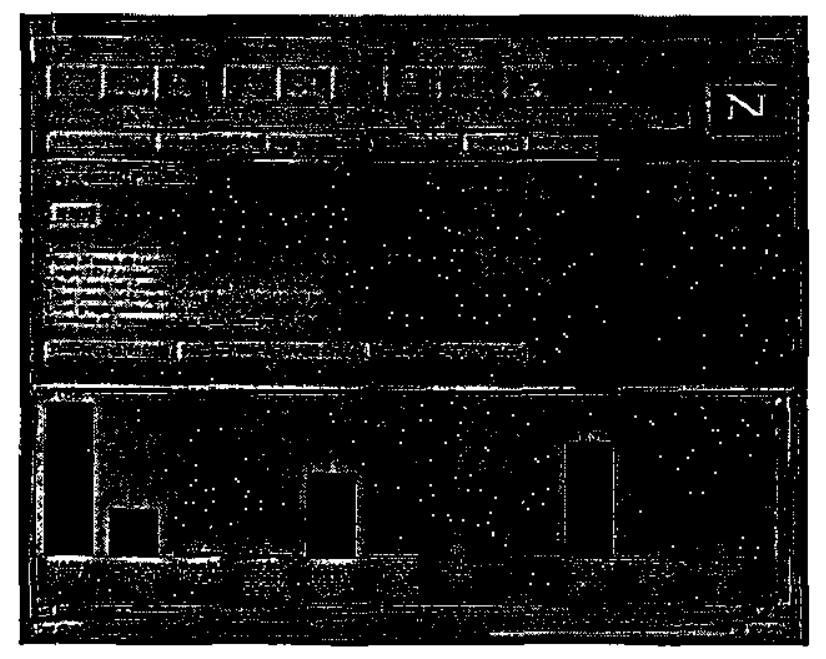

Figura 2.5. - Página de gerenciamento de cursos do WebCT

WebCT constitui-se numa ferramenta multifuncional para a criação de cursos na WWW, permitindo também seu completo gerenciamento, fornecendo ao instrutor diversos dados estatísticos sobre o andamento do curso e o progresso individual dos alunos. Atualmente, trata-se de um dos mais completos pacotes para desenvolvimento de cursos na WWW, e tem sido adotado por várias universidades, por exemplo University of Georgia, UCLA, Marshall University e outras, motivo pelo qual será utilizado para uma comparação com as ferramentas propostas no contexto deste trabalho, no Capítulo 6 desta dissertação. Apesar dos muitos recursos oferecidos pelo ambiente WebCT, o uso de uma estrutura proprietária para os documentos gerados dificuita os processos de reuso e intercâmbio com outros ambientes de autoria e apresentação.

\subsection{Ferramentas para autoria de questões eletrônicas}

Nesta seção são apresentadas algumas ferramentas destinadas à autoria e apresentação de questionários eletrônicos na WWW. É relevante observar que todas as ferramentas aqui reportadas permitem a autoria on-line de questionários através de documentos HTML disponibilizadas na WWW, não sendo possível a execução stand-alone das mesmas, além de utilizarem estruturas proprietárias para os documentos gerados.

\subsection{1 qForm}

A ferramenta qForm, criada por Bob Cunningham, da Hawaii University, Estados Unidos, em 1995, consiste de um pacote com dois programas (qForm, 1995): qform, usado para criação de 
um teste em linguagem HTML, e qscore usado para a correção dos testes criados pelo pacote qform. Este conjunto de programas torna fácil a criação e a correção automática de questões de múltipla escolha e verdadeiro ou falso em servidores WWW baseados no protocolo HTTP.

O formato do arquivo dos testes é simples, não sendo necessário conhecimento da linguagem HTML para escrever um teste, embora seja possível colocar seu próprio código HTML nos testes. $\mathrm{O}$ arquivo que contém os testes deve ser colocado em um diretório apropriado em um servidor HTTP. Neste ponto, existe uma meta-linguagem para a ferramenta qForm, que consiste de várias palavras-chaves que definem a formatação dos testes:

- question: o texto que segue é apresentado como uma questão;

- right: o texto que segue é apresentado como uma resposta correta para a pergunta;

- wrong: o texto que segue é apresentado como uma resposta incorreta para a pergunta;

- comment: o texto que segue é apresentado como um comentário;

- header: o texto que segue é apresentado como um cabeçalho;

- instructions: o texto que segue é apresentado como texto normal.

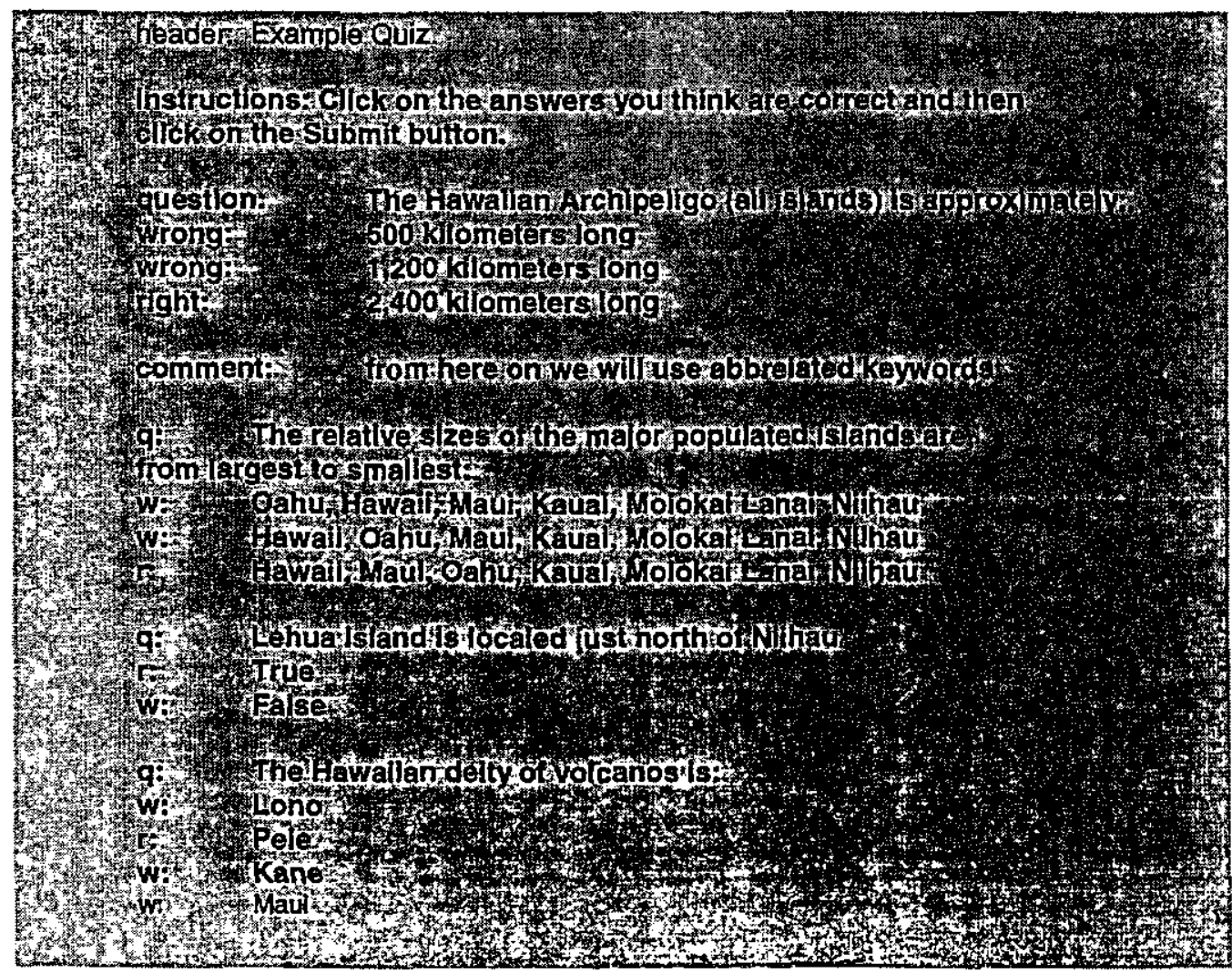

Figura 2.6 - Formato do arquivo de testes usado por qForm 
A Figura 2.6 apresenta um arquivo gerado pela ferramenta $\mathrm{qForm}$ contendo a estrutura de formatação dos testes. Já na Figura 2.7 é apresentado um documento HTML correspondente ao arquivo texto gerado pela ferramenta qForm.

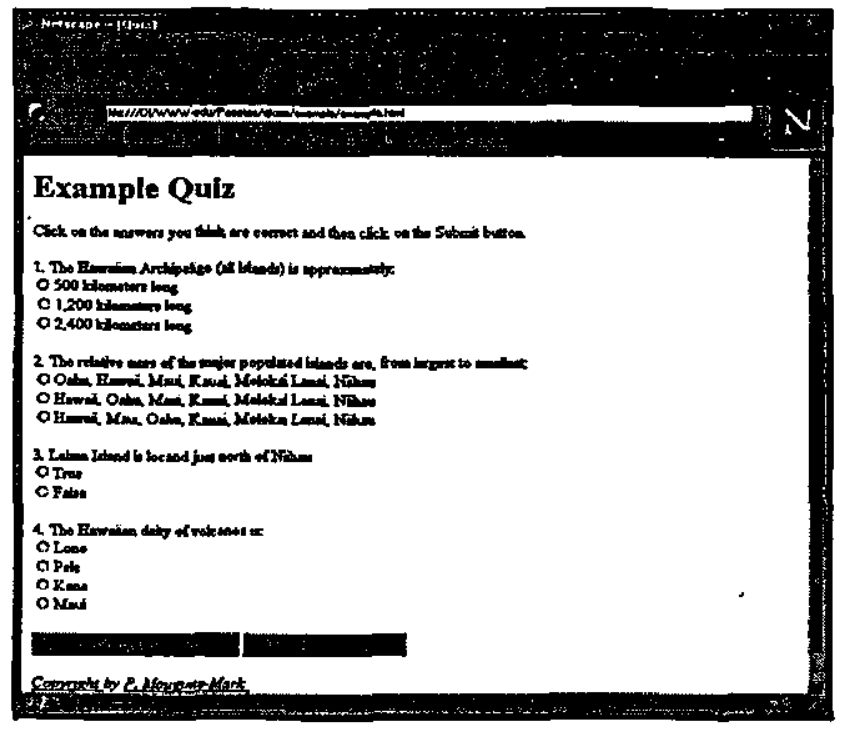

Figura 2.7 - Página de testes criada pela ferramenta qform

Apesar de apresentar uma interface de autoria simples que permite o uso fácil por qualquer autor, a ferramenta qForm gera documentos baseados em uma estrutura proprietária o que restringe $o$ reuso por outras ferramentas de autoria e/ou ambientes de apresentação.

\subsubsection{QuizMaker}

A ferramenta QuizMaker, criada por Veng-Ly Tong, da North Dakota State University, Estados Unidos, em 1996, destina-se à geração de formulários de questões de múltipla escolha na WWW (QuizMaker, 1996). Seu objetivo principal consiste em prover a professores a facilidade para .criar testes, assim como permitir aos alunos realizarem uma auto-avaliação sobre o conteúdo apresentado em aulas convencionais.

A ferramenta QuizMaker possui dois módulos: um para criar um novo teste ou modificar um já existente, e outro para avaliação. Ao entrar no programa, o usuário deve definir o nome do arquivo a ser criado. Basicamente, um autor deve preencher um formulário com os seguintes campos:

- Form Title: os dados inseridos serão apresentados na barra de título do browser;

- Form Header: os dados inseridos serão apresentados no topo do formulário; 
- Special Instructions: esse é um campo opcional, permitindo ao instrutor inserir instruções, propósitos dos testes e informações adicionais;

- Image File: esse campo é apresentado para cada questão, permitindo a inserção de uma imagem na questão;

- Question: campo utilizado para inserir o enunciado da questão;

- Numbered List: uma lista que apresenta o número de alternativas para cada questão;

- The Answer is \# : campo para definição da resposta correta da questão.

Ao término do preenchimento dos campos de formatação, deve-se acionar a opção Generate Form para gravar os dados. Um formulário preliminar é apresentado para visualização do layout de apresentação das questões. A Figura 2.8a mostra o documento para criação de questões de múltipla escolha, enquanto que a Figura $2.8 \mathrm{~b}$ apresenta um documento contendo os testes criados.

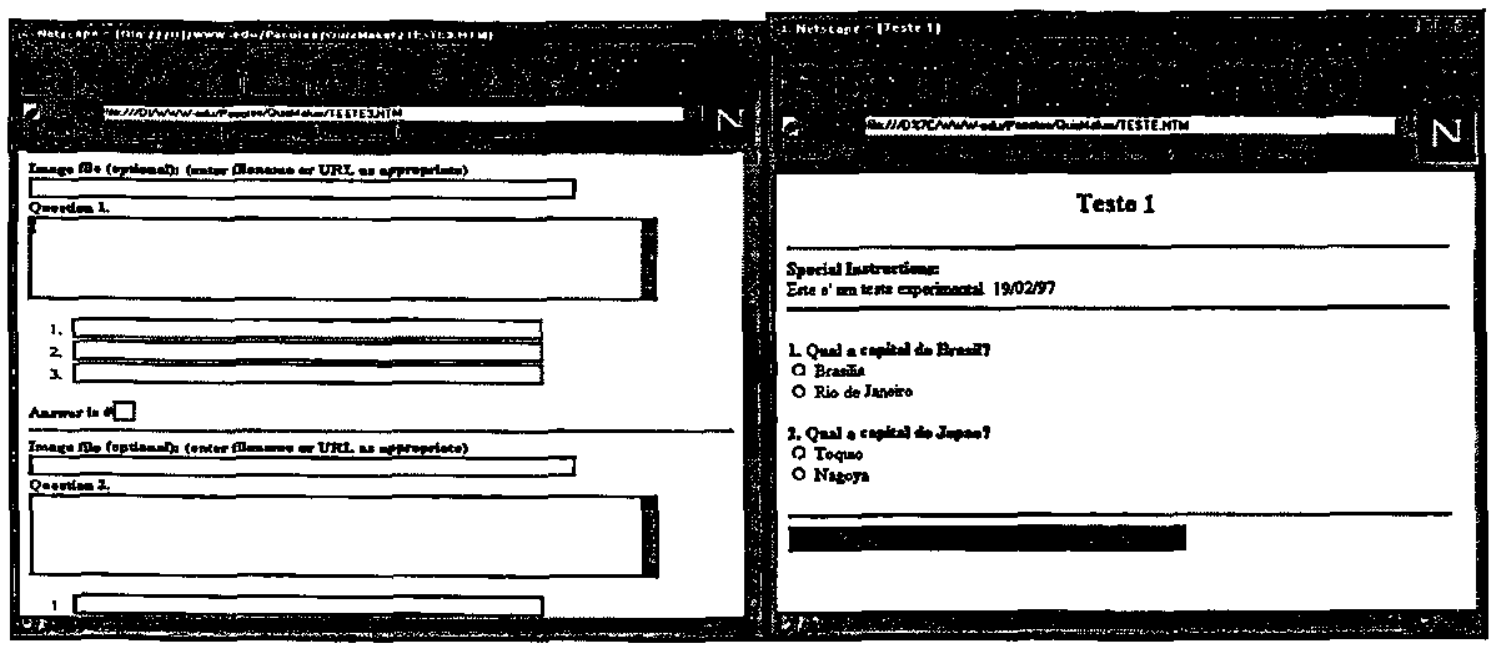

(a)

(b)

Figura 2.8 - (a) Documento para criação de testes do QuizMaker (b) Documento para apresentação de testes

A ferramenta QuizMaker não apresenta uma estrutura definida para os documentos que contêm os questionários elaborados. Apesar da interface com o usuário ser simples e facilitar a autoria e apresentação das questões, a ausência de uma estrutura de suporte aos elementos das questões dificulta o reuso e intercâmbio dos documentos gerados. 


\subsubsection{CUQuiz}

A ferramenta CUQuiz, proposta por Kevin Cox, da City University of Hong Kong, em 1995, é destinada à criação de questões de múltipla escolha e de preenchimento de lacunas, para serem inseridas em documentos HTML para a WWW (CUQuiz, 1995). A criação das questões é feita através de um documento HTML, no qual o autor deve fornecer uma senha para ter acesso à criação dos testes. As questões podem ser armazenadas em um arquivo texto na máquina do cliente e transferidas como documentos HTML para um servidor HTTP. Em adição, as informações sobre o desempenho de cada aluno podem ser visualizadas pelo professor, além do fornecimento de relatórios de desempenho que podem ser emitidos ao aluno. A Figura 2.9 mostra testes criados pela ferramenta CUQuiz.

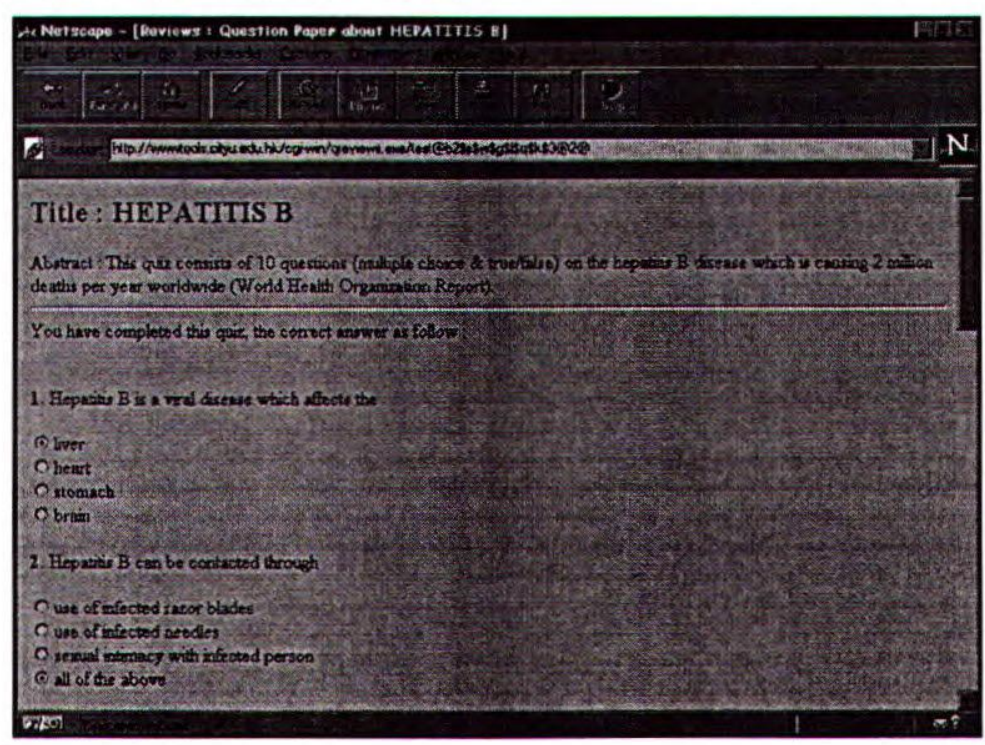

Figura 2.9 - Página de testes de múltipla escolha gerada pela ferramenta CUQuiz

Assim como a ferramenta QuizMaker, a ferramenta CUQuiz não apresenta uma estrutura definida para os documentos que contém os questionários, dificultando o reuso e intercâmbio dos documentos gerados.

\subsubsection{QuizTest}

A ferramenta QuizTest, criada por Kristina Pfaff-Harris, da empresa Linguistic Foundation, Estados Unidos, em 1996, foi implementada na linguagem Perl 5 permitindo a criação on-line de testes de múltipla escolha e verdadeiro ou falso (QuizTest, 1996). 
Os autores criam os testes usando a linguagem HTML, gerando um arquivo de respostas sobre o qual um script CGI verifica a resposta dada pelo estudante ao teste. A Figura 2.10 exibe um documento HTML que apresenta os testes criados com a ferramenta QuizTest.

A ferramenta exibe o resultado obtido pelo aluno nos testes que realizou, indicando as questóes erradas, e também envia uma mensagem de correio eletrônico com os resultados obtidos pelos alunos para um instrutor especificado, juntamente com a data e o horário que o estudante realizou o teste.

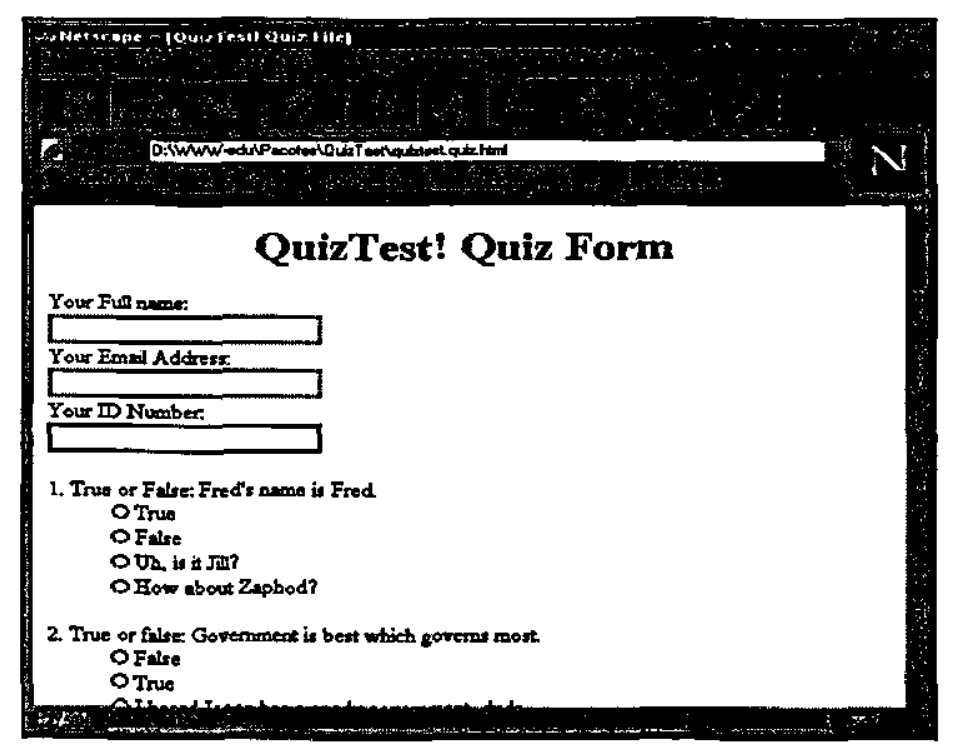

Figura 2.10 - Documento para apresentação de testes criados com a ferramenta QuizTest

A ferramenta CUQuiz possui o mesmo estilo de manipulação de documentos das ferramentas anteriores, cuidando apenas da interface para e geração de documentos HTML para o ambiente WWW. Como todas as ferramentas descritas até o momento, a ferramenta CUQuiz não apresenta uma estrutura definida para os documentos que contém os questionários, e que permita o reuso e intercâmbio dos documentos gerados.

\subsubsection{WebWorksheet}

O WebWorksheet, um pacote desenvolvido por Mark Scott e Marcus Richardson, da Washington University, Estados Unidos, em 1996, tem por objetivo principal possibilitar aos autores a criação de exercícios multimídia e disponibilizá-los na WWW (WebWorksheet, 1996). 
O WebWorksheet provê aos autores o desenvolvimento de exercícios práticos on-line sem exigir conhecimento da linguagem HTML.

O WebWorksheet possibilita a autoria de questões de múltipla escolha, verdadeiro ou falso, preenchimento de lacunas e resposta livre. Cada questão possui campos para a incorporação de feedback do autor.

A ferramenta WebWorksheet também não apresenta uma estrutura definida para os documentos que contém os questionários, e que permita o reuso e intercâmbio dos documentos gerados.

\subsection{Conslderações finals}

Este capítulo apresentou algumas iniciativas recentes, no Brasil e no exterior, em termos da produção de ferramental para apoio à autoria e disponibilização de material didático no ambiente WWW. Um ponto relevante observado é que a maioria das ferramentas que se destinam à autoria de material didático e questionários utiliza o ambiente WWW como suporte ao processo de autoria, exigindo que o autor esteja conectado de forma on-line a servidores WWW durante o processo de autoria.

Nota-se, ainda, que todas as ferramentas apresentadas fazem uso de estruturas proprietárias para representação dos documentos correspondentes ao material didático e questionários de avaliação. Este fator, conforme comentado, restringe os aspectos de reuso dos documentos e intercâmbio destes com outras ferramentas de autoria e/ou ambientes de apresentação. Em adição, o fato das ferramentas estarem suportadas por estruturas proprietárias torna-se um agente motivador para a proposta apresentada neste trabalho. A proposta de formalização da estrutura dos documentos didáticos utilizando o padrão SGML é feita visto que, por ser aberto, aumenta a visibilidade dos documentos manipulados pelas ferramentas de autoria aqui propostas.

Por outro lado, as características distribuídas e o uso de hipertextos tornam o ambiente WWW uma plataforma interessante para o suporte à apresentação do material didático ao estudante. Este aspecto é reforçado pela multidisciplinaridade dos trabalhos reportados. 


\section{INTERAÇÃO USUÁRIO-HIPERTEXTO}

\subsection{Considerações iniciais}

A interface com o usuário é um ponto cada vez mais importante à medida que o uso do computador cresce consideravelmente, podendo-se dizer que a interface é a embalagem do software, sendo que o usuário fará bom uso do software quanto mais fácil e amigável for a interface. $\mathrm{O}$ desenvolvimento de interfaces usuário-computador é altamente criativo e diferentes projetistas usam diferentes técnicas. Por envolver um projeto multidisciplinar, várias formas de "enxergar o mundo" são aplicadas, onde projetistas enfocam "como o usuário trabalha e o que é importante para ele" (Pressman, 1995).

Neste capítulo, fatores estudados pela área de HCI (Human-Computer Interaction) são apresentados, destacando-se as aplicações dos conceitos na construção de interfaces para o contexto do ensino, tanto ao nível de ferramentas de autoria para os professores, quanto ao nível de ambientes de aprendizagem para os estudantes baseados em hipertextos. Neste ponto, o estudo de aspectos de HCI é relevante em termos da construção de interfaces orientadas às tarefas que os usuários potenciais, professores e estudantes, realizam na preparação e uso dos materiais didáticos, respectivamente.

\subsection{Interação usuário-computador tradicional}

O projeto de interfaces de aplicações possui características diferentes do projeto de software. Fatores humanos tais como percepção visual, psicologia cognitiva, memoria, dedução e intuição devem ser considerados em parceria com o comportamento do usuário executando as tarefas na interação com o computador.

O ser humano possui um sistema perceptivo sensorial e paralelo. Uma especificação adequada da comunicação visual é um elemento chave de uma interface amigável. De forma geral, as informações são armazenadas no cérebro em uma memória STM (Short Time Memory), ou seja, que podem ser reusadas imediatamente; ou em uma memória LTM (Long Time Memory), onde é formado o conhecimento (Preece, 1994). A Figura 3.1 ilustra este modelo. Além disso, um 
usuário utiliza heurísticas (diretrizes, regras e estratégias) que influenciam uma informação ou conhecimento em um certo contexto da interação.

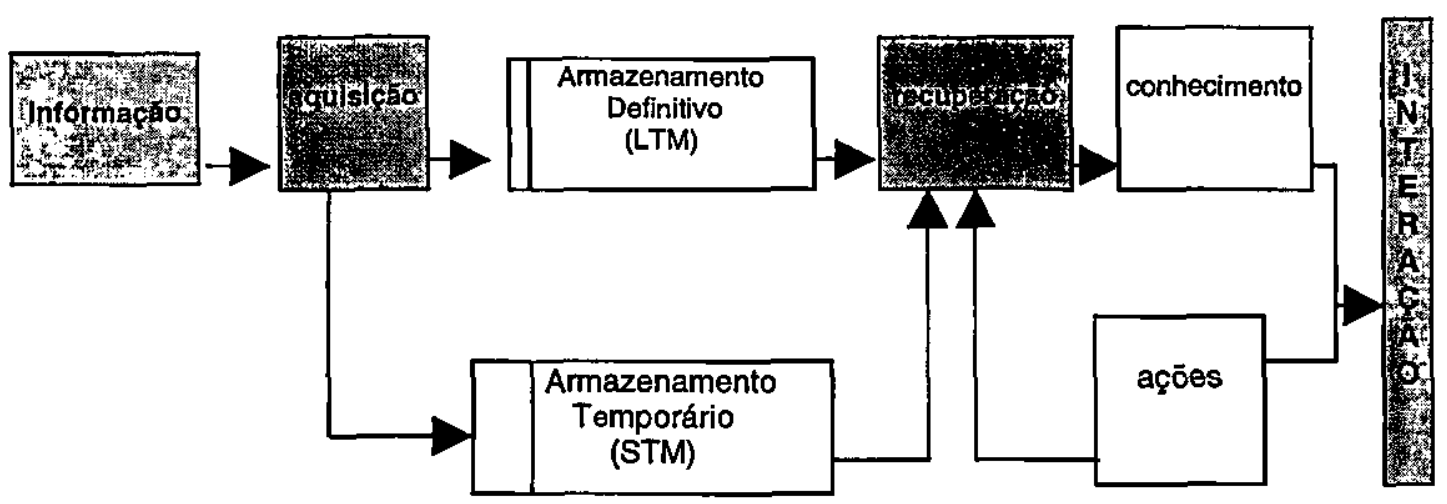

Figura 3.1 - Modelo de representação da memória do ser hụmano (Preece, 1994)

O sistema perceptivo humano tem capacidades e fraquezas com relação ao movimento de objetos com os quais interage. A manutenção da atenção do usuário é um ponto importante quando se projeta uma interface, uma vez que os seres humanos são sujeitos a aspectos emocionais e outras influências, como por exemplo, tensão, cansaço e preferências de uso. Neste sentido, alguns aspectos de diferentes áreas são importantes para o projeto de interfaces mais humanas, como:

- psicologia cognitiva: o que o usuário é capaz ou não de fazer;

- psicologia social: a relação do usuário não só com o computador (interface) e também com o ambiente;

- linguística: compreensão sintático-semântica da linguagem natural;

- processo cognitivo: entendimento, memória, razão, aprimoramento, criação;

- manipulação da informação: estímulo externo, interpretação, comparação, execução;

- psicologia organizacional: a relação dentro do ambiente de trabalho.

A abordagem cognitiva tradicional enfoca a utilização de cenários de execução de tarefas, ou seja, deve-se enxergar o ser humano como um ator capaz de controlar as tarefas e o ambiente no qual essas tarefas estão inseridas (Shneiderman, 1991). Neste contexto, um sistema de computador é usado para automatizar tarefas que, em suma, são formadas por eventos e relacionamentos. Apesar das tarefas serem distintas, existe uma divisão em categorias globais, 
tais como tarefas de comunicação, tarefas de diálogo, tarefas cognitivas e tarefas de controle, que devem ser consideradas no projeto de quaisquer interações usuário-computador.

A análise e modelagem de tarefas é aplicada às atividades humanas. Basicamente, deve-se entender como as tarefas são executadas convencionalmente e então construir um modelo. As tarefas devem ser elaboradas passo a passo, e somente então classificadas. O modelo da interface deve acompanhar a percepção do usuário e, em adição, a definição de objetos e ações sobre as tarefas são necessários. Uma abordagem inicial pode ser descrita em termos de:

- definir metas e intenções das tarefas;

- definir a seqüência de ações específicas de cada tarefa;

- definir a sequiência de ações na interface;

- definir mecanismos que forneçam o estado da interface;

- detectar mecanismos de controle que afetem o estado do sistema;

- analisar como o usuário interpreta o estado do sistema.

De modo geral, a modelagem de tarefas pode ser vista em termos de quatro modelos de construção da interação usuário-computador (Pressman, 1995). O modelo de projeto é feito através de especificações de requisitos que ajudam a definir quem é o usuário. $O$ modelo do usuário descreve o perfil dos usuários finais do sistema, procurando categorizá-los em principiantes, instruídos e intermitentes, e instruídos e freqüentes. $O$ modelo de percepção do sistema é uma imagem do sistema sob o ponto de vista do usuário final. Por fim, o modelo de imagem do sistema combina a interface gerada com toda a documentação de uso da memória. Pode-se dizer que o ponto marcante dos modelos resume-se ao conhecimento do usuário e ao conhecimento das tarefas que o usuário realiza.

\subsection{Interação usuário-hipermídia}

Existe uma estreita ligação entre a evolução dos computadores e as tendências dos projetos envolvendo interação usuário-computador. A interação, nos primórdios da computação interativa, era feita através das linhas de comando e consulta, portanto puramente textual. Um segundo estilo apresentou os menus simples através de uma lista de códigos de opçð̃es que poderiam ser selecionadas pelo usuário. A evolução mais significativa deu-se com o avanço da 
tecnologia de hardware e dos fatores humanos, chegando-se às interfaces baseadas em janelas, que são caracterizadas pela execução de tarefas simultâneas, menus ao estilo pull-down, ícones, botões, técnicas de rolagem e outros. $\mathrm{O}$ atual estilo de interação, e que tem sido alvo de pesquisas, combina o ambiente de janelas com uso de hipertextos e multitarefas, sendo que nos últimos anos temos visto uma explosão de interesse neste estilo de interação usuário-computador. Um documento multimídia é aquele composto de diferentes tipos de mídia, normalmente uma delas contínua. Um documento hipermídia é definido como um documento multimídia que também possui uma estrutura subjacente de hipertexto. Desta forma, um documento hipermídia é um documento hipertexto que permite incorporar um número significativo de tipos de mídia distintos. De forma geral, há dois aspectos importantes dos sistemas hipermídia:

- construção de aplicações (autoria);

- disponibilização destas aplicações aos usuários (apresentação).

Quanto ao processo de autoria, pode-se dizer que os autores são pessoas competentes em suas áreas de atuação, porém não são especialistas em software. Dadas as características dos documentos da WWW, em particular considerando a interatividade permitida pelas linguagens JAVA e JAVAScript, a tarefa de autoria pode tornar-se cada vez mais uma forma de programação. É nesse sentido que as ferramentas de autoria propostas neste trabalho se enquadram: deixar programadas nas ferramentas as tarefas específicas, e disponibilizá-las aos autores de documentos.

\subsection{Aspectos de interação em ambientes de ensino}

No contexto dos ambientes de ensino, a interação usuário-computador necessita de um projeto criterioso com vistas à obtenção de interface com alto grau de usabilidade.

Em sistemas hipertexto, a estrutura baseada em nós e ligações permite a construção de hiperdocumentos complexos, do ponto de vista dos níveis de profundidade e aninhamento das ligações. No entanto, a complexidade das ligações pode levar à sobrecarga cognitiva e a desorientação, fatores marcantes de sistemas hipertex to (Conklin, 1987). 
Observa-se que, ao empregar sistemas hipertexto no contexto do ensino, tornam-se necessários mecanismos que diminuam a desorientação do usuário enquanto este navega pelo hiperdocumento. Um destes mecanismos pode ser implementado através de um guided tour, que sugere rotas de navegação, como implementado no SASHE (Nunes \& Fortes, 1997). Com tal recurso, é possível orientar o usuário em relação ao conteúdo que deve ser visitado em um determinado domínio ou mesmo em contextos dentro de um hiperdocumento. Observa-se que a utilização de um guided tour requer a estruturação do hiperdocumento.

Em adição, tanto as interfaces de autoria, que serão utilizadas pelo professor, quanto os ambientes de aprendizagem do estudante, devem ser orientados à execução de tarefas relativas ao conteúdo didático, bem como fornecer mecanismos que facilitem a percepção desse conteúdo pelo estudante.

Ao nível do professor, as interfaces das ferramentas devem permitir a elaboração do material didático, uma vez que é aceitável o uso dessas ferramentas por usuários leigos em informática. Neste ponto, a ênfase deve ser voltada às tarefas que o professor deve realizar para construir e disponibilizar o material didático, contribuindo para a construção de um processo sistematizado. Em termos do estudante, as interfaces devem apresentar elementos de fácil identificação e percepção, contribuindo para a correta execução das tarefas. Neste contexto, a ênfase pode ser voltada aos processos de monitoramento da navegação do estudante em hiperdocumentos, e na orientação do aprendizado em termos do conteúdo disponibilizado.

\subsection{Problemas com a autoria de material didático para a WWW}

Em linhas gerais, os hiperdocumentos WWW são produzidos com o uso de HTML com possibilidade de incrementos através de applets JAVA. Observa-se, portanto, que o processo de autoria fica comprometido quando o autor não domina os elementos que compõem a linguagem HTML ou não conhece programação de computadores para inserir recursos JAVA nos hiperdocumentos. Portanto, esse processo requer a presença de autores com conhecimento especializado. 
Em adição, os hiperdocumentos construídos com HTML não possuem orientação quanto à estrutura, uma vez que os elementos HTML permitem a construção de hipertextos gerais sem fornecer recursos que auxiliem a estruturação dos mesmos. Entretanto, observa-se que hiperdocumentos contendo material didático podem ser formatados com base em características estruturadas, como por exemplo identificação do material, do autor, do público a que se destina, índice de tópicos, conteúdo dos tópicos, avaliação e outros. A necessidade de definição de uma estrutura genérica para hiperdocumentos de material didático reside no fato de que a WWW tem sido utilizada para a livre publicação de materiais destinados ao ensino e que, na maioria das vezes, não possuem características didáticas, sendo vistos, simplesmente, como uma página ou um conjunto de páginas que objetiva a disponibilização de um determinado conteúdo. Em adição, a maioria das ferramentas existentes para construção de hiperdocumentos para a WWW, tais como HTMLed, Microsoft FrontPage e outras, destina-se à formatação da apresentação dos recursos e aspectos visuais da interface, sem fornecer qualquer tipo de orientação quanto à estrutura do hiperdocumento a ser publicado e mecanismos de associação ao domínio de aplicação. De modo geral, existem ferramentas que orientam a inserção de elementos HTML, convertem textos comuns para formatos de publicação, além de fornecer recursos de programação visual para construção do layout da interface do usuário.

Neste contexto, torna-se importante a implementação de ferramentas de autoria que permitam a construção de hiperdocumentos estruturados e sua disponibilização na forma de material didático na WWW, sem a necessidade de conhecimento de linguagens de formatação de hipertextos ou mesmo de programação de computadores.

\subsection{Interação do usuário no ambiente WWW: utiiidade e usabilidade}

A necessidade de integração e troca de informações entre usuários, que possuem muitas vezes características distintas, impulsionaram e continuam impulsionando o crescimento do ambiente WWW. Neste contexto, torna-se importante a realização de estudos dos fatores humanos envolvidos na interação do usuário com hiperdocumentos. Em particular para aplicações voitadas ao ensino, a usabilidade pode ser indicada pelo desempenho do usuário na execução de suas tarefas, pelo grau de aprendizado durante a realização das tarefas, pela adaptação às variações (transiçōes) das tarefas, e pela satisfação do usuário com o sistema (Gaines, 1996). 
Independentemente do domínio de aplicação, entretanto, uma análise inicial é importante no sentido da utilidade da tecnologia, antes mesmo que qualquer análise de usabilidade seja realizada (Gaines, 1996). Desta forma, analisar as necessidades funcionais é um passo fundamental para se entender os problemas que os usuários terão no uso do sistema. De modo geral, os fatores humanos podem ser analisados em termos de conceitos que fornecem as características dos sistemas que envolvam pessoas e serviços computacionais.

Inicialmente, a definição das comunidades de usuários é importante no sentido da identificação do domínio da aplicação. A partir dessa definição, os usuários podem ser tratados através de sua intenção em usar as tarefas que o sistema permite. Neste ponto, o conhecimento do usuário pode influenciar diretamente no grau de habilidade que o mesmo apresenta na realização das tarefas. As intenções de uso são então transformadas em ações através da interação usuário-computador que, em suma, é a forma de expressão das sequiências de ações exigidas pela tarefas. Por fim, as ações são transformadas em efeitos físicos resumidos na percepção do usuário.

Observa-se que as questões de usabilidade estão presentes nos conceitos de conhecimento, habilidade, interface e acesso às tarefas. Isto reforça a idéia preliminar de que o grau de usabilidade aumenta de acordo com aumento do conhecimento (background) do usuário sobre as tarefas que irá realizar. Em adição, ação e expressão são conceitos distintos para permitir a abstração de uma ação e também a expressão dessa abstração como sequiência de atos. A usabilidade pode ser vista em termos de uma avaliação de como os usuários podem traduzir suas intenções em ações efetivas.

Neste ponto, a identificação correta do tipo de usuário do sistema torna-se um ponto importante na busca de usabilidade. De forma geral, as comunidades podem ser distinguidas em (Gaines, 1996):

- comunidades altamente coordenadas, ou seja, que têm objetivos direcionados;

- comunidades de interesses especiais;

- comunidades não-coordenadas, que são as maiores no ambiente WWW, de modo geral. 
Como consequüência desta diferenciação das comunidades de usuários, uma conceituação através de observações empíricas torna-se necessária. Neste contexto, uma comunidade pode ser definida como um grupo de indivíduos em termos dos recursos que precisa utilizar e que lhes são fornecidos e conhecidos.

\subsection{Consideraçōes Finais}

Este capítulo discutiu conceitos relacionados à interaçāo usuário-computador de modo geral, e à interação usuário-hipertex to de modo particular.

Em seguida, comentou-se sobre a especialização exigida, por parte do autor de documentos, em relação à autoria de documentos estruturados e ou estendidos através de JAVA e JAVAScript. Os problemas decorrentes da autoria de material didático para a WWW com as ferramentas usuais e também os aspectos de interação em sistemas hipertexto, constituem-se nos argumentos utilizados para justificar a construção de ferramentas específicas para facilitar as tarefas de autoria e publicação de material didático na WWW. 


\subsection{Consideraçöes iniciais}

A expansão da Internet, e do correspondente aumento da comunidade de usuários da WWW, tem provocado um crescente interesse pela disponibilização de material nesse ambiente, principalmente aquele cujo conteúdo seja direcionado ao ensino.

Atualmente, os documentos disponibilizados na WWW são estruturados de acordo com o padrão HTML, que impõe uma estrutura simples aos hiperdocumentos e que é suportada pelos browsers existentes. Em complemento, aplicações utilizando a linguagem JA.VA vêm sendo desenvolvidas e embutidas nos hiperdocumentos, através dos applets e scripts, expandindo e incrementando os serviços disponibilizados ao usuário final. Esse crescimento implica a necessidade de implementação de ferramentas que facilitem o processo de autoria, bem como da utilização de mecanismos de avaliação de fatores de usabilidade por parte do usuário final, inclusive sobre o quão fácil é navegar e obter as informações realmente desejadas.

Neste capítulo, discute-se os aspectos de modelagem de hiperdocumentos, em particular para o caso dos documentos HTML. Em seguida, discute-se a necessidade da modelagem do domínio de aplicação dos hiperdocumentos. O capítulo é finalizado com apresentação do RMM (Relationship Management Model) - metodologia utilizada na modelagem do domínio de aplicação ensino apresentada no próximo capítulo.

\subsection{Hiperdocumentos HTML simples e estendidos}

A autoria de hiperdocumentos para a WWW passa pela construção de hiperdocumentos baseados no padrão HTML. Hiperdocumentos HTML herdam da tecnologia da segunda geração de hipertextos (Halasz, 1988) o modelo de nós-ligações para associação de documentos externos, e a forma de apresentação e interação disponibilizadas pelos navegadores.

A navegação em documentos HTML, suportada pelos navegadores (browsers) atuais, se faz através das operações básicas definidas pela tecnologia de hipertextos: escolha livre de seleção 
de ligações, complementada por operações de backtracking, bookmarks e algum controle de caminho percorrido (Pimentel \& Buford, 1996).

Pelo fato da estrutura estabelecida pelo HTML ser muito simples, um hiperdocumento construído com HTML não pode apresentar, por si só, uma estruturação elaborada. Assim, os elementos são colocados livremente na composição do hiperdocumento, conforme mostra o trecho de codificação HTML da Figura 4.1, e sua visualização na Figura 4.2.

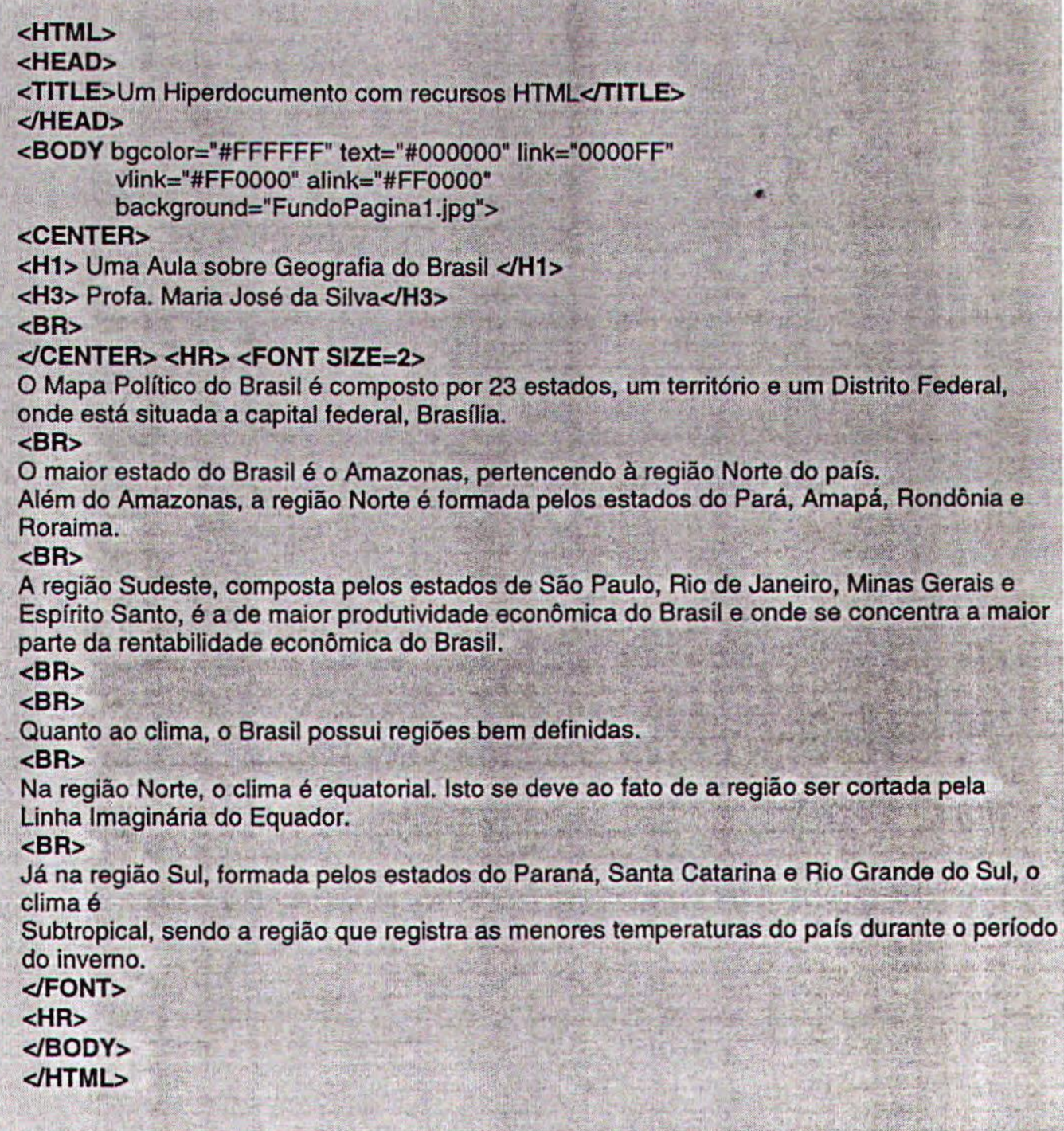

Figura 4.1 - Exemplo de um documento HTML simples

Um documento HTML é composto pelos elementos (tais como TITLE e BODY) e pelo conteúdo propriamente dito. Um exemplo de documento HTML é apresentado na Figura 4.1; a Figura 4.2 
corresponde à apresentação desse documento em um browser. Esse documento é bastante simples, e apresenta a definição de elementos estruturais (HEAD, TITLE, BODY) lado a lado com elementos associados à forma de apresentação (CENTER, HI, H2, HR, FONT, BR). Essa mistura de elementos estruturais com elementos relativos à forma de apresentação é muito comum em HTML. Essa característica se deve ao fato de que a estrutura imposta pelo padrão é muito simples (HEAD, TITLE, BODY) e os elementos de apresentação inseridos (H1, HR, FONT) permitem amenizar esse fato.

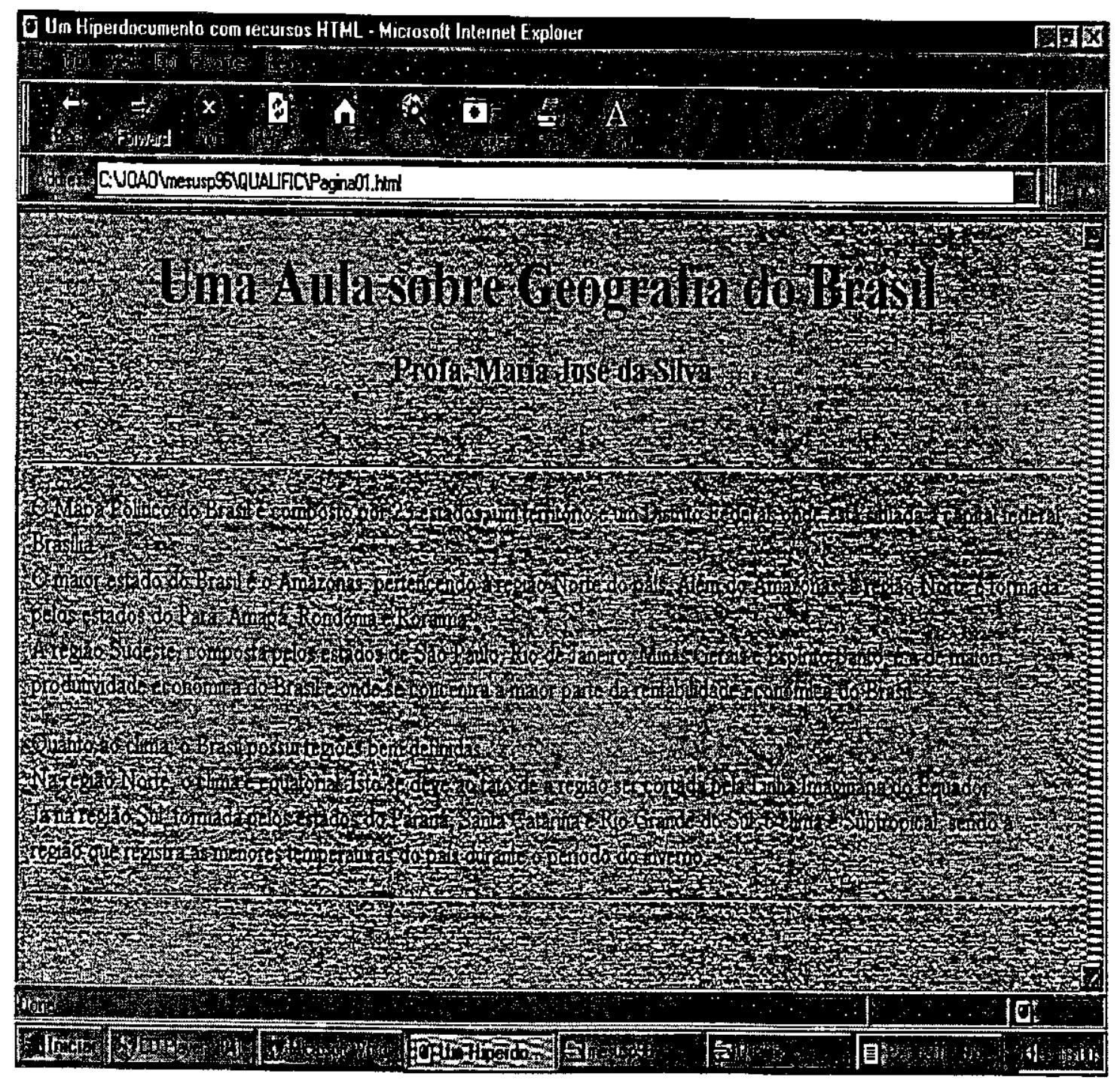

Figura 4.2 - Apresentação em um browser do documento correspondente à Figura 4.1

A simplicidade do modelo HTML limita, ainda, a estrutura de ligações que pode ser associada à coleção de documentos. Por exemplo, é possível a definição de ligações ponto-a-ponto e ponto-a- 
nó, mas não de ligações 1:N, N:M e trilhas. É relevante para o contexto deste trabalho observar que, quando sistemas hipermídia convencionais são utilizados em ensino, o usuário é livre para aprender sozinho, e pode ser visto como uma versão suportada eletronicamente de auto-didata (Pimentel \& Hagui, 1996). Neste contexto, o usuário é exposto aos problemas tradicionais de navegação em hipertexto: desorientação e sobrecarga cognitiva (Conklin, 1987). Uma situação distinta ocorre em sistemas adaptativos tradicionais (tutor, guides e outros), que utilizam um modelo do usuário que possui informação a respeito do conhecimento do domínio do usuário (Beaumont, 1995).

Sistemas hipermídia adaptativos atuam como intermediários entre essas duas abordagens: a iniciativa de navegação é do estudante, entretanto o sistema se adapta ao estudante com o objetivo de guiá-lo implicitamente, mas significativamente, ao manipular o conteúdo das ligações e dos nós (Beaumont, 1995). Entre as razões para uso de sistemas hipermídia adaptativos, encontram-se o fato de que o hiperdocumento pode ser utilizado por diferentes classes de usuários, de que a orientação do sistema auxilia na redução do problema de desorientação intrínseco de sistemas. Naturalmente, a especificação de documentos suportados em sistemas hipermídia adaptativos exige a utilização de elementos estruturais muito mais complexos do que os definidos por HTML.

Seja no contexto de sistemas hipermídia adaptativos ou convencionais, a estrutura dos documentos HTML pode ser elaborada de modo a conter elementos específicos a serem explorados em material didático. Neste caso, a contrapartida está em como suportar uma estrutura elaborada e ainda fazer uso da flexibilidade dos documentos HTML.

A estrutura e o conteúdo dos hiperdocumentos HTML podem ser elaborados com o uso de applets JAVA, programas executáveis que são transferidos através da rede e executados pela ferramenta de navegação (browser) (Sun, 1996). Um applet JAVA é inserido em uma página HTML através do elemento <APPLET>, como ilustrado ao final do documento apresentado na Figura 4.3. As Figuras 4.4a e 4.4b ilustram a apresentação da página correspondente. 


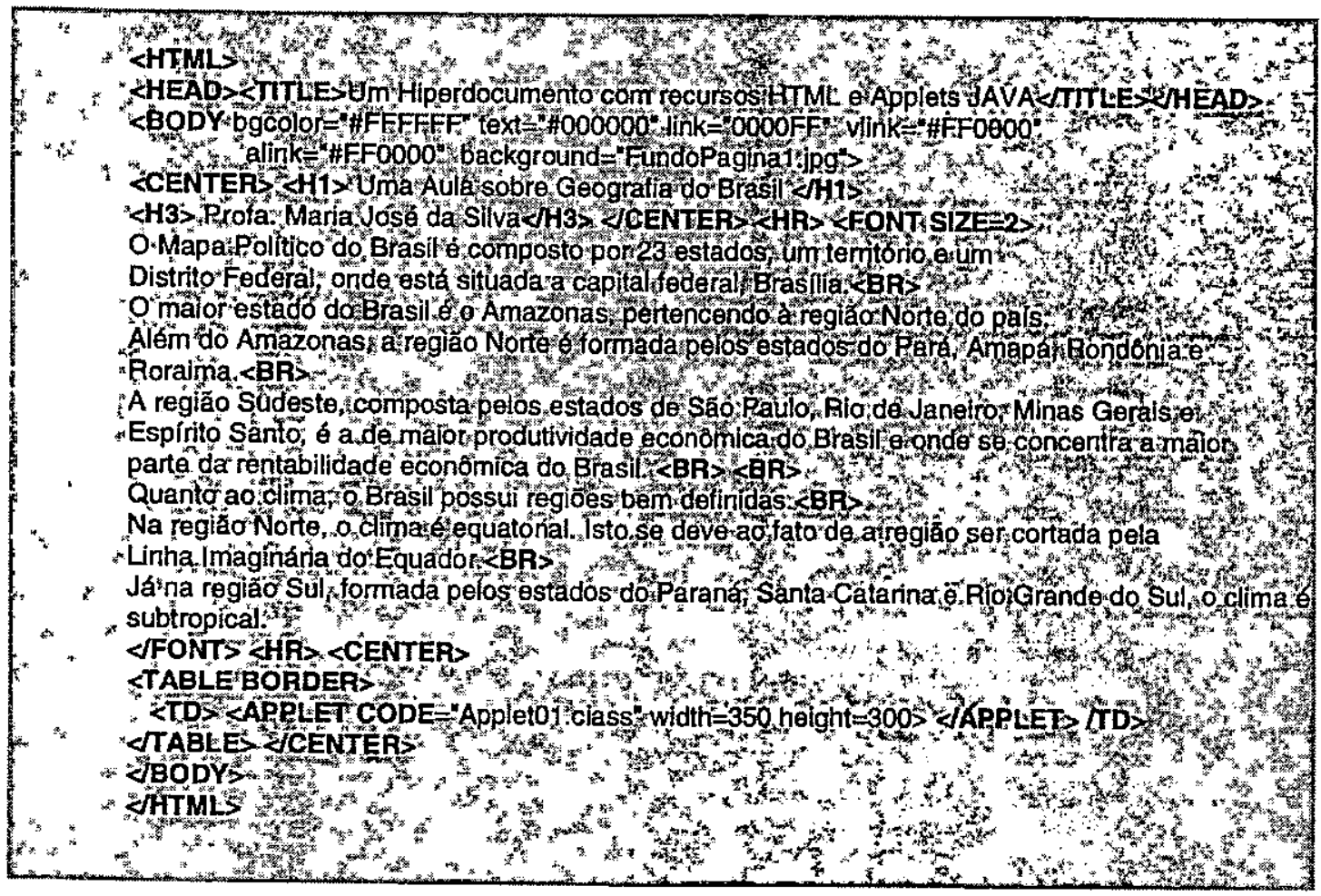

Figura 4.3 - Exemplo de um documento contendo applet JAVA

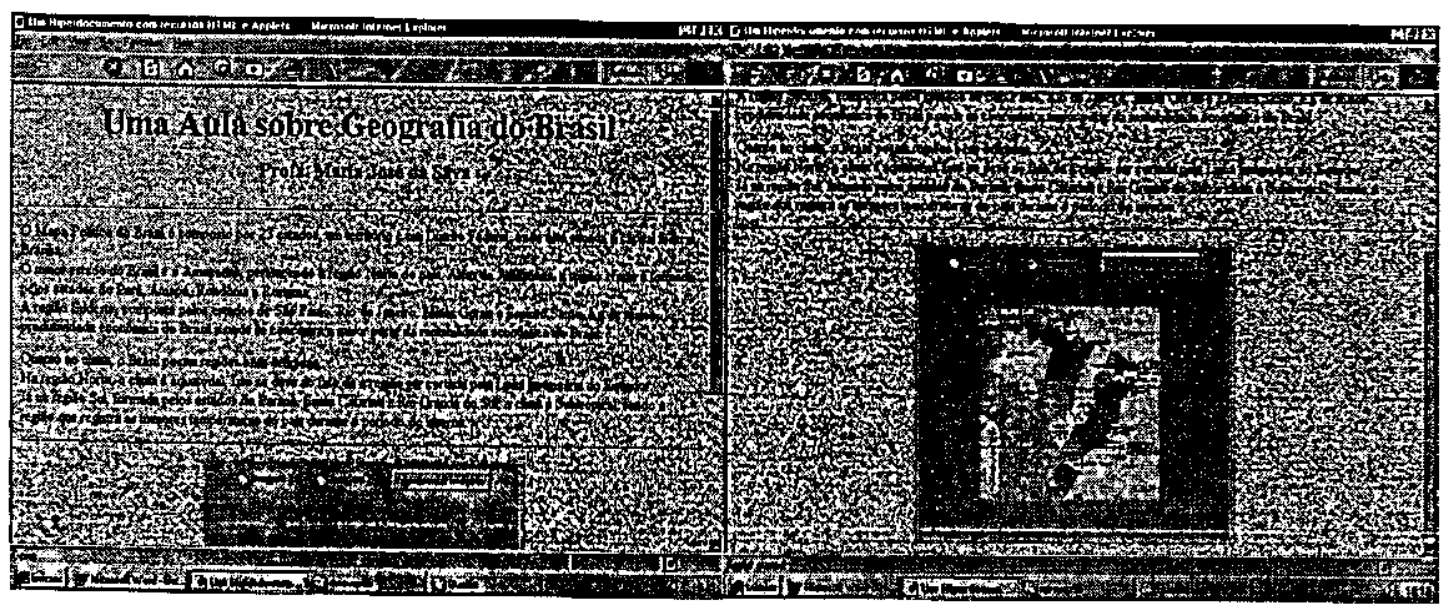

(a)

(b)

Figura 4.4 - (a) Apresentação do documento da Figura 4.3 (b) Apresentação do documento da Figura 4.4a após interação usuário-applet

De modo similar, código JAVAScript pode ser inserido diretamente em um documento HTML. O código JAVAScript possui sintaxe semelhante a de programas $\mathrm{C}$ e $\mathrm{C}++$, sendo permitida a declaração de variáveis e estruturas de dados, e codificação de estruturas para controle de fluxo de programa. Observa-se que um código JAVAScript é compilado e interpretado no momento em que a página HTML é interpretada pelo browser. 


\subsection{Modelagem de um sistema de informação baseado na WWW}

Neste tópico é apresentado o método WBIS para análise e projeto de sistemas de informação baseados na WWW, proposto por (Takahashi, 1997). O método focaliza a arquitetura e as funções' dos sites da WWW, ao invés de simplesmente cuidar da construção, em termos de layout, dos mesmos. O objetivo é o desenvolvimento eficiente de hiperdocumentos com base em um modelo E-R (entidade e relacionamentos) para os aspectos estáticos dos sistemas de informação e em um modelo de cenários para os aspectos dinâmicos. Neste ponto, o modelo E-R é baseado no método RMM (Relationship Management Model) (Isakowitz, 1995).

Um sistema baseado na WWW tem como finalidade não simplesmente disseminar informaçб̃es, mas também sistematizar os processos que acompanham as tarefas dos usuários. Desta forma, a análise e o projeto de WebSis necessita de uma modelagem específica e diferente das utilizadas em sites que simplesmente apresentam informações. Neste contexto, tem-se observado esforços no projeto de interfaces (Nielsen, 1995) e também na modelagem de hiperdocumentos para a WWW (Isakowitz, 1995), sem, no entanto, sistematizar a modelagem da estrutura do hiperdocumento.

Conforme citado, o método para análise e projeto de sistemas para a WWW consiste do uso de modelagem E-R e cenários. O modelo E-R define quais são as entidades e como elas se relacionam. O método de cenário define como os recursos disponíveis na WWW são acessados, usados, e modificados.

De modo geral, o método para análise e projeto de WBIS consiste das seguintes atividades:

- análise de entidades e relacionamentos (E-R);

- análise de cenários;

- projeto da arquitetura;

- definição de atributos.

Inicialmente, o domínio de aplicação dos hiperdocumentos é analisado pela aplicação do modelo E-R. Em seguida, uma análise de cenário determina como os usuários em potencial interagem com o sistema de informação baseado na WWW. Com base nos resultados desta análise, a 
arquitetura do sistema é projetada e, então, os atributos dos recursos que formam os hiperdocumentos são definidos.

\subsubsection{Análise E-R do domínio do problema}

Dado um domínio de aplicação, é necessária uma análise para compreensão desse domínio e determinação dos objetivos do sistema de informação em termos das relações das entidades. As entidades e suas relações são baseadas na estrutura do WebSis, sendo categorizadas em agentes, eventos e produtos. Os agentes são entidades que afetam outras entidades, incluindo grupos e indivíduos. Os eventos são agentes esquematizados e que indicam uma forma de conduta para os agentes. Os produtos são produzidos pelos agentes e resultados dos eventos.

\subsubsection{Análise de cenário}

Após a análise E-R, uma análise de cenário é realizada para identificar quais são os usuários potenciais, quais os recursos web necessários, e como os usuários poderão visitar e usar os recursos, e também como o sistema de informação emitirá respostas ao usuário quando este atingir o seu objetivo.

A análise de cenário evidencia os caminhos navegacionais e os recursos da WWW necessários ao usuário. De modo geral, esses caminhos navegacionais e recursos forma blocos no projeto da arquitetura do sistema de informação. Desta forma, uma vez projetada a arquitetura, pode-se validá-la através dos cenários. Assim, através da análise e projeto, as entidades e suas relações no modelo E-R são transformadas em recursos providos pelo ambiente WWW e links de navegação na arquitetura, respectivamente. Neste contexto, programas que processem tarefas do usuário, tais como CGI e JAVA applets, são projetados com base nos cenários.

\subsubsection{Projeto da arquitetura}

Com base na análise de cenário, a arquitetura de um sistema de informação é projetada e representada em um diagrama RMDMW (Relationship Management Data Model for WebSis) que é uma extensão do RMDM (Relationship Management Data Model) para diferenciar agentes, eventos e produtos, e evidenciar como os recursos web são compostos de entidades. 


\subsection{Modelagem de hiperdocumentos}

No projeto de um hiperdocumento que será utilizado por um grupo de usuários, deve-se procurar acompanhar as tarefas desses usuários, sendo necessário reorganizar as informações em um modelo conceitual (Schwabe, 1996).

A definição de um modelo navegacional como uma visão do modelo conceitual permite o relacionamento das tarefas do usuário. Isto indica que, em hiperdocumentos, o espaço de navegação deve ser projetado em termos do tipo de usuário e o conjunto de tarefas que ele realiza usando a aplicação. Diferentes modelos navegacionais podem ser construídos para um mesmo modelo conceitual, o que torna possível a construção de várias aplicações, cada qual para um grupo de usuários e tarefas distintas.

No contexto de documentos HTML, urn modelo navegacional é expresso em termos de nós e links, onde um nó é uma entidade que identifica um determinado conteúdo no contexto da aplicação em termos das tarefas do usuário. Em adição, um link estabelece um relacionamento entre nós ou partes dos nós, e modela a transição de um estado a outro da aplicação. $O$ acionamento de urn link reflete a execução de uma tarefa do usuário e, conseqüentemente, o situa em um determinado estágio de navegação no contexto da aplicação.

Uma vez definido o modelo navegacional, é necessário construir o que será perceptível ao usuário através da interface da aplicação, o que geralmente é feito em etapas a partir de um modelo abstrato da interface advindo dos requisitos do usuário. Isto implica em definir quais objetos da interface serão percebidos pelo usuário e, em particular, a forma na qual diferentes objetos navegacionais aparecem, como são ativados e sincronizados nas transições da interface.

A literatura de hipermídia destaca as características dos principais métodos para modelagem de hiperdocumentos, que auxiliam um autor na representação de um domínio de informação de um hiperdocumento para posterior disponibilização em um sistema hipertexto. De modo geral, os modelos propõem a modelagem lógica de um hiperdocumento, com recursos para definição de esquemas conceituais de dados. 
O HDM (Hypertext Design Model) foi o primeiro método formal de projeto de hiperdocumento voltado especialmente para aplicações hipermídia (Garzoto, 1993). Ele sugere a utilização de uma abordagem estruturada para o desenvolvimento de hiperdocumentos, com a modelagem do domínio de informações de uma aplicação como suporte para a autoria das páginas e links para porçōes destas. A proposta do HDM visa diminuir os dois problemas típicos da utilização de sistemas hipertexto: desorientação e sobrecarga cognitiva. Dentre as inovações de HDM destacam-se:

- a noção de perspectiva;

- a identificação de diferentes categorias de links (estruturais, de aplicação e de perspectiva) com diferentes papéis de representação;

- a distinção entre a hiperbase (como é denominada a base de documentos) e as estruturas de acesso;

- a possibilidade de integrar facilmente a estrutura de uma aplicação hipertexto à sua semântica de navegação.

Assim, o autor de aplicações hipertexto se confronta com pelo menos duas categorias de tarefas fortemente correlacionadas:

- globais: atividades como definir classes gerais de elementos de informação e estruturas de navegação;

- locais: atividades relativas ao preenchimento dos conteúdos dos nós.

Uma das principais vantagens da modelagem através do HDM para projeto e construção de aplicações hipertexto é a derivação automática da definição de um número significativo de links a partir de uma descrição em nível de projeto conceitual.

Outro modelo foi proposto como uma extensão do HDM de modo a explorar os recursos da orientação a objetos no projeto de aplicações hipermídia (Schwabe, 1996). Trata-se de uma proposta sistemática de projeto denominada OOHDM (Object-Oriented Hypermedia Design Model). Além de subsidiar as fases de desenvolvimento de hiperdocumentos para aplicações hipermídia, o OOHDM possui um diferencial importante, que é a visão orientada a objetos na fase de modelagem das informações contidas no hiperdocumento. 


\subsection{Relationship Management Model}

De modo geral, pode-se afirmar que existem diferenças entre o desenvolvimento de um conjunto de páginas para um website e o desenvolvimento de um sistema que manipule informações na WWW. O RMM (Relationship Management Model) (Isakowitz, 1995) é uma metodologia para o projeto de sistemas web.

As aplicações WWW envolvem uma coleção de páginas HTML que são acessadas com alta freqüência e de forma não-linear. O RMM visa facilitar o projeto de sites WWW, sobretudo quando as aplicações são dinâmicas e para as quais os dados estão armazenados em bases de dados e hiperlinks são gerados para a navegação do usuário. O RMM consiste de sete passos bem delineados que orientam o projeto e o desenvolvimento de sistemas baseados na WWW.

O RMM fornece um modelo estruturado para o projeto, eliminando problemas navegacionais gerados por codificações-spaghetti em favor de um site bem estruturado no que se refere à navegação do usuário. O RMM promove a separação dos dados, estrutura e interface do usuário. Neste contexto, o RMM conserva estes três elementos separadamente e permite que eles sejam manipulados.

Com relação aos dados, observa-se o gerenciamento eficiente dos diversos tipos de arquivos presentes em websites, tais como imagens, elementos multimídia e outros. Quanto à estrutura, 0 problema maior é a dificuldade enfrentada pelos projetistas em implementar vários projetos navegacionais. Neste ponto, o RMM modela a estrutura do website em termos de diagramas de estados que podem ser implementados de diversas formas.

A motivação para a proposta do método RMM (Relationship Management Methodology) (Isakowitz, 1995), se destina prioritariamente à classe de aplicações que exibem uma estrutura regular no domínio de interesse, ou seja, em domínios onde existam classes de objetos cujos relacionamentos possam ser definidos entre essas classes e múltiplas instâncias de objeto dentro de cada classe. Além disso, muitas aplicações hipermídia pertencentes a essa classe possuem dados "voláteis" que requerem frequentes atualizaçōes, o que por sua vez configura a necessidade de meios para sistematizar e automatizar tanto o desenvolvimento inicial quanto os 
subseqüentes processos de atualização (Fortes, 1996). A Tabela 4.1 apresenta os casos de uso e a indicação de utilidade do RMM no desenvolvimento de aplicações hipermídia.

A proposta do Modelo de Gerenciamento de Relacionamentos deriva da visão da hipermídia como sendo um veículo para gerenciar relacionamentos de objetos de informação.

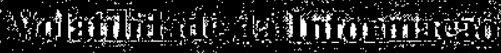

\begin{tabular}{|c|c|c|c|}
\hline \multirow{3}{*}{ ardo } & & Baixa & Alta \\
\hline & Alta & $\begin{array}{l}\text { Média utilidade } \\
\text { [Ex.: Kiosk de } \\
\text { Informąõos] } \\
\end{array}$ & $\begin{array}{l}\text { Alta utilidade } \\
\text { [Ex.: Interface para } \\
\text { um DBMS] }\end{array}$ \\
\hline & Baixa & $\begin{array}{l}\text { Sem utilidade } \\
\text { [Ex.: Trabalho literário] }\end{array}$ & $\begin{array}{l}\text { Baixa utilidade } \\
\text { [Ex.: ' Serviço de } \\
\text { Notícias Baseado em } \\
\text { Multimídia] }\end{array}$ \\
\hline
\end{tabular}

Tabela 4.1 - Indicação de uso do RMM

Conforme apresentado na Tabela 4.1, aplicações em domínios como catálogos de produtos e interfaces hipermídia para bases de dados, são altamente estruturadas e possuem informações altamente voláteis, fazendo com que a metodologia RMM seja particularmente apropriada. Por outro lado, um trabalho artístico pode não possuir uma estrutura clara em termos de leitura e usualmente não sofrer atualizações ao longo do tempo. Em adição, aplicações estruturadas que não sofrem atualizações ao longo do tempo podem se beneficiar do RMM durante as fases de projeto e construção, mas não requerem manutenção. Finalmente, aplicações que possuem estruturas irregulares e alta volatilidade de informações podem obter pouco ganho de desenvolvimento com o uso do RMM. Neste caso, o uso do RMM ainda é indicado quando se considera apenas que o domínio deva ser estruturado e, desta forma, as informações serão parcialmente referenciadas.

\subsubsection{Relationship Management Data Model}

Um modelo de dados é um conjunto de objetos lógicos usado para fornecer uma abstração de uma porção do mundo real. Neste contexto, modelos de dados são necessários para expressar o projeto de uma aplicação (Halasz \& Schwartz, 1994). 
Um modelo de dados para um sistema hipertexto detalha a sua arquitetura interna, mas é de pouco valor para a modelagem de aplicações hipermídia. Observa-se que, descrever o layout é um processo distinto de modelar o domínio de uma aplicação. Neste contexto, o RMDM (Relationship Management Data Model) fornece uma linguagem para descrição dos objetos de informação e mecanismos de navegação em aplicações hipermídia.

A metodologia RMM difere de outros modelos, como por exemplo o HDM (Garzoto, 1993), em muitos pontos, incluindo a recomendação de uma seqüência de passos, formalismos para estruturas de acesso, ênfase em um projeto incremental e representações gráficas, e um maior detalhamento dos procedimentos passo-a-passo para o projeto e desenvolvimento de aplicações hipermídia. Neste contexto, o RMDM é o coração da metodologia RMM. A Figura 4.5 apresenta as primitivas de modelagem do RMDM. As primitivas de modelagem do domínio modelam as informações em cima de um domínio de aplicação. Neste ponto, as entidades e seus atributos representam objetos físicos e abstratos.

Os relacionamentos associativos, que podem ser um-para-um ou um-para-muitos, descrevem as associações entre diferentes tipos de entidades. Neste ponto, assim como em modelagem de bases de dados, um relacionamento muitos-para-muitos deve ser dividido em dois relacionamentos um-para-muitos. Em adição, pelo fato de que uma entidade pode ser constituída de atributos de diferentes tipos (salário, fotografia do funcionário, nome e outros), pode-se tornar impraticável ou pouco viável apresentar todos os atributos de uma instância dessa entidade de uma só vez. Desta forma, os atributos podem ser agrupados em slices, que é uma primitiva $R \boldsymbol{M D}$ para modelagem do domínio. De modo geral, um slice define as formas de apresentação de uma instância de uma entidade ao usuário e, caso a aplicação suporte, o usuário poderá escolher a forma de visualização dos dados da entidade.

Por fim, a navegação é suportado no RMDM por seis primitivas de acesso. Os links unidirecionais e bidirecionais são usados para especificar o acesso a slices de uma entidade. Neste ponto, é importante ressaltar que os links podem ser usados somente para navegar dentro de instâncias de uma entidade. 
Em adição, o RMDM suporta a navegação cruzada entre diferentes entidades através dos índices, guided tours e grupamentos. Um índice atua como uma tabela de conteúdos para uma lista de instâncias de uma entidade, fornecendo o acesso direto a cada item da lista. Um guided tour implementa um caminho linear pela lista de itens, permitindo ao usuário mover-se para frente $\mathrm{e}$ para trás nesse caminho linear.

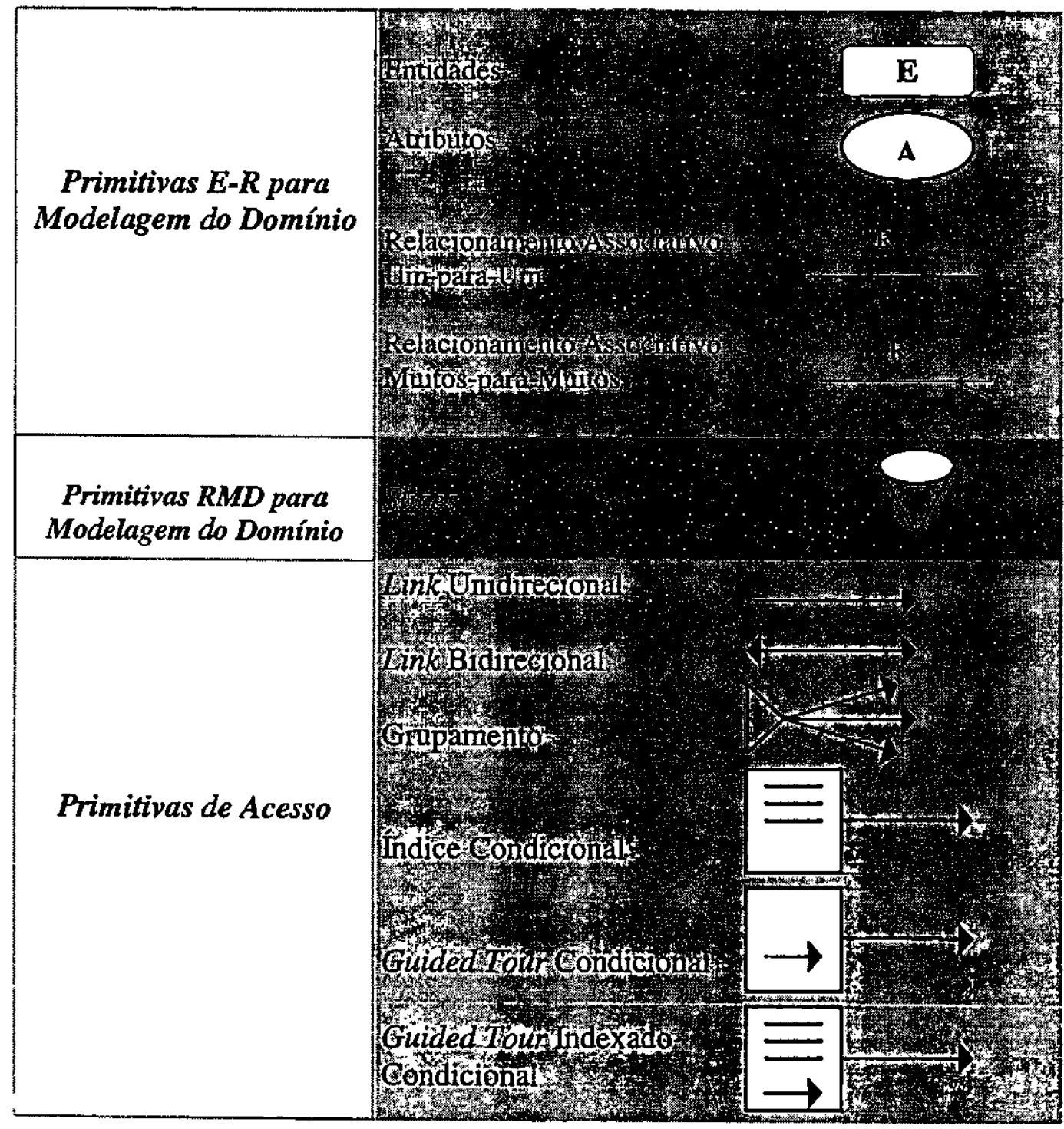

Figura 4.5 - Primitivas de modelagem do RMDM

O RMDM suporta todas as variações de implementação do guided tour, apesar de considerar como padrão a implementação de um guided tour genérico. Por fim, um construtor de grupamento é um mecanismo que constrói um menu genérico que habilita o acesso a outras partes de um documento hipermídia. Um exemplo bastante comum de grupamento é a construção 
de telas de abertura de muitas aplicações, através das quais é fomecido o acesso a outras funções da aplicações, tais como índices e guided tours. Em relação aos índices e guided tours, tem-se que as condições e predicados lógicos determinam quais instâncias de uma entidade são acessíveis a partir de uma construção de um grupamento. Com o uso de índices garante-se o acesso a determinadas informações de forma direta. Além disso, existe também links de retomo de cada nó da lista que compõe o indiçe. Em adição, guided tours indexados combinam as potencialidades dos índices 'e guided tours para fomecer uma estrutura de acesso bastante ampla. A Figura 4.6 apresenta casos de uso das primitivas de acesso entre duas entidades de um sistema de informações sobre cursos e professores de uma escola.

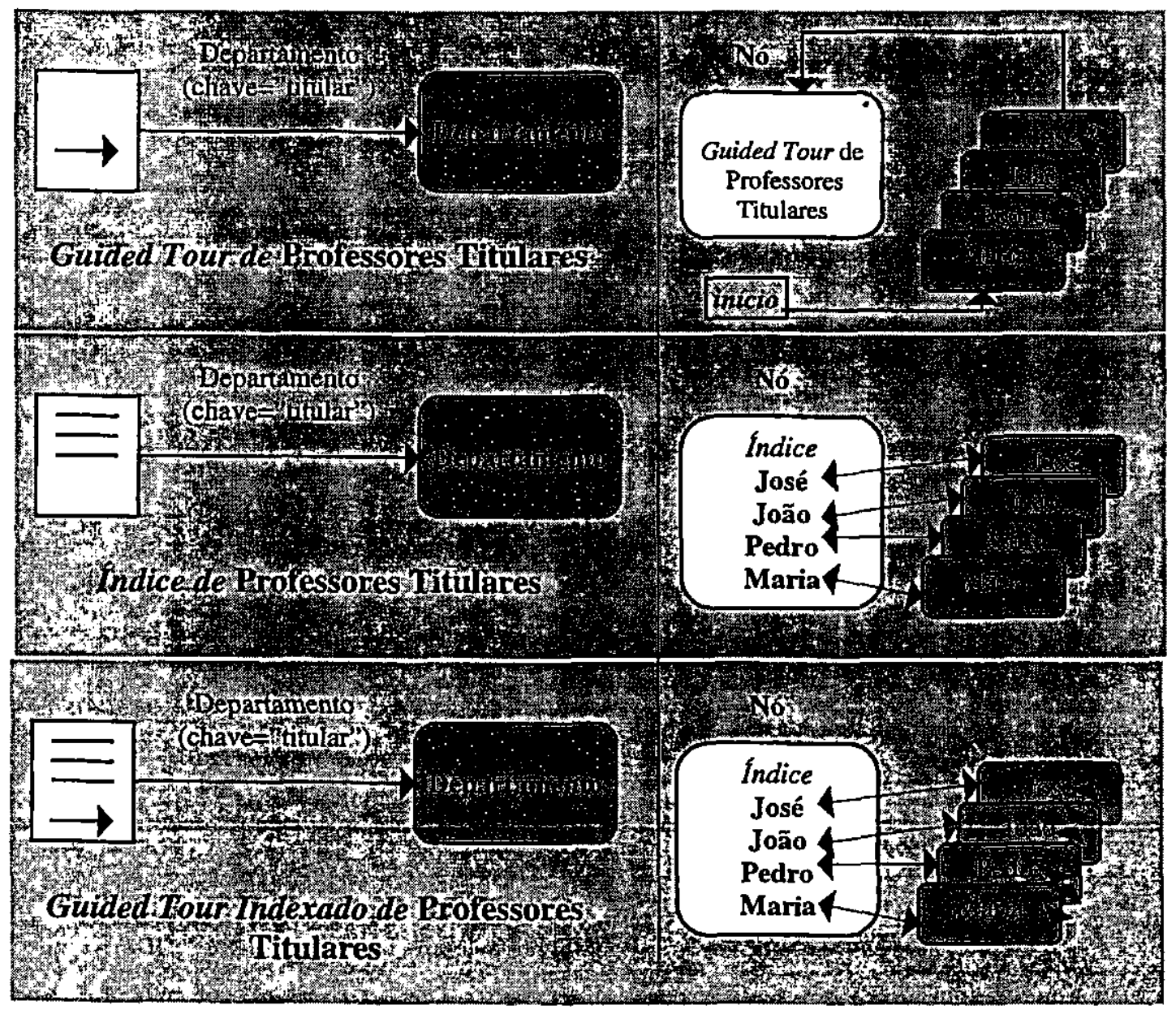

Figura 4.6 - Casos de uso das primitivas de acesso RMDM

\subsubsection{A metodologia RMM}

O RMM focaliza as fases de projeto, desenvolvimento e construção de aplicações hipermídia, estando inserido no contexto do ciclo de desenvolvimento de software, conforme apresenta a Figura 4.7. Neste contexto, observa-se que, apesar de as fases de análise de requisitos e testes 
serem importantes, a metodologia RMM concentra-se no projeto dos mecanismos de acesso que compreendem os passos 1, 2 e 3 apresentados pela Figura 4.7. Em adição, a avaliação de aplicações hipermídia pode ser realizada com o uso de técnicas propostas por (Botafogo et al., 1992). O modelo de dados RMDM fornece uma forte prescrição para seleção dos nós e links em uma aplicação hipermídia. Entretanto, decisões podem ser tomadas pelos projetistas, independentemente das especificações feitas no modelo. Desta forma, é necessário construir guidelines para cada passo da metodologia.

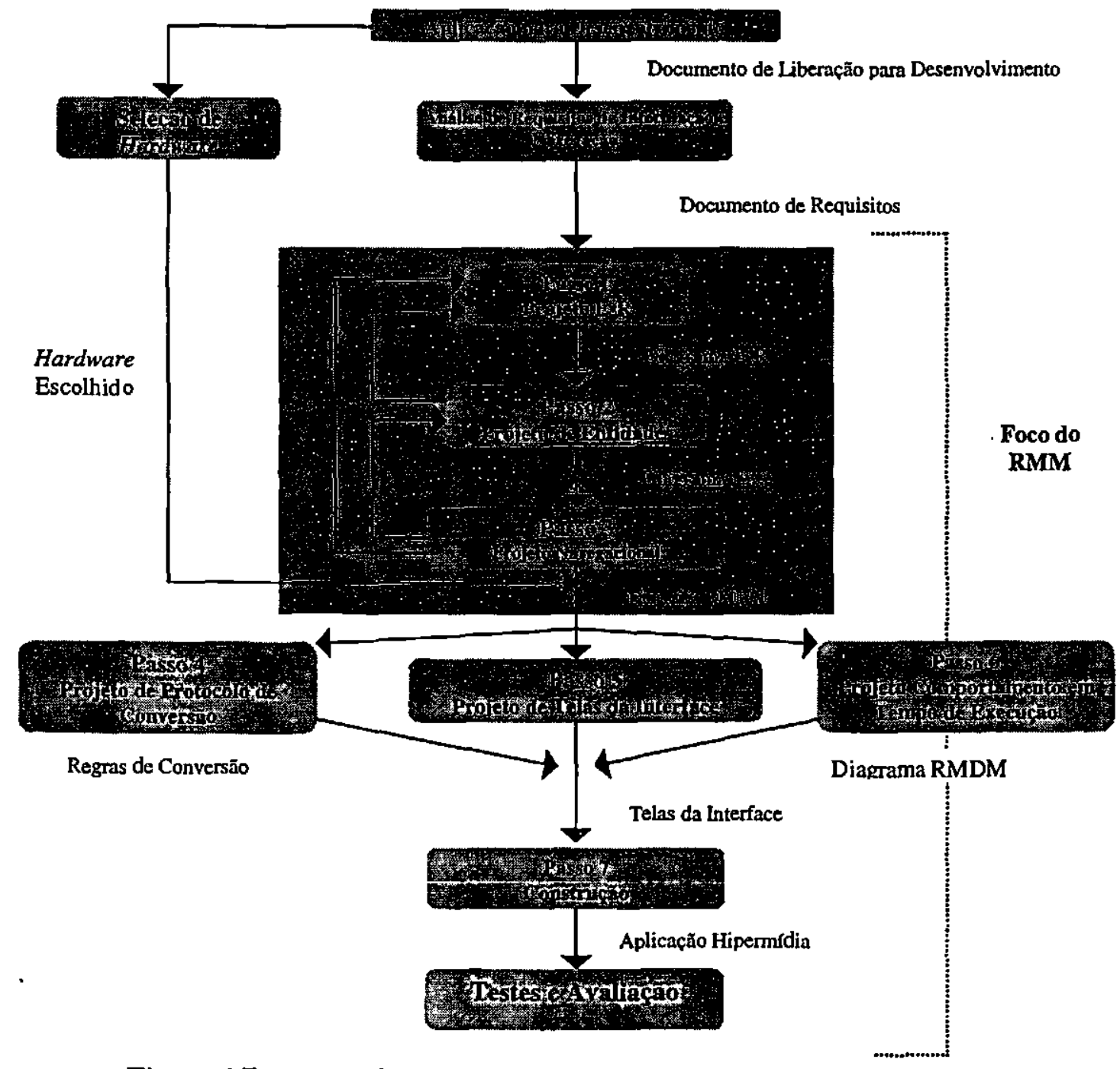

Figura 4.7 - Metodologia RMM e o ciclo de desenvolvimento de software

\subsubsection{Projeto das entidades e relacionamentos (E-R)}

O primeiro passo do projeto é representar o domínio de informação da aplicação através de um Diagrama de Entidades e Relacionamentos (E-R). O modelo E-R foi escolhido por ser familiar 
aos analistas de sistemas, além de bem documentado e aplicável ao projeto de um grande número de aplicações.

Este passo do projeto representa um estudo das entidades importantes da aplicação e seus relacionamentos no domínio. Tais entidades e relacionamentos forma a base da aplicação hipermídia e muitas delas serão apresentadas ao usuário na aplicação final, como nós e links de uma aplicação hipermídia.

De modo geral, pode-se observar as seguintes guidelines do projeto das entidades e relacionamentos:

- o objetivo no projeto de aplicações hipermídia é especificar os links entre os objetos da aplicação;

- uma análise do domínio usando o modelo E-R auxilia na identificação dos relacionamentos importantes que serão suportados pela navegação;

- se um caminho navegacional entre entidades é um requisito da aplicação, o relacionamento associativo correspondente deve aparecer no modelo E-R.

\subsubsection{Projeto de slices}

Este segundo passo, também denominado projeto de entidades e que é exclusivo para aplicações hipermídia, determina como a informação de uma determinada entidade será apresentada aos usuários e como estes poderão acessá-la. Este processo envolve a divisão da entidade em slices (partes menores para apresentação ao usuário) e organização destes em um sistema hipertexto. Essa organização de entidades em slices é denominada fase de projeto de slices, e resulta em um diagrama de slices, onde cada slice é um ou mais atributos de uma entidade.

Cada entidade possui um slice especial, denominado head, que é usado como âncora-padrão quando um link atinge a entidade. O diagrama de slices de uma entidade também modela a navegação entre os slices através de links unidirecionais e bidirecionais. Neste ponto, a rotulação das linhas que ligam os slices é efetuada de forma a identificar a direção da informação obtida através do link. Como convenção, o rótulo entre parênteses indica que o sentido da informação é 
para cima ou para esquerda; obviamente, o rótulo que estiver fora dos parênteses indica que o sentido da informação é para baixo ou para a direita.

Os links estruturais diferem-se dos relacionamentos associativos por conectarem informações dentro de uma entidade. De modo geral, e fazendo uma analogia com a análise e projeto estruturado de sistemas, é "como se fosse feita uma explosão da entidade". Por outro lado, os relacionamentos associativos interconectam diferentes instâncias de entidades.

Do ponto de vista navegacional, é importante diferenciar bem os dois tipos de conexão. Quando um usuário realiza uma visita a um link associativo, o contexto da informação muda, por exemplo, ele é levado da entidade departamento para uma entidade cursos do referido departamento. Entretanto, quando um link estrutural é visitado, o contexto da informação permanece inalterado, pois o usuário estará visitando partes de uma mesma entidade. Para dar suporte ao projeto de links estruturais e associativos, convencionou-se a seguinte representação na metodologia RMM:

- links estruturais são representados por linhas sólidas;

- links associativos são representados por linhas pontilhadas.

Ao final desta etapa, a saída da do projeto de entidades é uma diagrama E-R incrementado, denominado diagrama E-R+, que é o diagrama E-R acrescido do diagrama do projeto dos slices de cada entidade. De modo geral, pode-se observar as seguintes guidelines do projeto de entidades:

- dividir as entidades em slices;

- escolher um slice para ser o head da entidade;

- interconectar os vários slices;

- rotular os links que interligam os slices.

\subsubsection{Projeto navegacional}

Nesta etapa, devem ser projetados os caminhos que habilitam a navegação no hipertexto. Cada relacionamento associativo presente no diagrama E-R+ deve ser analisado. Se, em conformidade 
com a análise de requisitos, um relacionamento associativo puder toma-se acessível em termos de navegação, este deve então ser trocado por uma ou mais estruturas de acesso RMDM.

Conforme descrito no início, a metodologia RMM é relevante, em termos de aplicação, para os domínios de cujos as informações são atualizadas com relativa frequiência. Desta forma, todos os caminhos navegacionais são especificados de forma genérica, ou seja, sem codificação de links rígidos entre instâncias de entidades. No RMM, isto é possível através do uso dos elementos indice, guided tour, e guided tour indexado.

O projeto navegacional inicia-se com a definição da navegação entre as entidades, com base nos relacionamentos associativos. Em seguida, projeta-se as estruturas de acesso através do grupamento de itens de interesse. De modo padrão, o slice head é a estrutura de acesso de entrada de uma entidade. Entretanto, pode-se especificar um ponto qualquer de entrada para uma entidade, de acordo com as necessidades da aplicação.

Ao final do projeto navegacional, o diagrama E-R+ já terá sido transformado em um diagrama RMDM, que apresenta todas as estruturas de acesso a serem implementadas na aplicação. Em adição, o projeto pelo RMM, conforme apresentado até então, pode ser realizado com uso de um modelo bottom-up, que focalizam primeiramente cada entidade e posteriormente uma ou mais estruturas de acesso. Pode-se, ainda, realizar um processo inverso que resulta em um modelo topdown. De modo geral, pode-se observar as seguintes guidelines do projeto navegacional:

- identificar os componentes de informação e relacionamentos que poderão ser acessados através de navegação;

- identificar os grupamentos que poderão ser apresentados aos usuários;

- identificar as estruturas de acesso que serão utilizadas em cada caso.

\subsubsection{Projeto e construção da interface do usuárlo}

Como parte final da metodologia RMM, é apresentada uma discussão sobre os mecanismos de acesso e construção da interface do usuário. 
Atualmente, ferramentas como Toolbook, HyperCard, Director, bem como ferramentas para construção de documentos HTML, oferecem muitos recursos para suporte ao desenvolvimento de aplicações hipermídia, tais como widgets gráficos e bibliotecas de programação contendo construtores hipermídia. Entretanto, essas ferramentas apenas facilitam o processo de programação, sem fornecer auxílio às fases de projeto e desenvolvimento, em conformidade, por exemplo, com a proposta da metodologia RMM.

Neste contexto, quatro etapas são identificadas como suporte ao processo de construção da interface do usuário a partir dos resultados da modelagem obtida nos passos 1 (projeto E-R), 2 (projetos de entidades) e 3 (projeto navegacional).

Primeiramente, o quarto passo consiste do projeto do protocolo de conversão. Nesta etapa, devem ser usadas regras de conversão que permitam transformar cada elemento do diagrama RMDM em um objeto na plataforma final de apresentação. Como exemplo, pode-se observar que um formulário HTML pode ser usado para implementar um índice.

O quinto passo é o projeto da interface do usuário, que envolve a construção dos layouts de telas para todos os objetos presentes no diagrama RMDM obtido no terceiro passo.

No sexto passo, projeto do comportamento em tempo de execução, devem ser tomadas todas as decisões sobre como realizar a navegação pelos links, observando-se questões como backtracking e armazenamento do histórico de navegação. Ainda durante este passo, deve ser considerada a volatilidade da informação.

Finalmente, o sétimo passo consiste da construção e testes da aplicação hipermídia, assim como na Engenharia de Software tradicional.

\subsection{Considerações finais}

No contexto da WWW, um hipertexto pode ser visto como um conjunto de páginas formatado com o uso da linguagem HTML. Dado este processo de formatação, cada página pode ser visualizada pelo usuário final através de um navegador (browser). A característica de hipertexto 
é obtida uma vez que HTML permite o estabelecimento de ligações (links) entre porções dessas páginas.

De forma genérica, nos hiperdocumentos da WWW podem ser apresentados textos formatados, imagens estáticas e em movimento, tabelas de dados e sons, o que reforça sua indicação para o contexto dos ambientes de ensino. Em adição, a natureza distribuída do ambiente WWW incrementa e expande as fronteiras do relacionamento professor-estudante, permitindo a construção do conhecimento através de exploração individual de contextos ou ainda, por meio de mecanismos para suporte ao trabalho cooperativo (Kutova, 1998).

Neste capítulo foi discutida a necessidade da modelagem da estrutura e do conteúdo de hiperdocumentos, e ilustrado como isso pode ser obtido em documentos HTML. Em adição, foram apresentados alguns aspectos que apontam a relevância da modelagem do domínio de aplicação de hiperdocumentos. Um framework para a construção de sistemas de informação baseados na WWW foi apresentado, e ao final a metodologia RMM foi apresentada com vistas à sua aplicação na modelagem do domínio de aplicação ensino, proposta esta apresentada no próximo capítulo. 


\section{FERRAMENTAS PARA AUTORIA DE MATERIAL DIDÁTICO}

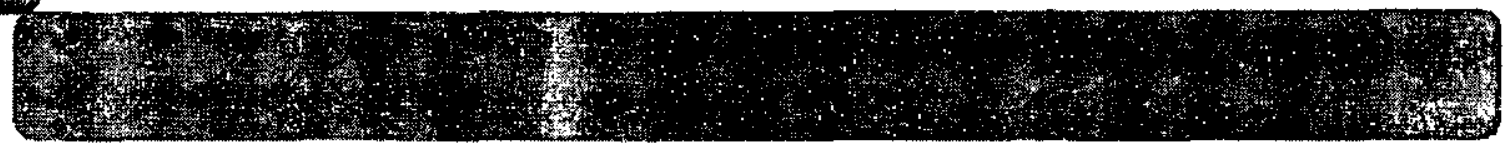

\subsection{Considerações iniciais}

A especificação de estruturas de documentos para o ambiente WWW é feita através do uso da linguagem HTML, sendo possível combinar os documentos a programas JAVA e código JAVAScript.

De modo geral, a disponibilização de material didático está inserida no contexto da construção de documentos HTML e da utilização de browsers para visualização e navegação desses documentos. O capítulo anterior apresentou argumentos favoráveis à construção de ferramentas específicas para auxílio à autoria de documentos elaborados.

Neste capítulo é apresentada, inicialmente, a modelagem do domínio de aplicação ensino, através do uso do RMM, para o qual o conjunto de ferramentas foi implementado. Em seguida, são apresentadas as ferramentas implementadas para autoria e disponibilização de material didático no ambiente WWW, e que fazem parte da arquitetura de software na qual este projeto se insere.

\subsection{Aplicação do RMM}

A metodologia RMM é aplicada a este projeto que tem por objetivo a construção de ferramentas de que dêem suporte à autoria e à disponibilização de material didático no ambiente WWW. Neste contexto, é necessária a modelagem do conjunto de ferramentas como uma aplicação hipermídia. Observa-se, ainda, que o domínio de aplicação ensino acolhe com precisão a metodologia RMM pelo fato de que as informaçōes referentes a uma aula necessitam de manutenção com relativa freqüência. Em adição, a metodologia RMM permite a modelagem do domínio de aplicação e, posteriormente, dos hiperdocumentos que o compõem.

Assim, o suporte de uma metodologia, como o RMM, é relevante e conveniente quando se deseja transformar um conjunto de ferramentas e hiperdocumentos em uma aplicação. 
Conforme a metodologia RMM apresentada, o primeiro passo consiste da construção de um diagrama de entidades e relacionamentos (E-R). Nesta fase inicial da modelagem, conforme mostra a Figura 5.1, identificou-se as entidades do domínio de aplicação ensino.

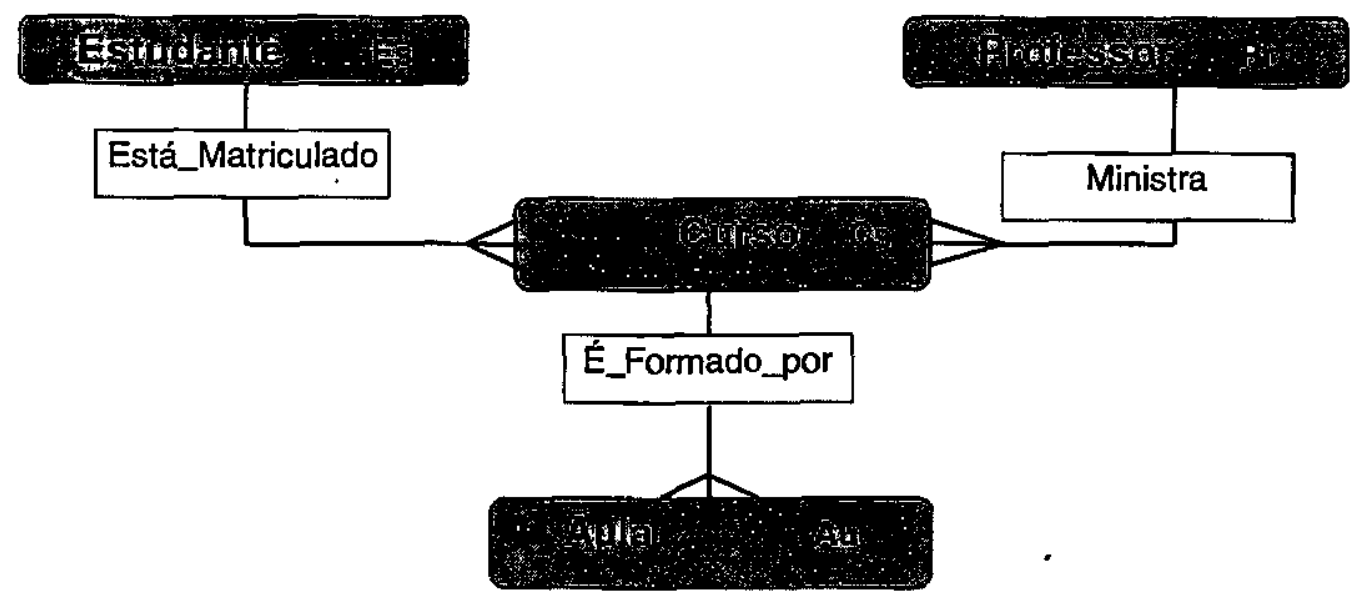

Figura 5.1 - Passo 1 - Diagrama E-R para o domínio de aplicação Ensino

Na seqüuência, modelou-se as entidades que compõem a entidade Curso com vistas à identificação dos componentes para implementação das ferramentas de autoria e apresentação. Neste ponto, a explosão originou as entidades Texto Didático, Tópicos da Aula, Questionário de Avaliação e Exercícios, além de seus relacionamentos. Além disso, rotulou-se os relacionamentos através da observação da cardinalidade (um-para-um ou um-para-muitos), conforme ilustra a Figura 5.2.

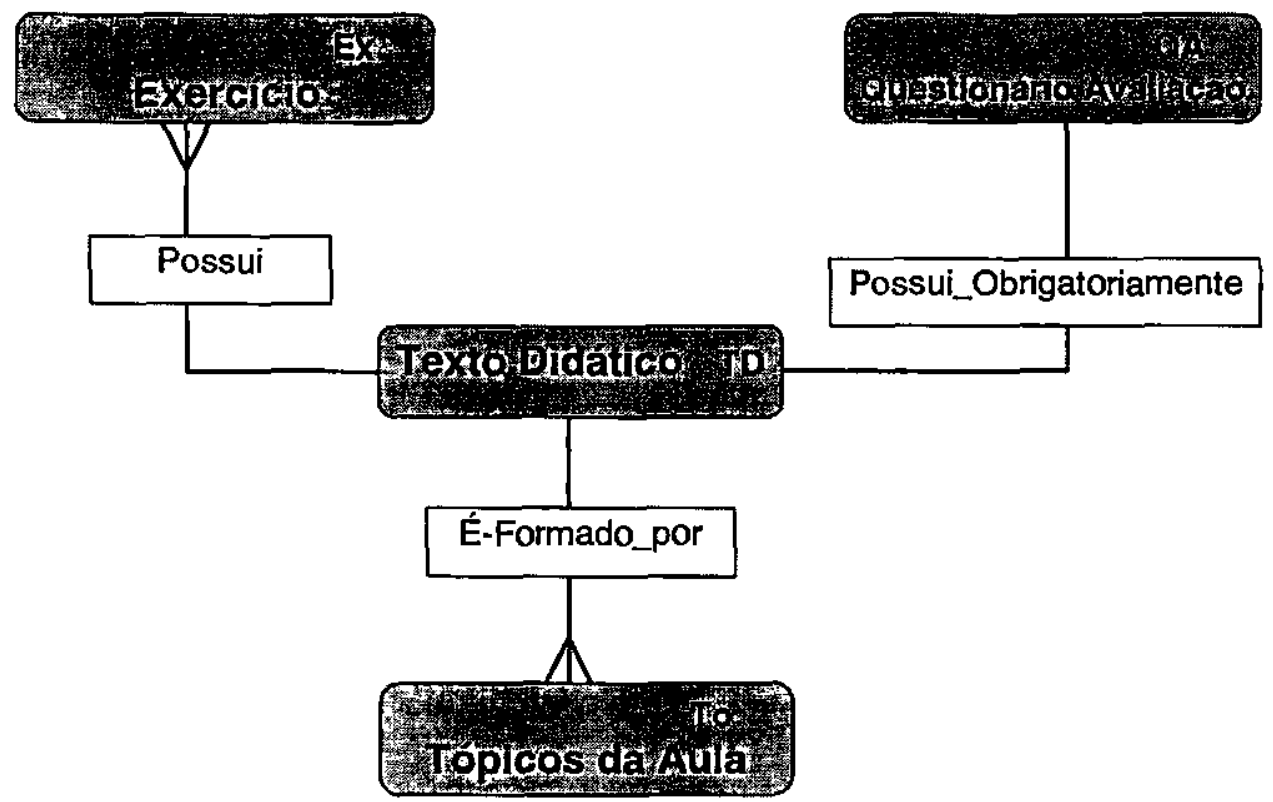

Figura 5.2 - Passo 1 - Diagrama E-R para a entidade curso da arquitetura proposta 
No segundo passo, tomando por base o diagrama E-R construído no primeiro passo, foi construído um diagrama de entidades (diagrama de slices) que, em suma, consiste em "explodir" uma entidade em partes que serão visualizadas pelo usuário. Nesta modelagem, conforme mostram as Figuras 5.3a, 5.3b e 5.3c, foram obtidos os slices de cada entidade presente no diagrama E-R, além dos relacionamentos estruturais. Ao anexar o diagrama E-R ao diagrama de entidades, obtém-se o diagrama E-R+.

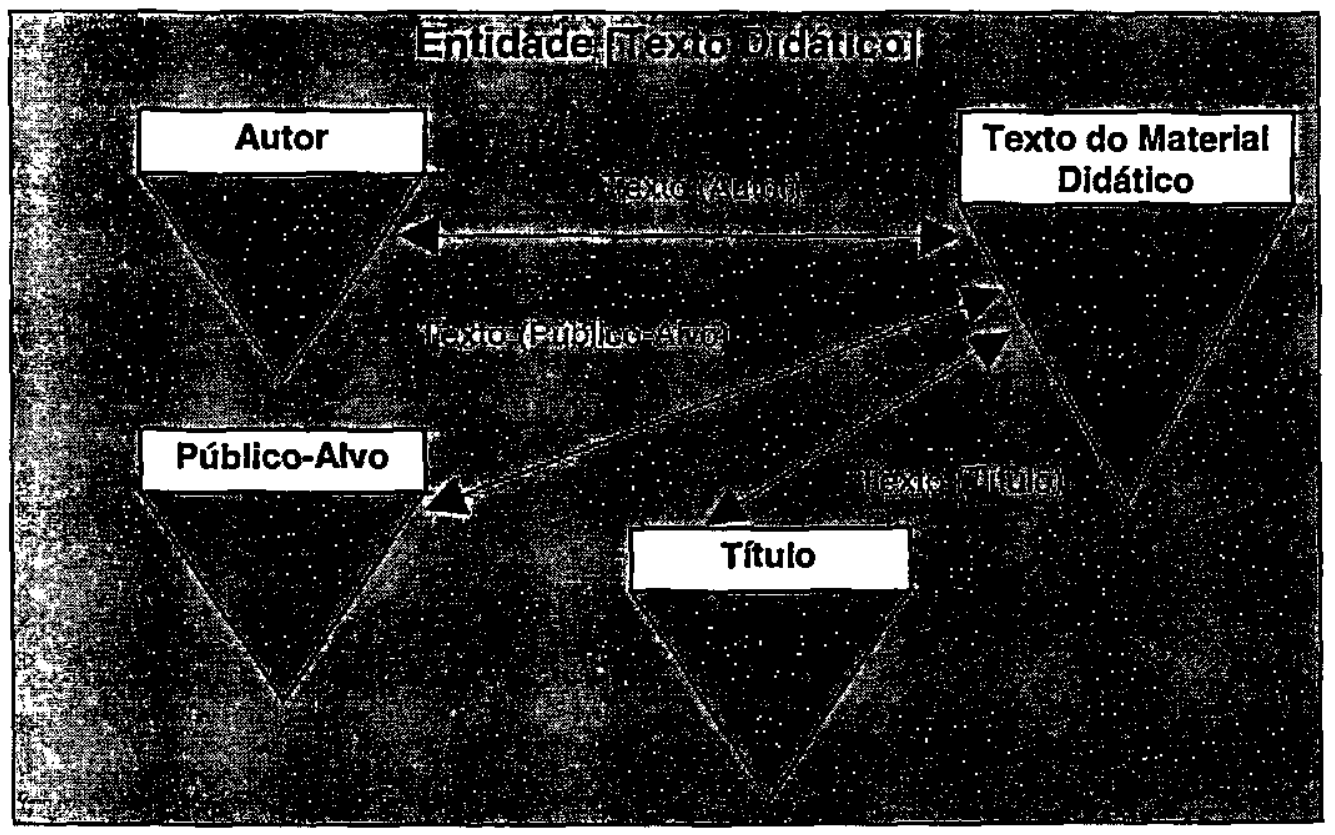

( a )

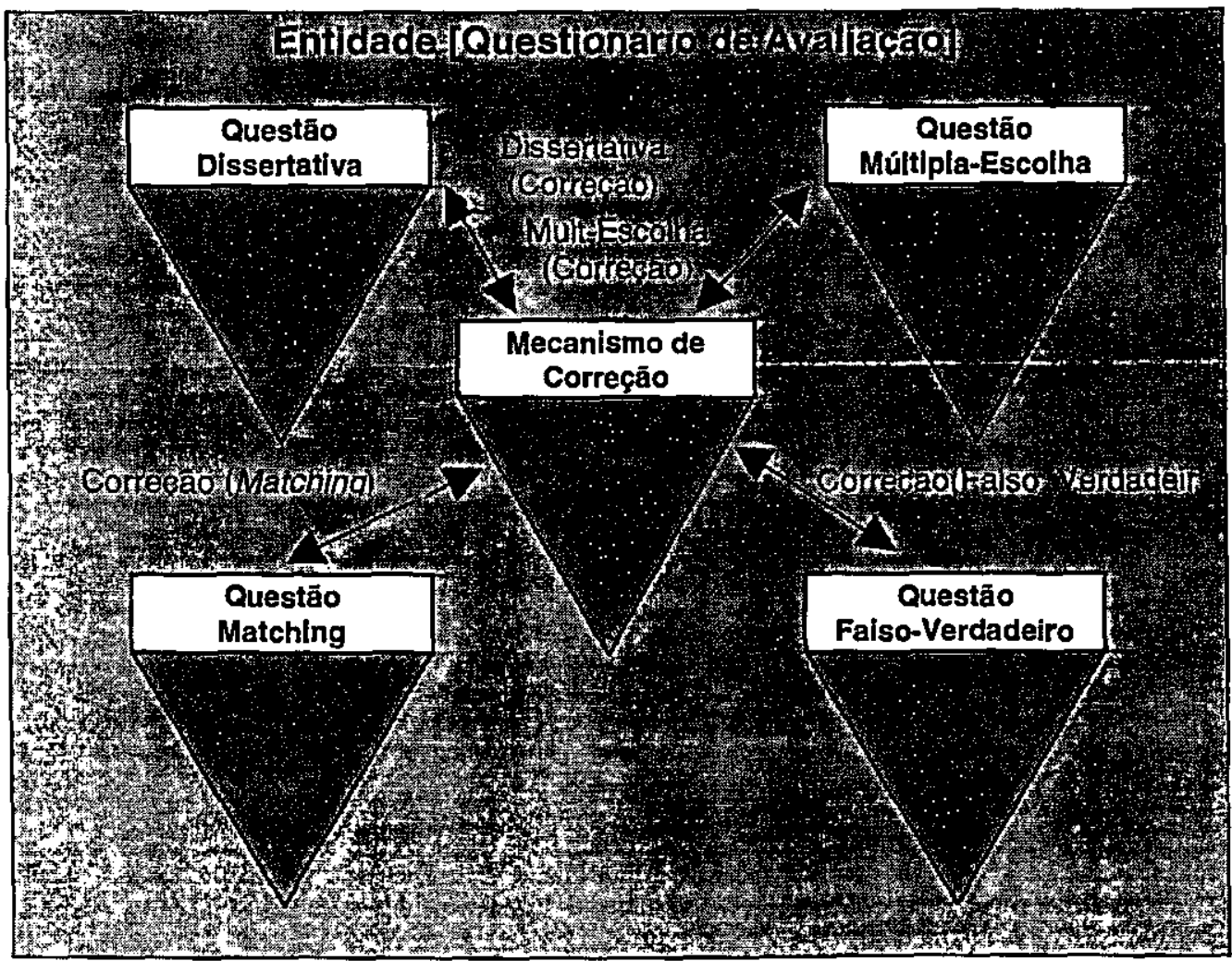

(b) 


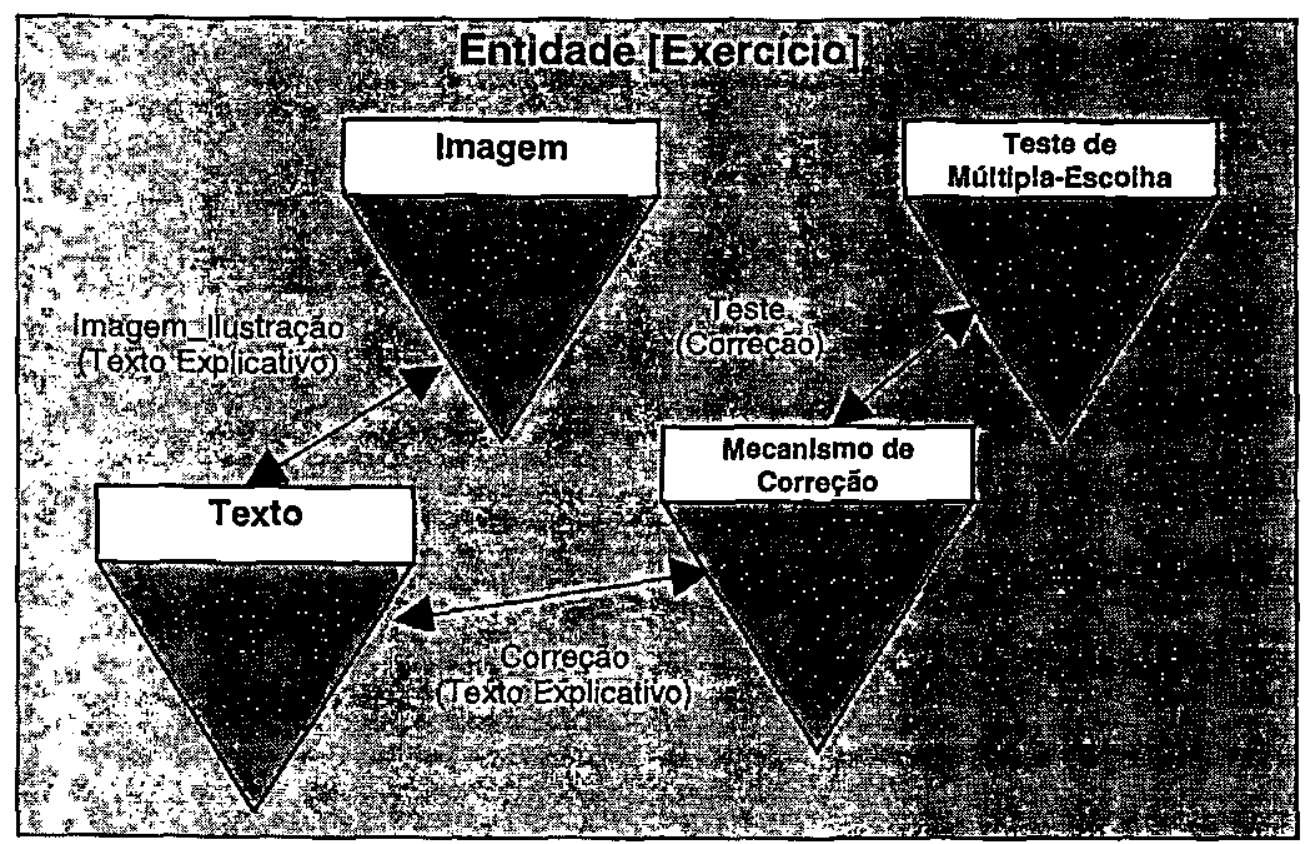

(c)

Figura 5.3 - (a)(b)(c) Passo 2: Diagrama de slices para o domínio de aplicação Ensino

No terceiro passo, tomando por base o diagrama E-R+ construído no primeiro e segundo passos, foi construído um diagrama RMDM (Relationship Management Data Model) que apresenta o domínio de aplicação através da parte E-R e especificações de estruturas de acesso para navegação nos hiperdocumentos. Observa-se, portanto, que o terceiro passo é o projeto navegacional que tem origem nas entidades do domínio de aplicação e é fundamentado no projeto de slices obtido a partir do diagrama E-R. A Figura 5.4 apresenta o diagrama RMDM construído.

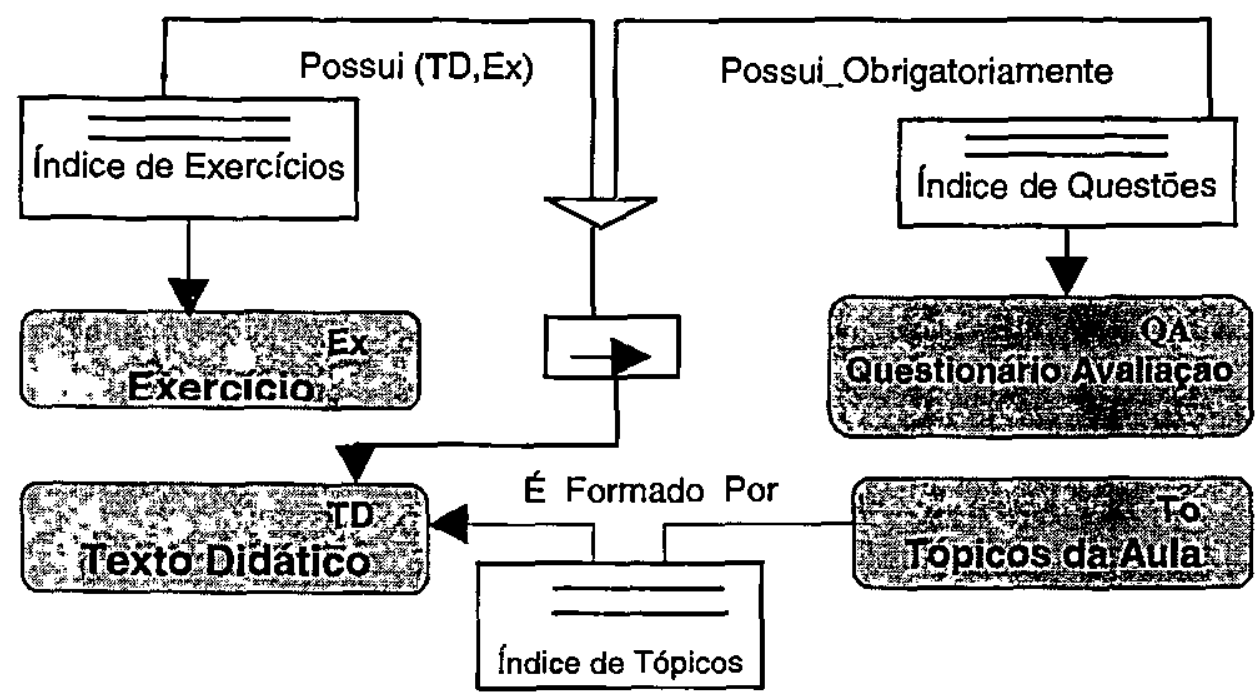

Figura 5.4 - Passo 3 : Diagrama RMDM para o domínio de aplicação Ensino 


\subsection{Um conjunto de ferramentas para disponibilização de material didático}

Conforme citado no Capítulo 1, este projeto tem como objetivo inicial a implementação de um conjunto de ferramentas para suporte ao processo de autoria e disponibilização de material didático na WWW. Desta forma, é válido observar a necessidade dessas ferramentas estarem integradas, de modo a facilitar que a comunicação entre elas seja transparente para o usuário final, tanto o professor quanto o estudante. Essa integração visa facilitar, ainda, o segundo objetivo deste trabalho, que é a modelagem dessas ferramentas como uma aplicação hipermídia voltada ao domínio educacional.

Este projeto propõe a integração de ferramentas correspondentes às tarefas de autoria de hiperdocumentos de texto didático, autoria de questionários de avaliação do aprendizado e autoria de exercícios baseados em textos, imagens e testes de múltipla escolha, bem como o provimento de mecanismos para publicação do material didático no ambiente WWW. A Figura 5.5 apresenta as ferramentas que correspondem a essas tarefas e os relacionamentos entre elas.

Inicialmente, observa-se que as ferramentas estão organizadas em dois módulos distintos: o módulo de ferramentas de autoria para o professor e o módulo de ferramentas para interação com o estudante.

O módulo do professor é composto por um conjunto de ferramentas stand-alone, onde cada ferramenta de autoria corresponde a uma tarefa especifica do professor no contex to da elaboração de material didático para a WWW. A tarefa I corresponde à ferramenta QuestBuilder, que tem como função permitir a autoria de questionários de avaliação do aprendizado. Um questionário, produzido pela ferramenta QuestBuilder é inserido no texto didático, produzido pela ferramenta correspondente à tarefa 3 , para posterior publicação.

A tarefa 2 corresponde, de fato, a uma ferramenta denominada TaskBuilder associada à autoria de exercícios. No contexto deste trabalho, um exercício é definido como um layout selecionado pelo autor e que pode ser formado por três tipos de componentes: texto explicativo, imagem para ilustração e um teste de múltipla-escoiha. 
A tarefa 3 corresponde à ferramenta HyperBuilder, que possibilita a autoria de textos didáticos na forma de hiperdocumentos estruturados contendo questionários de avaliação do aprendizado e exercícios. O hiperdocumento de material didático, resultante dos processos de autoria pelas ferramentas, constitui-se no objeto para publicação na WWW. Já as ferramentas correspondentes à interação com o estudante são caracterizadas por ambientes de apresentação que serão acolhidos por um browser. Este deve promover a visualização e navegação no hiperdocumento de material didático, através da estrutura de índice de tópicos e links para conteúdo do texto diđático, e a execução do código JAVA e JAVAScript, quando for o caso.
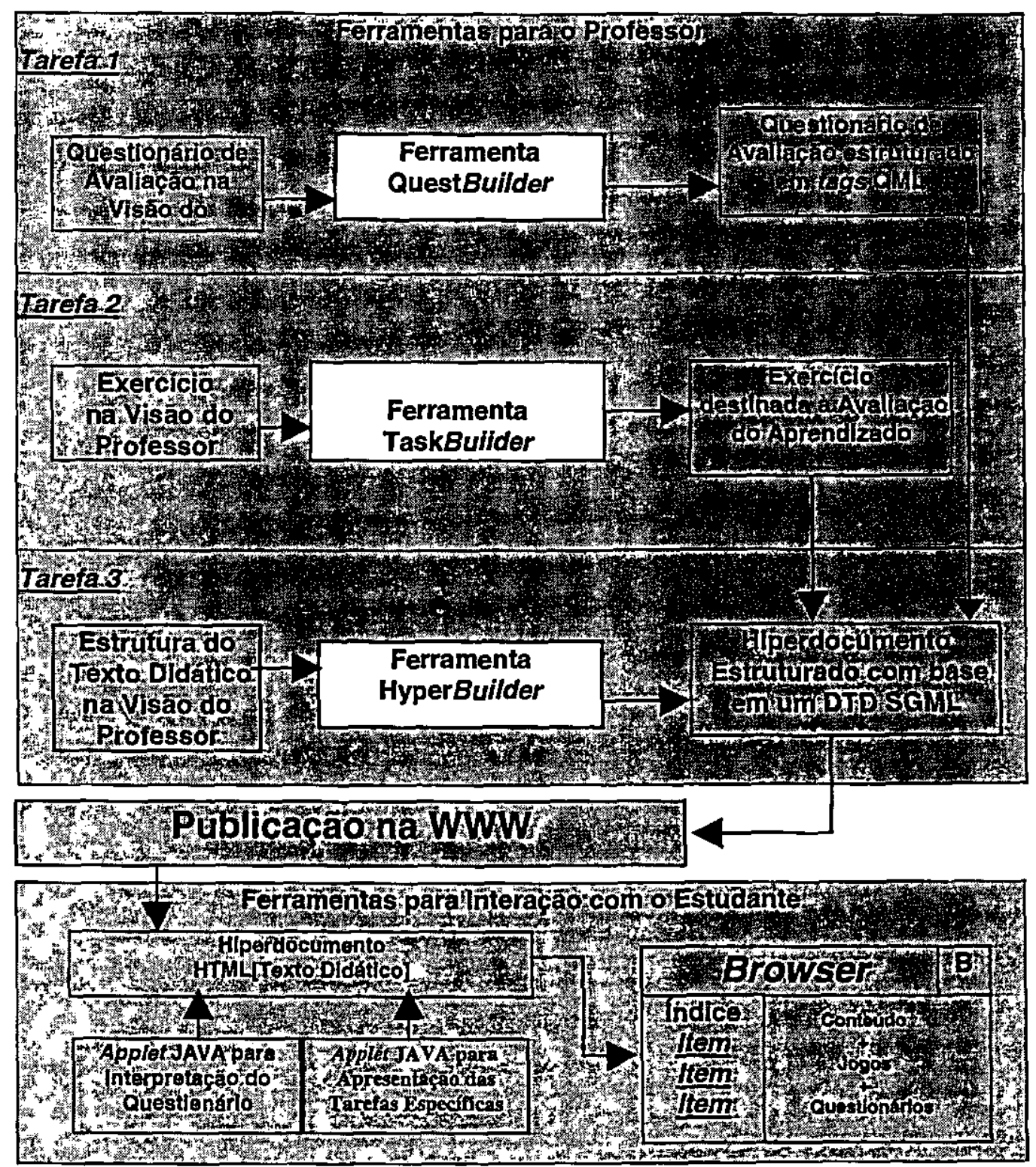

Figura 5.5 - Relacionamento entre as ferramentas de software propostas 
As ferramentas correspondem à camada "Ferramentas para elaboração e publicação de material didático" ilustrada na Figura 5.6.

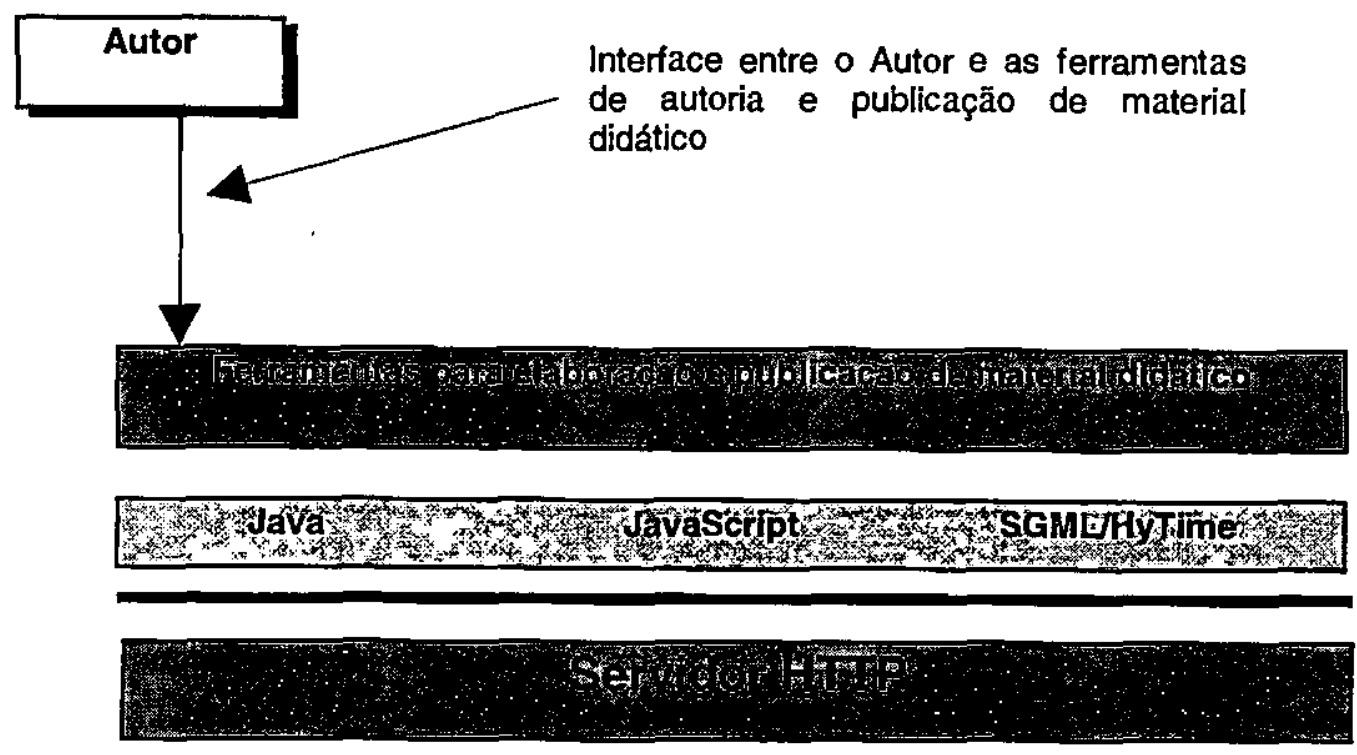

Figura 5.6 - Arquitetura completa proposta para o domínio de aplicação Ensino

\subsection{Estrutura dos hiperdocumentos}

O padrão SGML (Standard Generalized Markup Language) (ISO, 1986) permite que documentos armazenados eletronicamente sejam definidos em termos de seu conteúdo e sua estrutura, independentemente de sua forma de apresentação. SGML tem flexibilidade para definir um conjunto ilimitado de linguagens específicas, como por exemplo uma para memorandos, outra para artigos, outra para livros, e outros (Herwijnen, 1994). Cada documento SGML está associado a uma linguagem específica que define sua estrutura; essa definição é formalizada através da criação de um DTD (Document Type Definition). Assim, a linguagem definida em um DTD especifica a estrutura lógica correspondente a uma classe de documentos a qual é compartilhada por muitas instâncias de documentos.

Um DTD define a estrutura lógica de uma classe de documentos, e declara: que tipos de elementos podem existir em um documento - por exemplo, um livro pode conter capítulos, seções, subseções, etc.; que atributos esses elementos podem ter - por exemplo, o número de versão e data da última revisão; como as instâncias desses elementos estão hierarquicamente relacionadas - por exemplo, um livro contém capítulos, os quais contem seções, as quais podem 
conter subseções, etc. A aplicação que processa um documento SGML é responsável por especificar como as instâncias dos elementos devem ser visualizadas no documento final.

Um DTD define três tipos de comandos para marcação: elementos, atributos e entidades. Marcar um documento SGML significa classificar seus elementos, atributos e entidades conforme a árvore de estrutura genérica formalmente descrita pelo DTD correspondente à classe daquele documento (Herwijnen, 1994). Em SGML, um atributo é um qualificador que indica uma propriedade de um elemento.

A seguir, são apresentadas as estruturas dos documentos relativos ao Texto Didático e ao Questionario de Avaliação. Tal definição visa não apenas facilitar. a construção de ferramentas que suportem esses documentos, mas garantir que a estrutura possa ser explorada por várias ferramentas, num ambiente integrado de ferramentas de hipermídia.

Assim, dada a estrutura de questionários por exemplo, uma ferramenta que apresenta questionários interativamente ao seus usuários pode obter os dados para construção do questionário on the fly a partir do acesso a uma base de dados, na qual dados sobre o usuário (aluno) e o documento (conteúdo a ser avaliado no questionário) estão disponíveis.

\subsubsection{DTD para documento didático}

A Figura 5.7 corresponde à versão simplificada de um DTD para um texto didático (DidTML, Didactic Text Markup Language). Assim, para um texto didático são elementos: assunto, autor, nível, corpo do texto e indicador para questionário de avaliação associado (opcional).

O corpo do texto, por sua vez, é estruturado em itens e subitens, em cujo conteúdo pode existir ligações hipertexto e referências cruzadas (ID e IDREF). Um atributo importante que foi associado ao DTD é seu status, que pode ser concluído (ok) ou em preparação (draft). Aos itens e subitens, podem ser associados atributos de identificação para estabelecimento de ligações hipertexto. 


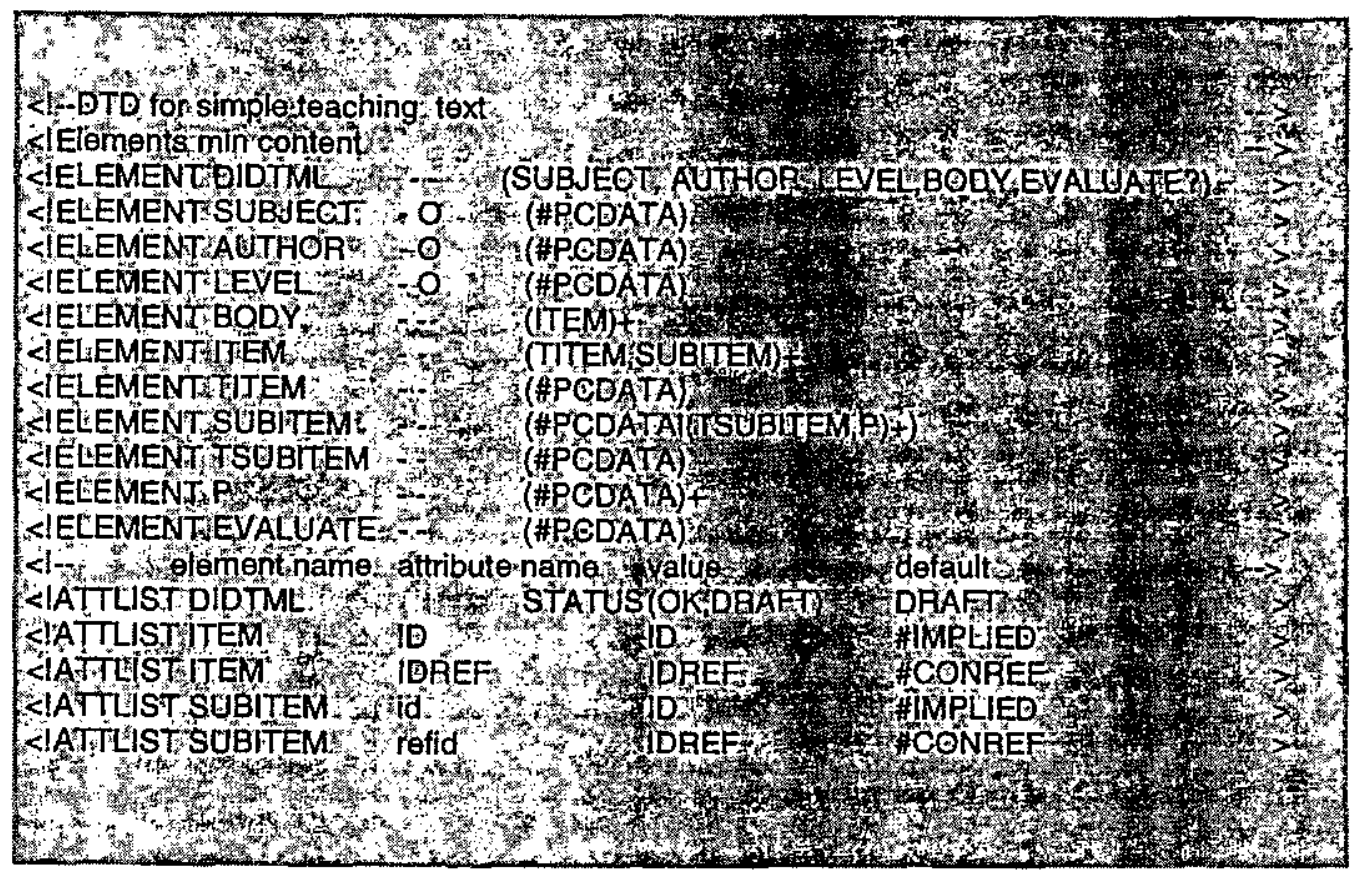

\section{Figura 5.7 - DTD simplificado para texto didático (DIDTML)}

\subsubsection{DTD para questionário}

A Figura 5.8 corresponde à versão simplificada de um DTD para um questionário, que define a QuestML (Questionnaire Markup Language). Essa estrutura também inclui elementos associados a autor, assunto e nível. São definidos vários tipos de questões, como testes de múltipla escolha e resposta aberta, e são definidos atributos de identificação para estabelecimento de ligações entre questões e outros elementos.

Para as questões do tipo teste e verdadeiro ou falso, são associados atributos que identificam a resposta correta. Para as questões do tipo resposta aberta, é definido um campo para identificação do destinatário da resposta.

Para o questionário de modo geral, é definido o elemento SUBMIT, que identifica para quem a resposta deve ser enviada (para um professor, o próprio aluno, ou ambos, por exemplo) e em que condiçōes (associado na aplicação, por exemplo, ao rendimento mínimo alcançado pelo aluno para consideração do resultado). 


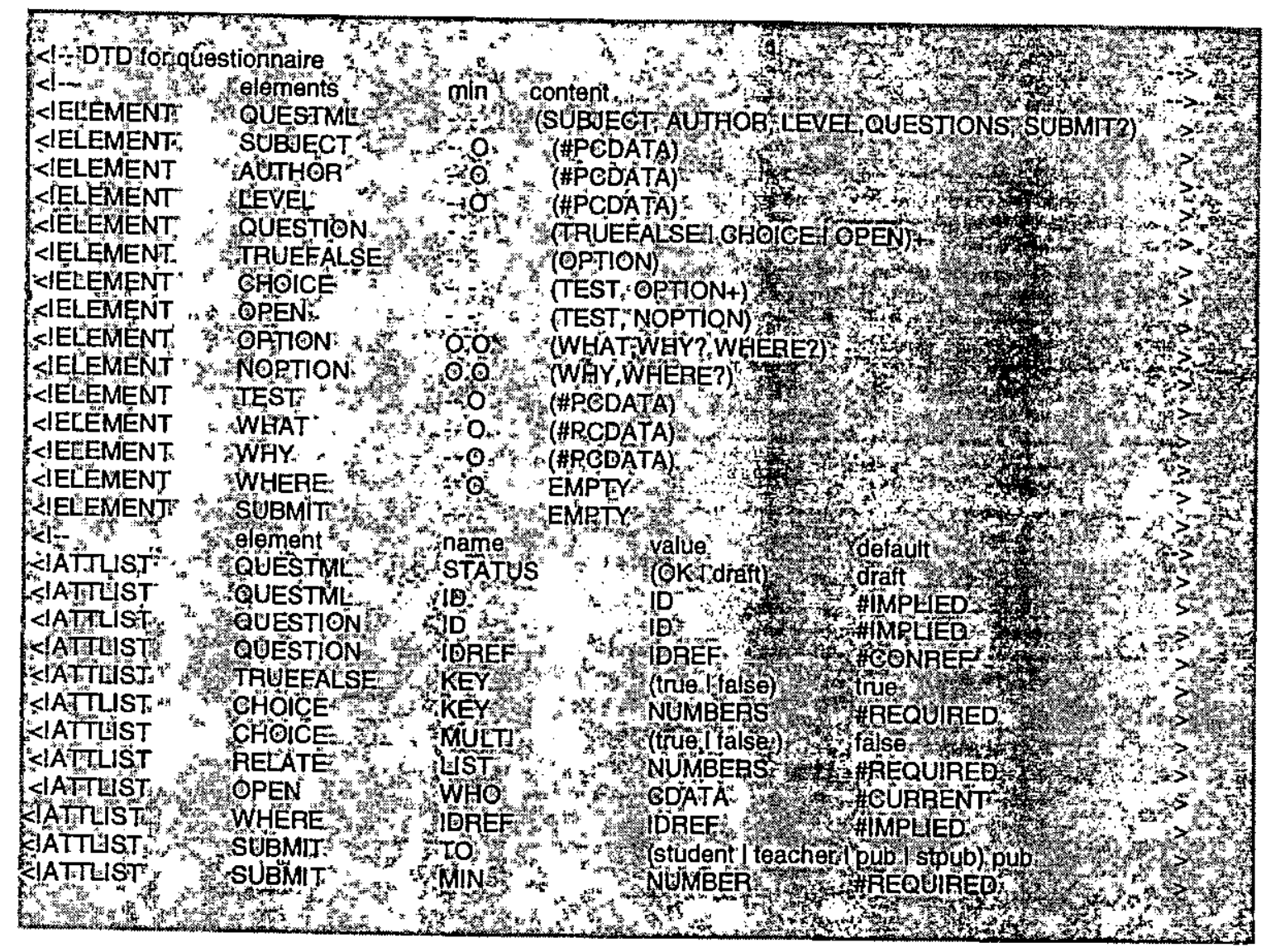

Figura 5.8 - DTD simplificado para questionário (QuestML)

A próxima seção discute aspectos da autoria e apresentação desses documentos no contexto da WWW.

\subsection{Autoria e apresentação dos hiperdocumentos na WWW}

O ambiente WWW, que obedece à arquitetura cliente-servidor, é caracterizado pela publicação, em servidores que suportam o protocolo HTTP, de hiperdocumentos construídos de acordo com a linguagem HTML.

A linguagem HTML é formalmente definida por um DTD SGML. HTML especifica, entre seus elementos, links hipertexto e inclusão de outras mídias, impondo uma estrutura simples aos hiperdocumentos disponibilizados pelo servidor HTTP, estrutura essa acatada pelos clientes existentes (browsers). A autoria de hiperdocumentos para a WWW passa pela construção de hiperdocumentos baseados no padrão HTML. Hiperdocumentos HTML herdam da tecnologia da segunda geração de hipertextos (Halasz, 1988) o modelo de nós-ligações para associação de 
documentos externos, e a forma de apresentação e interação disponibilizadas pelos navegadores. A navegação em documentos HTML, suportada pelos navegadores (browsers) atuais, se faz através das operações básicas definidas pela tecnologia de hipertextos: escolha livre de seleção de ligações, complementada por operações de backtracking, bookmarks e algum controle de caminho percorrido.

Pelo fato da estrutura estabelecida pelo HTML ser muito simples, um hiperdocumento construído com HTML não pode apresentar, por si só, uma estruturação elaborada. A simplicidade do modelo HTML limita, ainda, a estrutura de ligações que pode ser associada à coleção de documentos. Por exemplo, é possível a definição de ligações ponto-a-ponto e ponto-a-nó, mas não de ligações $1: \mathrm{N}, \mathrm{N}: \mathrm{M}$ e trilhas.

É relevante para o contexto deste trabalho observar que, quando sistemas hipermídia convencionais são utilizados em ensino, o usuário é livre para aprender sozinho, e pode ser visto como uma versão suportada eletronicamente de auto-didata (Pimentel \& Hagui, 1996). Neste contexto, o usuário é exposto aos problemas tradicionais de navegação em hipertexto: desorientação e sobrecarga cognitiva (Conklin, 1987).

Uma situação distinta ocorre em sistemas adaptativos tradicionais (tutor, guides e outros), que utilizam um modelo do usuário que possui informação a respeito do conhecimento do domínio do usuário (Beaumont, 1995). Seja no contexto de sistemas hipermídia adaptativos ou convencionais, a estrutura dos documentos HTML pode ser elaborada de modo a conter elementos específicos a serem explorados em material didático. Neste caso, a contrapartida está em como alterar a estrutura e ainda fazer uso da flexibilidade dos documentos HTML. Para alcançar esse objetivo, podem ser utilizadas em documentos HTML programas executáveis permitidos pelas tecnologias JAVA e JAVAScript. É importante observar que tanto JAVA como JAVAScript fornecem meios de elaborar não apenas a estrutura do documento, mas também a interação do usuário com o documento. Portanto, os hiperdocumentos HTML podem ser incrementados através da inserção de applets JAVA (Sun, 1996) e de código em JAVAScript (Sun, 1996), entre outros. Uma vez publicados no servidor, esses hiperdocumentos são 
disponibilizados pelo servidor mediante consulta realizada por clientes, os web browsers, a partir de qualquer ponto da Internet.

\subsubsection{Texto didático: estrutura e autoria}

A estrutura do hiperdocumento para disponibilização de texto didático é definida como uma classe de documentos formalizada no DTD DIDTML apresentado na Figura 5.7.

Conforme citado, um dos problemas para a autoria de hiperdocumentos elaborados é a necessidade de conhecimentos especializados em programação de computadores. Observa-se, então, que apenas a definição de uma estrutura para o hiperdocumento não soluciona os problemas de autoria e publicação do mesmo. Neste contexto, é relevante a implementação de ferramentas de autoria que incorporem a estrutura definida no DTD DIDTML e que forneçam recursos para elaboração do hiperdocumento.

A ferramenta HyperBuilder foi inspirada no modo de edição outline existente em ferramentas como o Microsoft Power Point (Microsoft, 1995). A ferramenta promove a orientação ao professor na inserção dos tópicos do texto didático, observando o DTD DIDTML. Esta orientação é realizada através de botões na interface. Inicialmente, apenas o botão para inserção de título está ativado para uso pelo usuário. Após a inserção do título, desativa-se o botão correspondente ao mesmo e é ativado o segundo botão que corresponde à inserção do assunto a que se refere o texto didático.

Através do processo de edição de textos, o autor pode inserir os dados que identificam o hiperdocumento (título, assunto, nível, público-alvo, resumo dos objetivos e autor), além de definir a nomenclatura de cada tópico do conteúdo do hiperdocumento e suas relações em termos de itens e subitens. Quando o usuário salva o arquivo editado, a ferramenta gera uma versão correspondente ao DTD DIDTML, e uma versão HTML do documento, que pode ser imediatamente visualizada em um browser. A Figura 5.9a apresenta o diálogo para seleção do layout (com ou sem frames) enquanto a Figura 5.9b apresenta a estrutura de um hiperdocumento sendo editado na ferramenta HyperBuilder. 


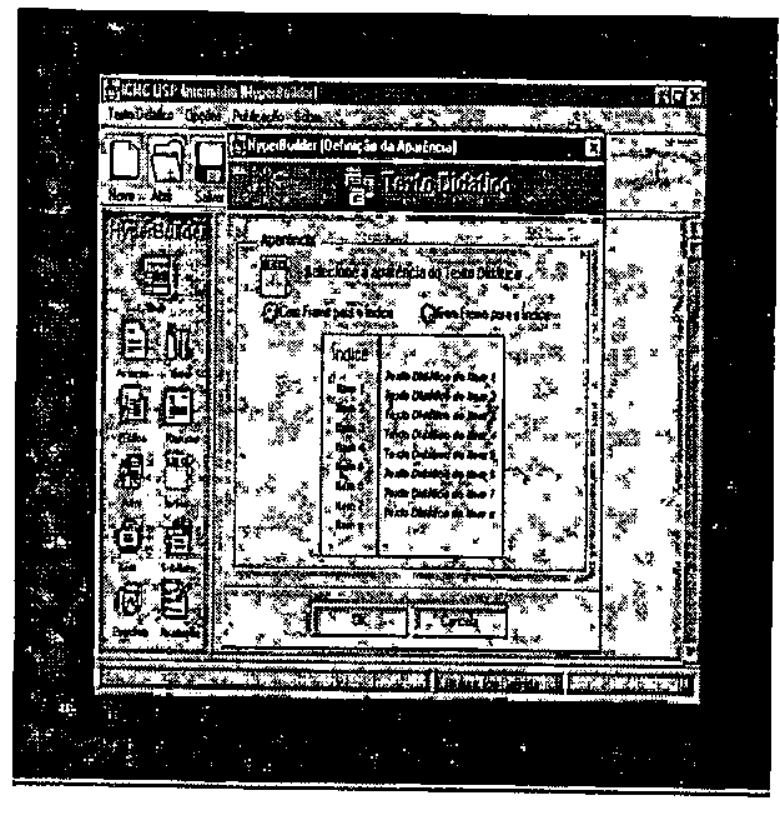

(a)

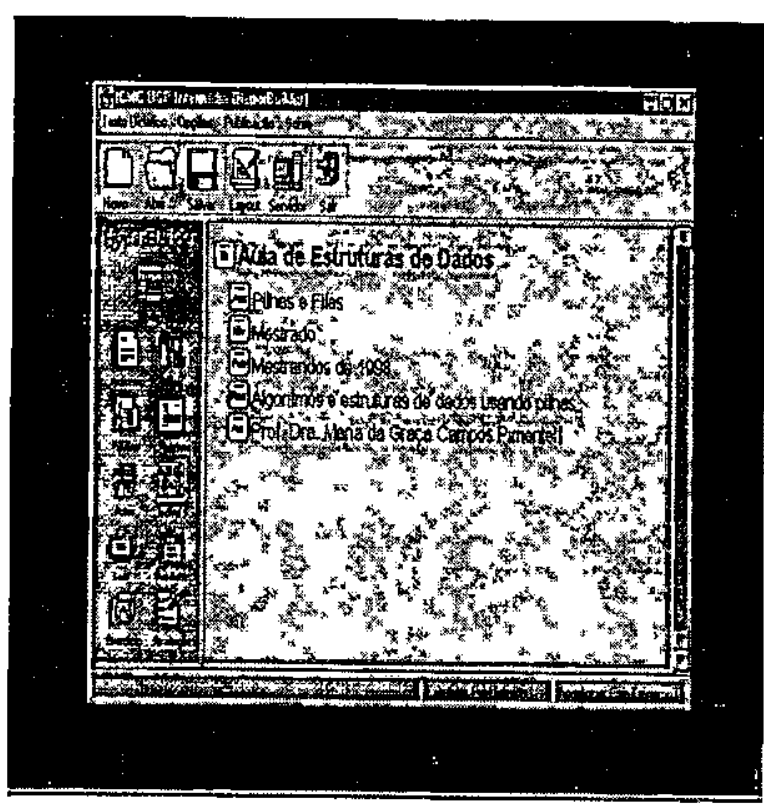

(b)

Figura 5.9- (a) Interface da ferramenta HyperBuilder para seleção do layout

(b) um hiperdocumento de texto didático em edição na ferramenta HyperBuilder

Os arquivos HTML gerados pela ferramenta HyperBuilder possuem dois tipos de estruturação: baseadas em frames e baseadas em índice (sem frames). Neste contexto, a versão HTML do documento contém vários arquivos: um deles possui o índice dos tópicos do texto didático e que é apresentado à esquerda da área de visualização dos browsers, e um segundo arquivo que corresponde ao conteúdo do texto didático a ser disponibilizado. Um exemplo é apresentado na Figura 5.10.

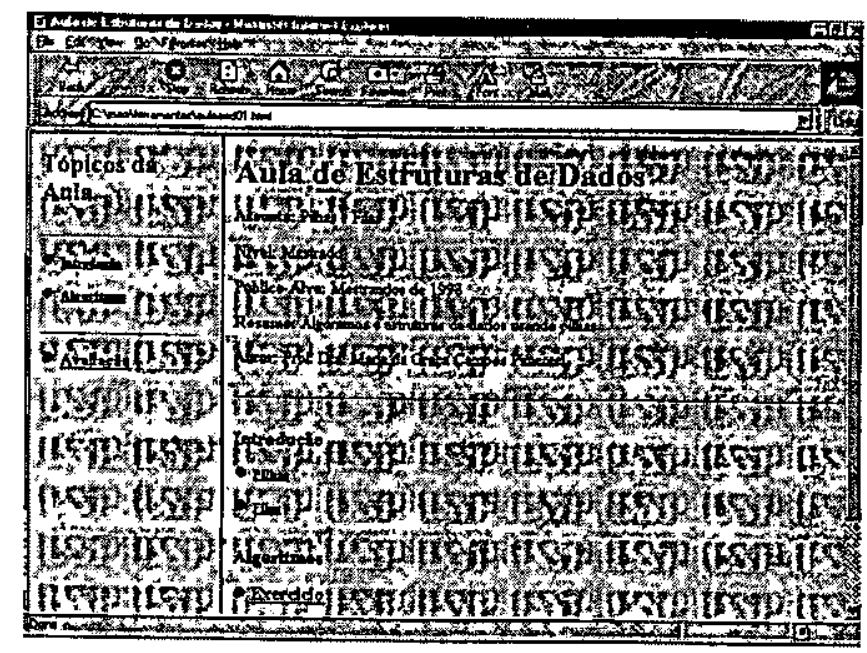

Figura 5.10 - Apresentação de um hiperdocumento de texto didático estruturado 
Neste ponto, observa-se a ligação automática entre o índice e o conteúdo, criada pela ferramenta HyperBuilder. Em adição, documentos complementares são criados para apresentar o conteúdo dos subitens. É importante notar que apenas a estrutura do documento é preparada através da ferramenta HyperBuilder: o autor deve carregar o documento preparado em um editor de documentos HTML convencional e gerar o conteúdo correspondente aos itens e subitens. Essa abordagem é similar à adotada em várias ferramentas, em particular a QuizML (Tínoco, 1996) e - Web Course Tool (WebCT, 1996a). Complementando, na estruturação do hiperdocumento didático pode-se inserir questionários de avaliação e exercícios criados pelas outras ferramentas que compõem a arquitetura, conforme apresenta a Figura $\mathbf{5 . 1 1}$.

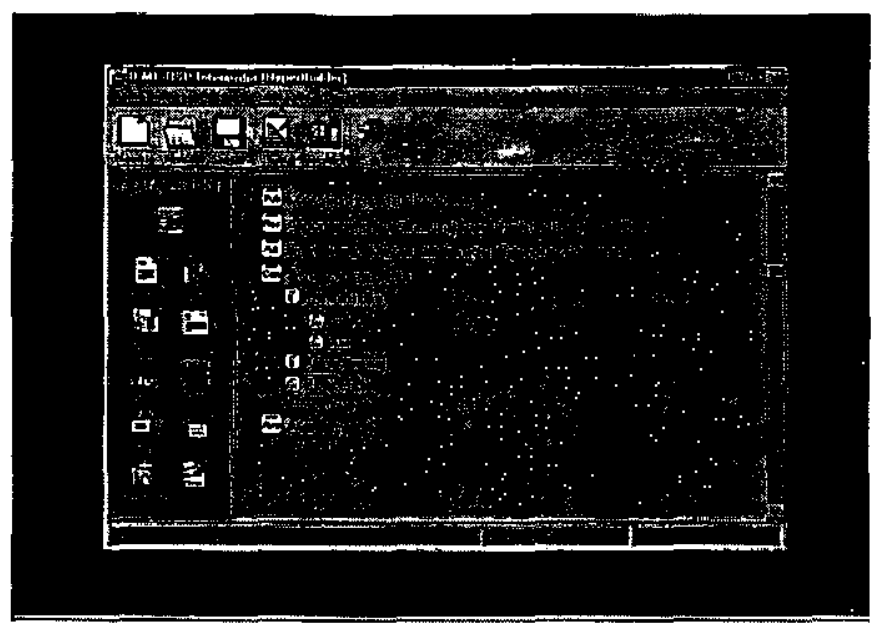

Figura 5.11 - Mecanismo de inserção de questionários e exercícios no texto didático

\subsubsection{Questionários: estrutura e autoria}

Conforme pode ser observado no DTD DIDTML, um dos itens que compõem um material didático é um questionário de avaliação. Neste trabalho, o processo de avaliação está direcionado para a disponibilização de questionários on-line inseridos nos hiperdocumentos de texto didático construídos com a ferramenta HyperBuilder. Com a inserção de questionários on-line, permite-se o processo de correção automática das questões, o que possibilita a avaliação do grau de aprendizado do estudante pelo professor, além de possibilitar ao estudante a observação do seu rendimento em relação ao conteúdo didático apresentado. Assim, foi construída uma ferramenta de apoio ao processo de autoria de questionários pelo professor. Na ferramenta QuestBuilder, o professor encontra suporte para criação de questões dissertativas, de múltipla escolha, questões de falso ou verdadeiro, e questões que envolvem o relacionamento de colunas (matching), 
conforme a interface apresentada nas Figuras 5.12a, 5.12b, 5.13a e 5.13b. Cada tipo de questão está disponível ao autor a partir do item Questões no menu principal da ferramenta.

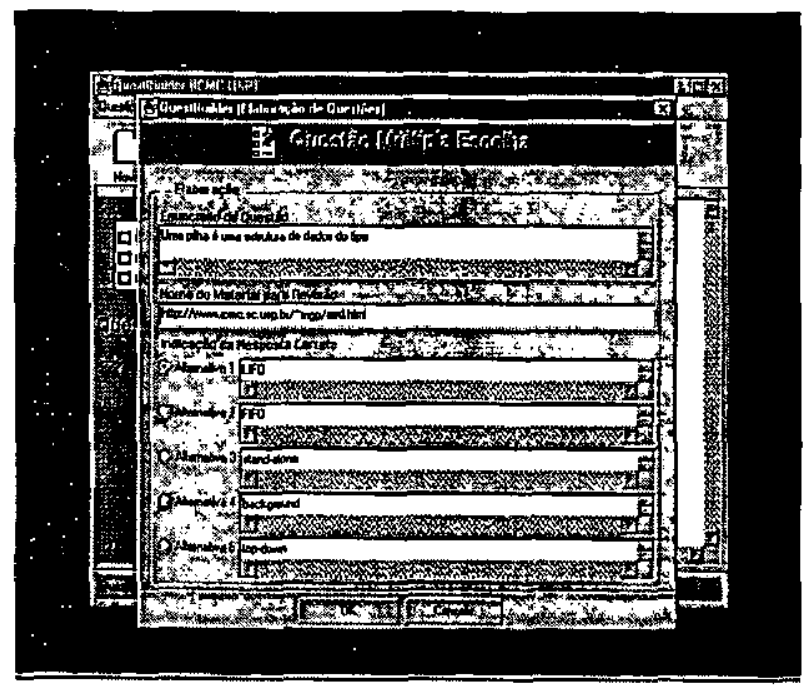

(a)

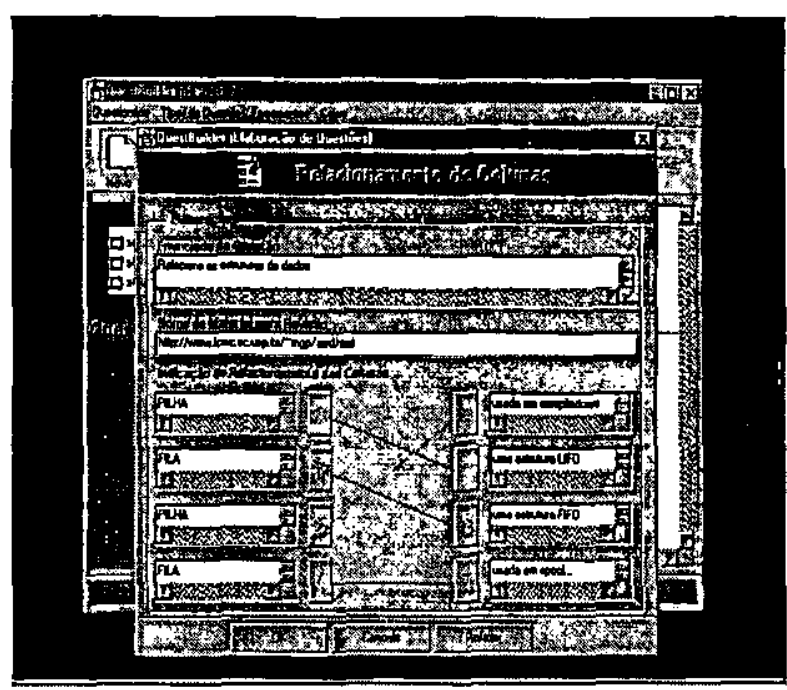

(b)

Figura 5.12 - (a) Questão múltipla-escolha sendo construída com a QuestBuilder (b) Questão de matching sendo construída com a QuestBuilder

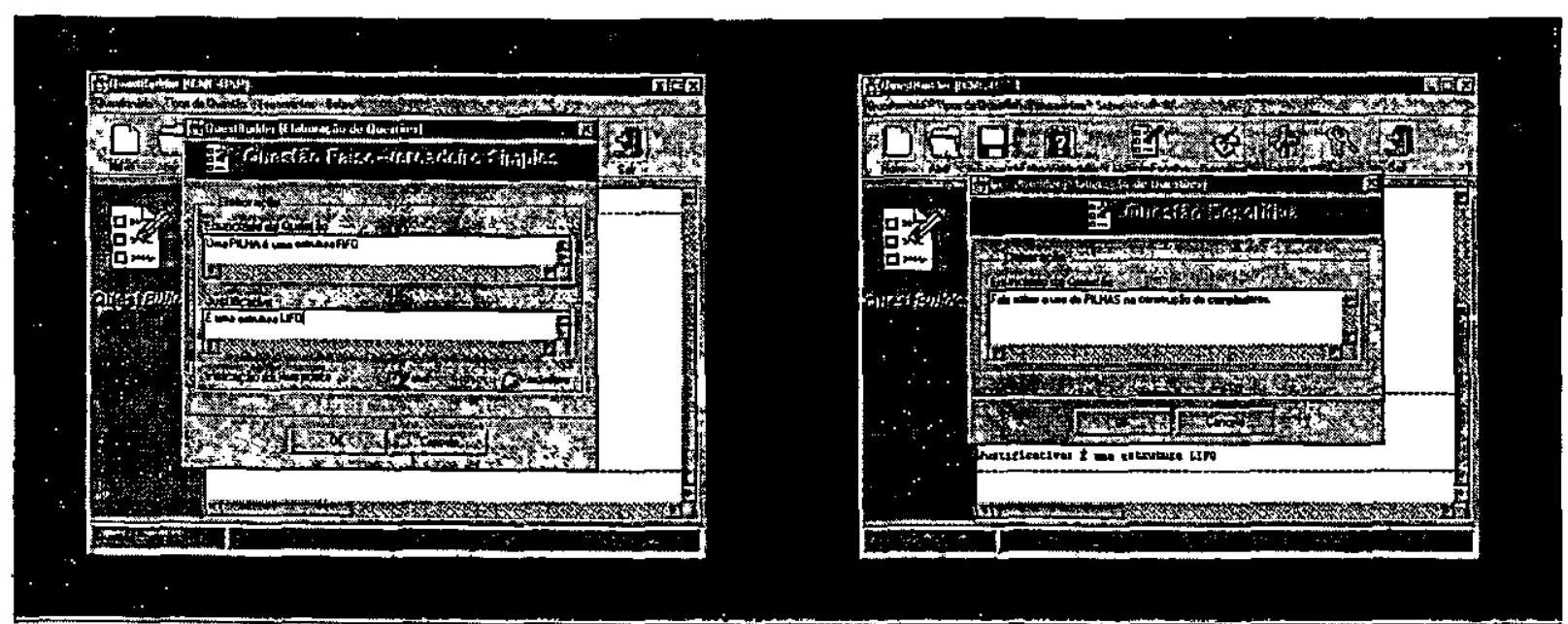

(a)

(b)

Figura 5.13 - (a) Questão falso ou verdadeiro sendo construída com a QuestBuilder (b) Questão dissertativa sendo construída com a QuestBuilder

Após a criação das questōes pelo professor, a ferramenta QuestBuilder gera um arquivo de acordo com o DTD QuestML. Para apresentação do questionário na WWW, o arquivo QuestML é submetido a um parser e, caso esteja correto quanto à sua estruturação, poderá ser visualizado por um applet JAVA acionado pelo item de avaliação do hiperdocumento que contém o texto didático. É relevante observar que, apesar da ferramenta permitir a autoria de questōes 
dissertativas, pretende-se no contexto deste projeto realizar a correção automática apenas das questões do tipo teste. Em adição, o autor tem à sua disposição um modo de rascunho no qual podem ser visualizadas as questões em construção, conforme mostra a Figura 5.14.

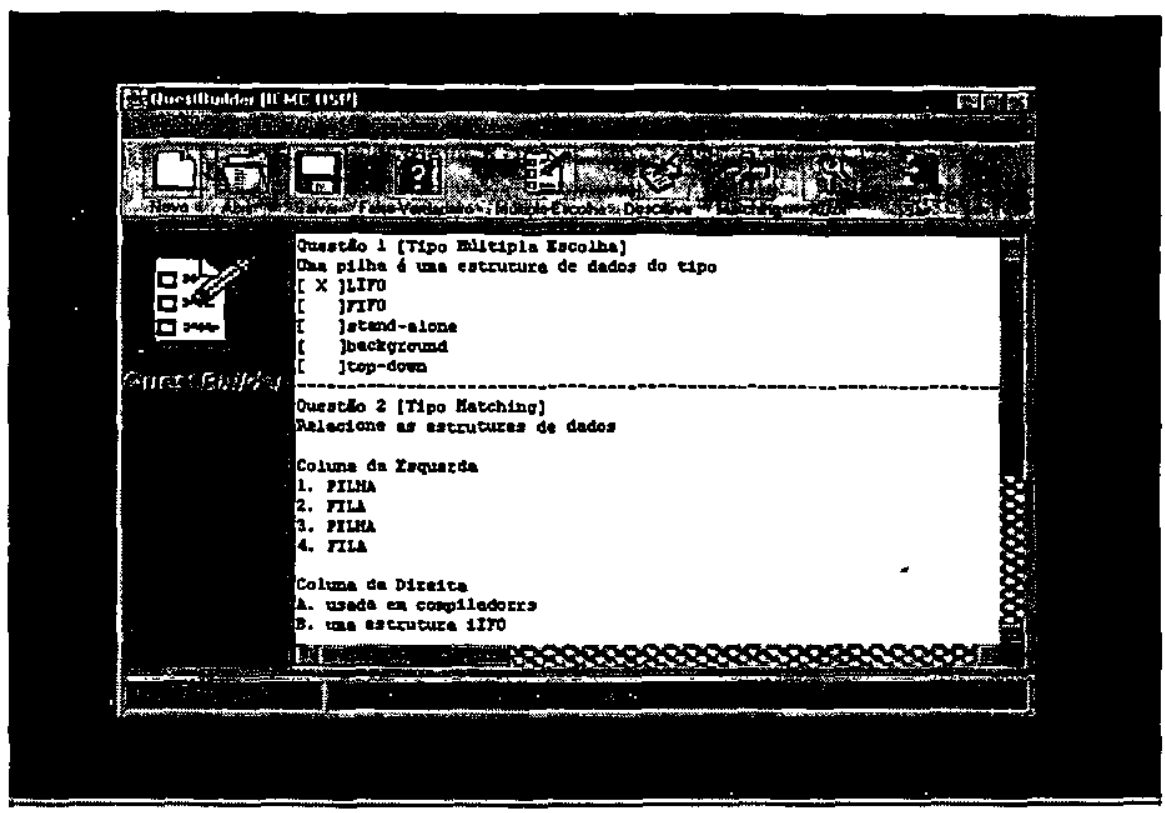

Figura 5.14 - Modo de visualização das questões em construção

\subsubsection{Exercícios: estrutura e autoria}

No DTD DIDTML, além do questionário de avaliação é especificado um item denominado exercício, que permite a inserção de um exercício no texto didático. No contexto deste trabalho, um exercício $\varepsilon$ definido como um layout que permite a inserção de três tipos de componentes: texto explicativo, imagem para ilustração e teste de múltipla-escolha. Neste ponto, o autor tem à sua disposição uma ferramenta denominada TaskBuilder que provê mecanismos para definição do layout de apresentação, bem como os componentes do exercício, gerando um arquivo HTML para inserção no texto didático.

Na ferramenta TaskBuilder o autor encontra suporte para criação de um teste de múltiplaescolha, bem como recursos para edição de textos simplificados e inserção de imagens ilustrativas. As Figuras 5.15a, 5.15b, 5.16a e 5.16b ilustram as funcionalidades da ferramenta TaskBuilder. 


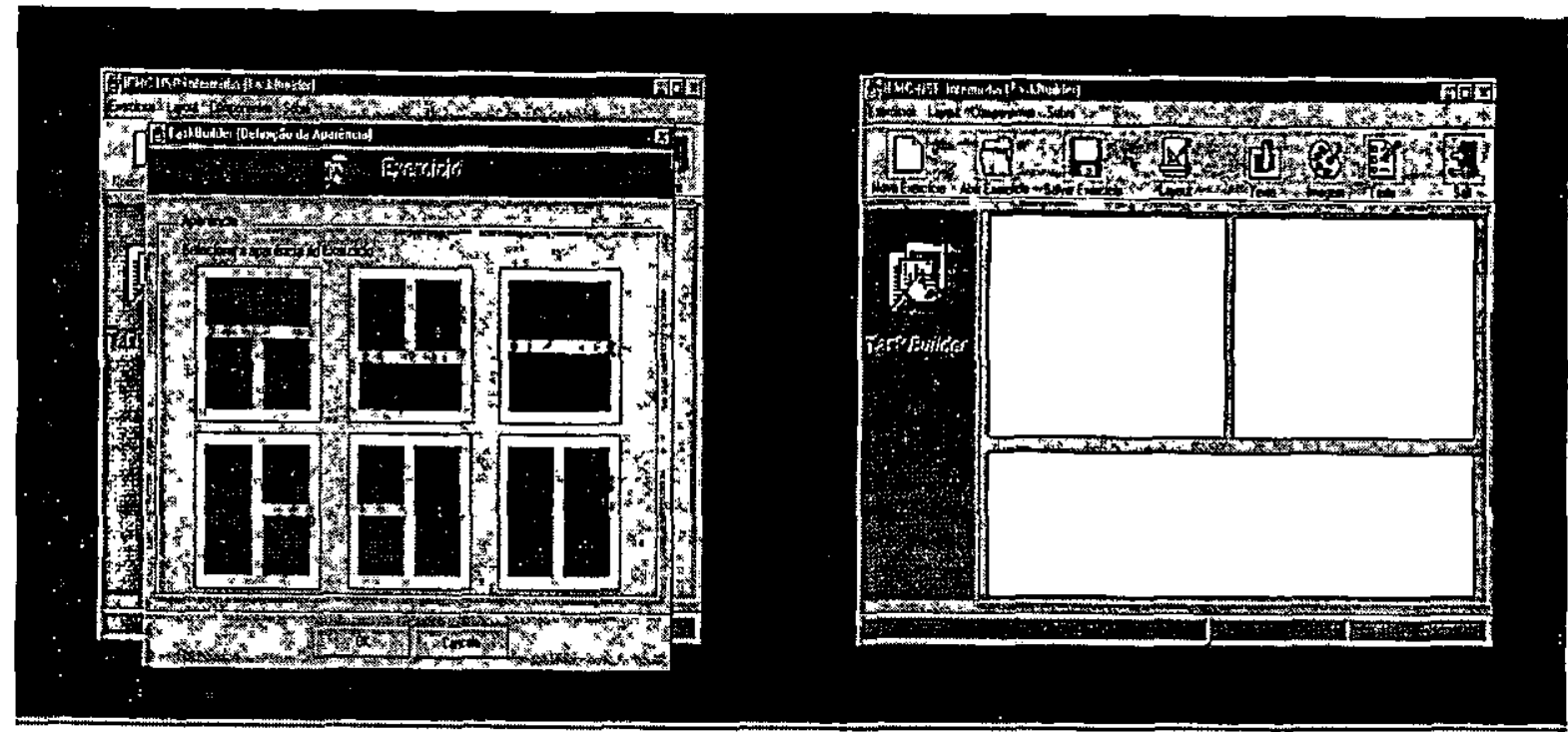

(a)

(b)

Figura 5.15 - (a) Modo de seleção de layout da ferramenta TaskBuilder

(b) Modo de apresentação do layout selecionado

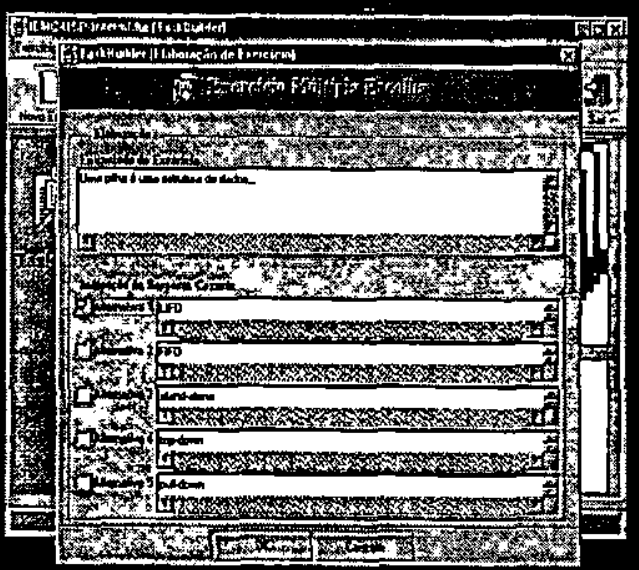

(a)

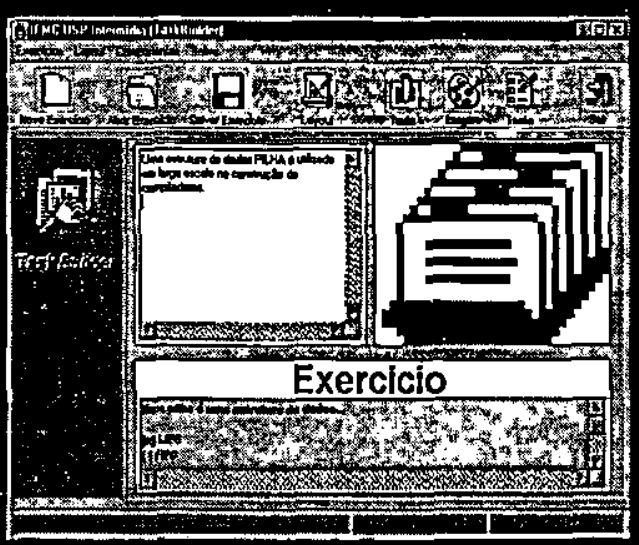

(b)

Figura 5.16 - (a) Um teste de múltipla-escolha sendo construído na ferramenta TaskBuilder

(b) um layout completo construído

\subsubsection{Mecanismo para disponibíilização do material didático na WWW}

Conforme apresentado anteriormente, a arquitetura de software proposta fornece suporte à autoria e à disponibilização de material didático no ambiente WWW. Assim como o processo de autoria objetiva isolar o autor da complexidade da programação de computadores (conhecimento de HTML, JAVA, JAVAScript e outros), o processo de disponibilização deve promover a 
colocação do material didático no ambiente WWW de forma transparente ao autor, ou seja, sem que este deva conhecer sistemas de arquivos ou mesmo utilizar ferramentas para transferência de arquivos.

Neste contexto, o processo de disponibilização é especificado em termos de uma opção de menu presente na ferramenta HyperBuilder. Neste ponto, observa-se que autor, após elaborar a estrutura do texto didático e inserir o questionário de avaliação, fará uso da opção publishing para enviar o conjunto de arquivos, formalizados com SGML e formatados no padrão HTML, que formam o material didático a um WebServer. A Figura 5.17 apresenta o processo de autoria e publicação do material didático.

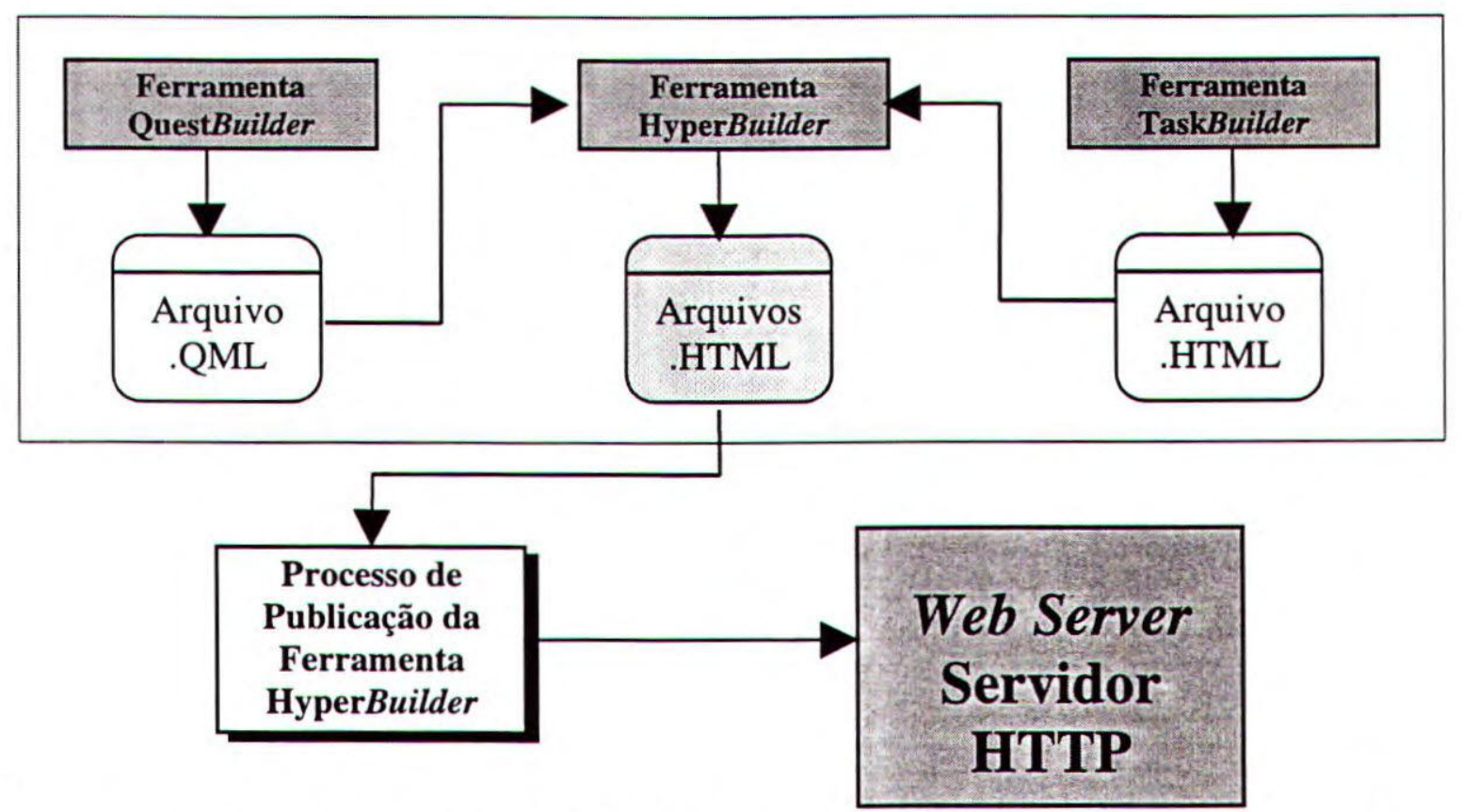

Figura 5.17 - Mecanismo de publicação do material didático no ambiente WWW

Em termos genéricos, o processo de publicação do material didático utiliza diretamente os recursos da classe FTP (File Transfer Protocol) presente na linguagem JAVA. Neste ponto, quando o autor seleciona a opção de publicação, é estabelecida uma conexão com o WebServer desejado e, então, é realizado o processo de transferência dos arquivos para uma área pública do referido servidor. 


\subsection{Ambientes de apresentação do material didático ao estudante}

O resultado material didático elaborado pelo autor é um conjunto de páginas HTML devidamente estruturadas em conformidade com os DTDs especificados. O processo de publicação supracitado é responsável por coletar todos os arquivos que compõem o material didático e enviá-los para um servidor HTTP. Neste ponto, observa-se que a natureza HTML dos documentos didáticos permite sua apresentação automática pelos browsers usuais.

Neste contexto, um ambiente inicial é apresentado ao estudante na forma de uma página HTML que contém toda a estrutura do hiperdocumento de material didático (com ou sem frames). As Figuras 5.18a e 5.18b apresentam o ambiente inicial contendo a estrutura do hiperdocumento e os links especificados para os itens, inclusive questionário de avaliạção e exercícios, do material didático. Em adição, a Figura 5.19 apresenta uma página isolada que representa um subitem do texto didático, localizado no segundo nível de profundidade no grafo de navegação do hiperdocumento.

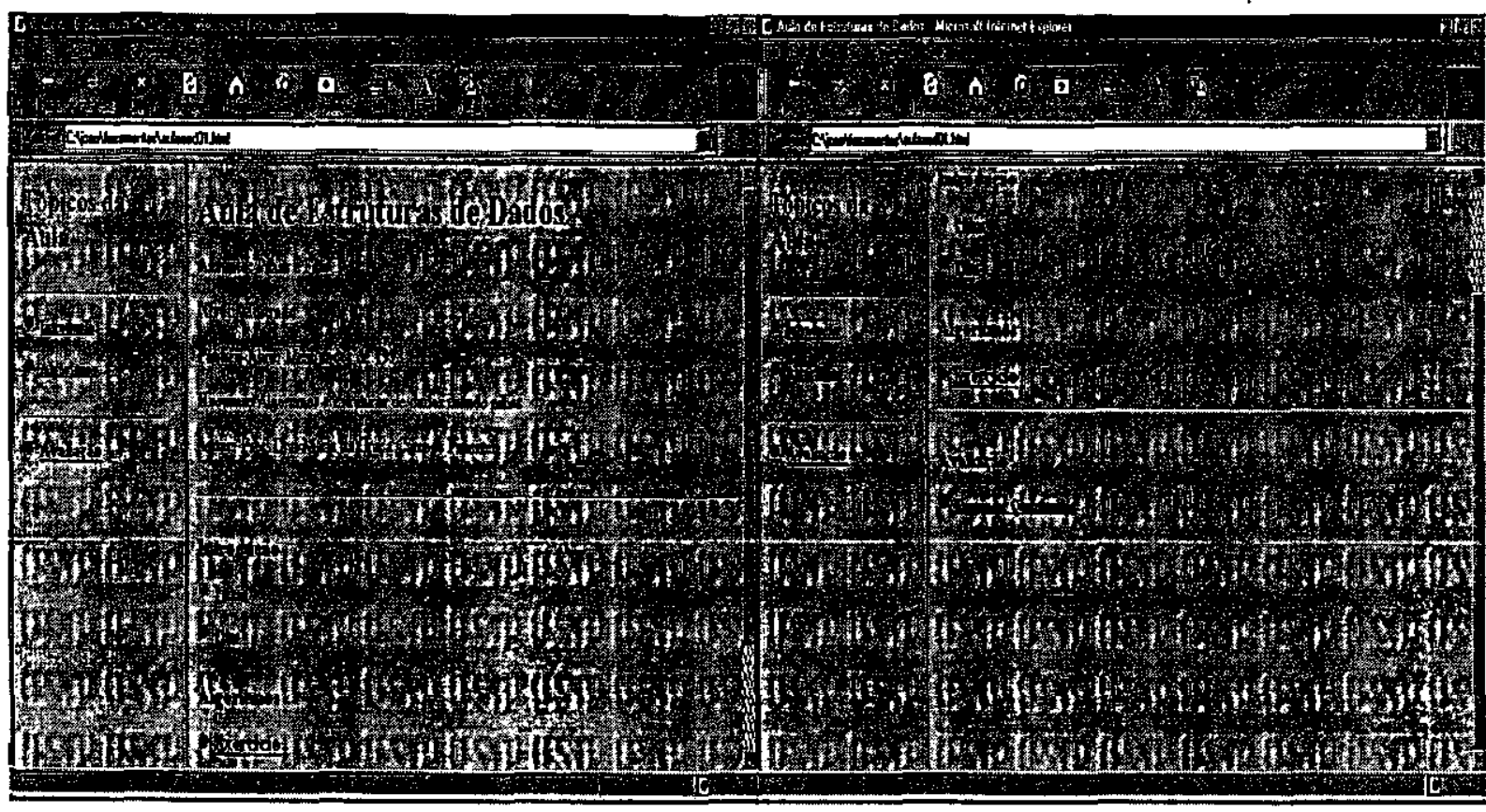

(a)

(b)

Figura 5.18 - (a) Ambiente inicial do material didático apresentado ao estudante

(b) ambiente apresentado ao estudante após acionado link da lista de tópicos 


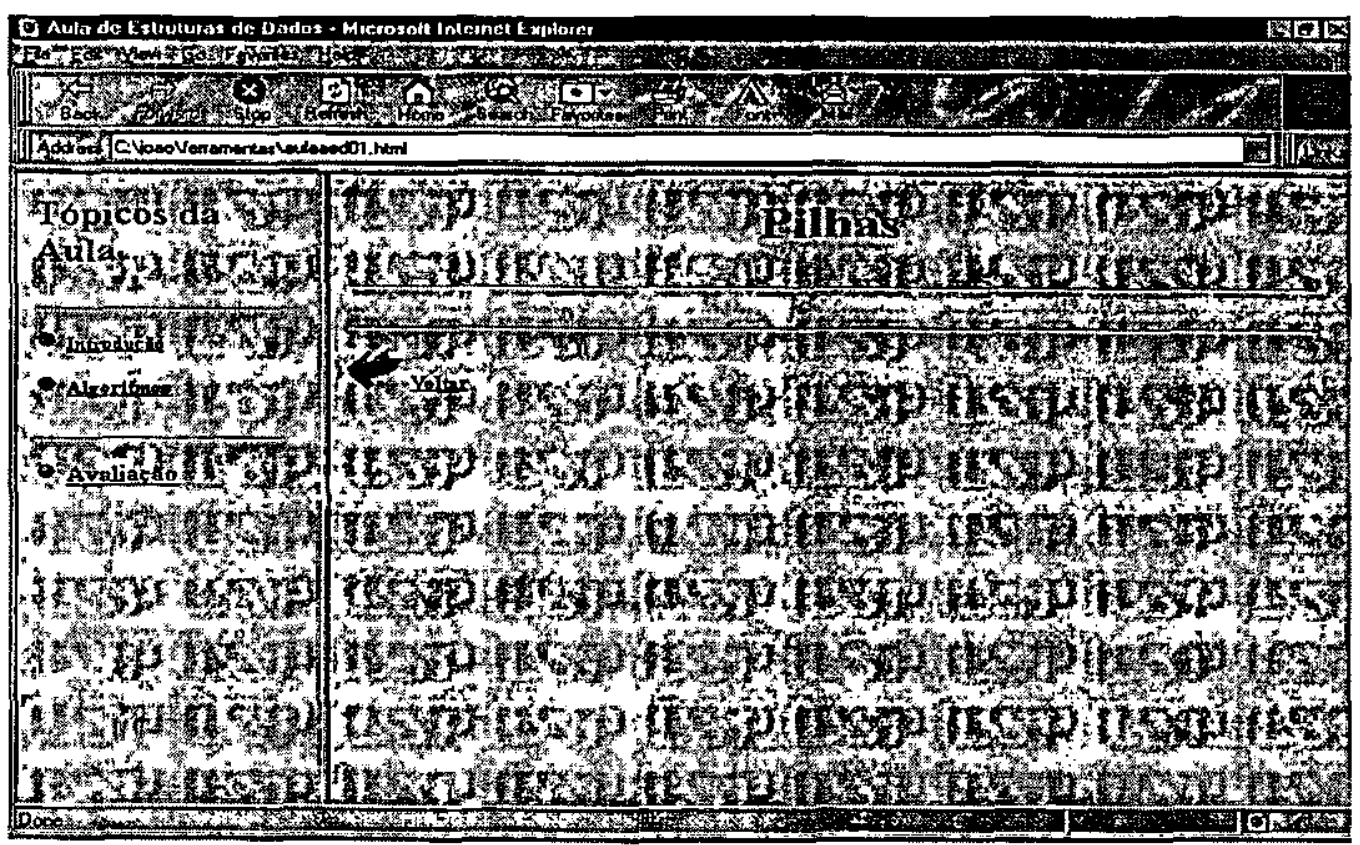

Figura 5.19 - Ambiente apresentado ao estudante após ser acionado um subitem do texto

Finalizando, os links para exercício e questionário de avaliação apresentam ao estudante ambientes de interação baseados em applets JAVA. Tais ambientes, apresentados na Figuras 5.20 e 5.21, permitem o fornecimento de respostas pelo estudante e a correção automáticas dessas respostas.

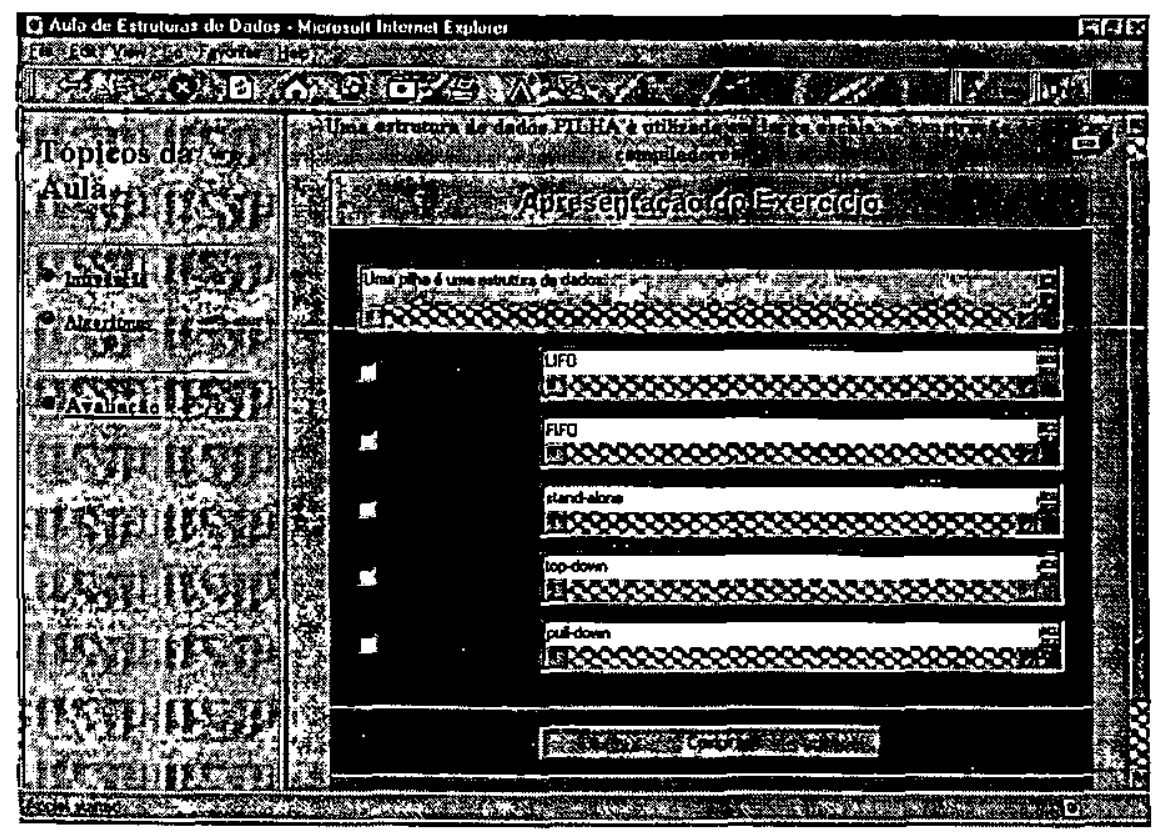

Figura 5.20 - Exercício apresentado ao estudante 


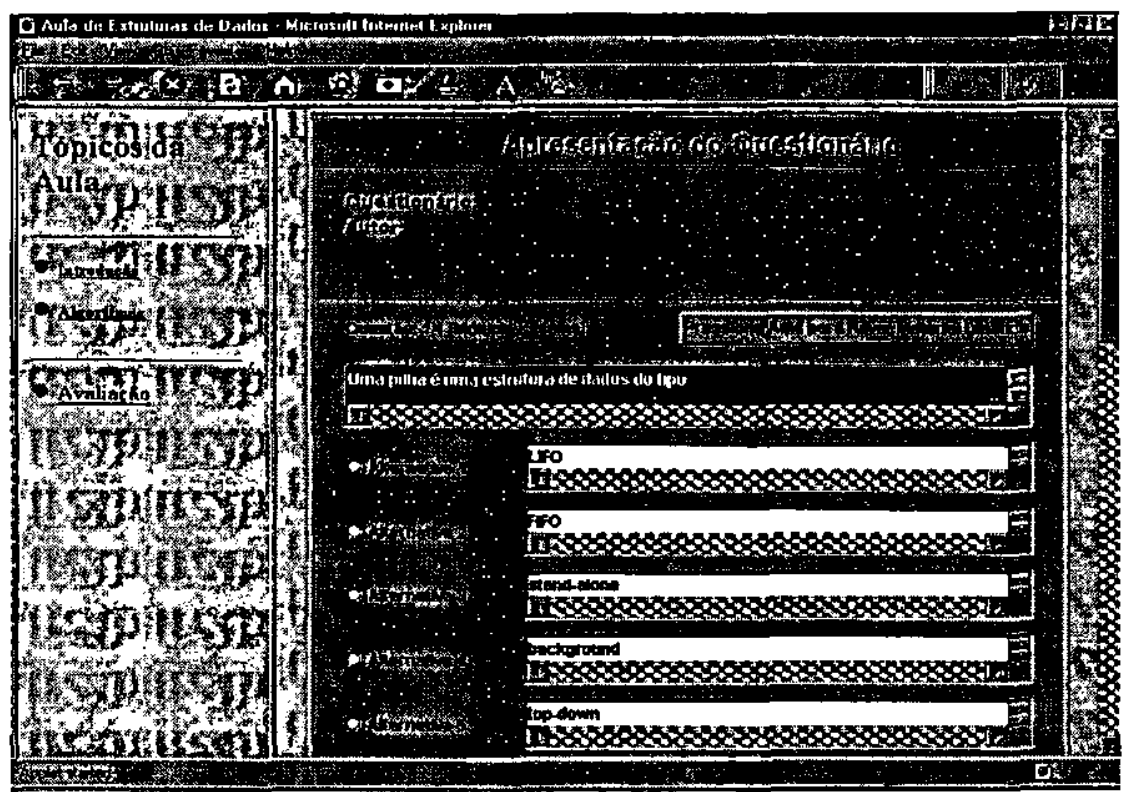

Figura 5.21 - Questionário, baseado em applet JAVA, apresentado ao estudante

\subsection{Considerações finais}

Este capítulo apresentou as ferramentas de autoria propostas e implementadas. Tais ferramentas fazem parte de um conjunto integrado de ferramentas hipermídia para o domínio de aplicação ensino, cuja modelagem foi realizada com o RMM. Neste ponto é válido ressaltar que o uso de JAVA para a implementação das ferramentas estende o escopo de utilização das mesmas em virtude das características de execução em multi-plataformas (Sun, 1996). Ressalta-se, ainda, que a implementação das ferramentas em modo stand-alone permite o uso local das mesmas, fazendo com que o autor não dependa de conexões on-line a servidores WWW durante o processo de autoria.

A modelagem da estrutura dos documentos didáticos através de DTDs SGML consiste em um ponto relevante deste trabalho, visto que o uso de um padrão aberto possibilita o intercâmbio dos conteúdos gerados com outros ambientes de autoria e apresentação.

Em adição, os mecanismos implementados para integração das ferramentas permitem ao autor a criação de todos os componentes da estrutura do material didático propostos na arquitetura de software. Neste ponto, as ferramentas isolam o autor das complexidades dos componentes usuais de autoria e disponibilização de material didático no ambiente WWW. 


\section{ANÁLISE DAS FERRAMENTAS DE AUTORIA PROPOSTAS}

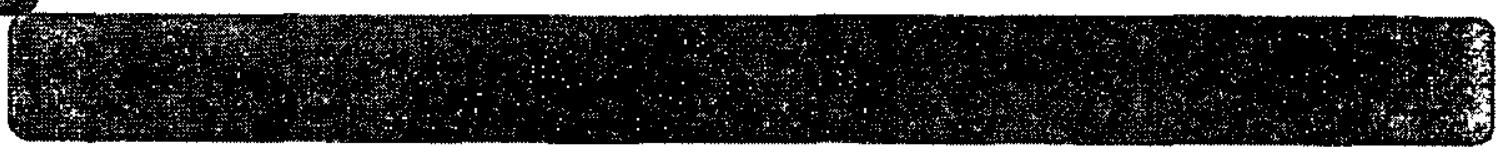

\subsection{Considerações iniciais}

Conforme apresentado, a motivação para a implementação de um conjunto de ferramentas para autoria e disponibilização de material didático reside na proposta de isolar o autor das complexidades de componentes para autoria e publicação de material didático na WWW, tais como HTML, JAVA e JAVAScript.

Para a implementação das ferramentas, foram observados aspectos de orientação às tarefas que o autor deve realizar na elaboração de um material didático, além de aspectos para construção de hiperdocumentos didáticos estruturados, com vistas ao armazenamento e recuperação em bases de dados, facilidade de intercâmbio do conteúdo, bem como a apresentação estruturada ao estudante.

Neste contexto, torna-se relevante analisar o uso das ferramentas pelos usuários potenciais, no caso professores e alunos, em ambientes reais de ensino. Inicialmente, um estudo detalhado da ferramenta WebCT é apresentado com vistas ao estabelecimento de parâmetros de comparação entre os recursos providos por tal ambiente e pelas ferramentas propostas por este trabalho e por outras ferramentas em desenvolvimento no contexto no qual este projeto está inserido. A seguir, são apresentados o planejamento e a execução de um experimento com vistas à obtenção de dados sobre o uso das ferramentas de autoria implementadas.

\subsection{Um estudo da ferramenta WebCT}

WebCT é um conjunto de ferramentas que facilitam a criação de materiais didáticos sofisticados baseados na WWW, primando-se por permitir sua utilização por autores sem conhecimentos técnicos em computação. Todo o ambiente de autoria do WebCT é on-line, podendo-se criar cursos completos através das interfaces providas por um conjunto de documentos HTML e, em seguida, disponibilizar os cursos criados no próprio ambiente WWW. Além de fornecer as ferramentas para a autoria dos materiais didáticos, o ambiente WebCT possui ferramentas para facilitar a organização dos cursos, que incluem: 
- um sistema de marcação de conferências (reuniões);

- um sistema de chat on-line;

- mecanismos de acompanhamento do estudante;

- suporte à construção de material didático por grupos de trabalho;

- mecanismos de auto-avaliação do estudante, que incluem a autoria e apresentação de questionários eletrônicos;

- ferramentas para controle do acesso e navegação pelo estudante;

- serviço de mail;

- geração automática de índice, referências bibliográficas e glossário.

Quando se acessa a ferramenta WebCT, a primeira página (módulo Homepage Design) permite ao autor construir o layout de apresentação do curso, uma espécie de página de abertura do material didático que se deseja elaborar, conforme mostra a Figura 6.1. Uma estrutura básica dos componentes do material didático é apresentada, sendo permitido ao autor selecionar quais componentes ele deseja manter no curso e quais devem ser mantidos ocultos quando da apresentação do material didático ao estudante.

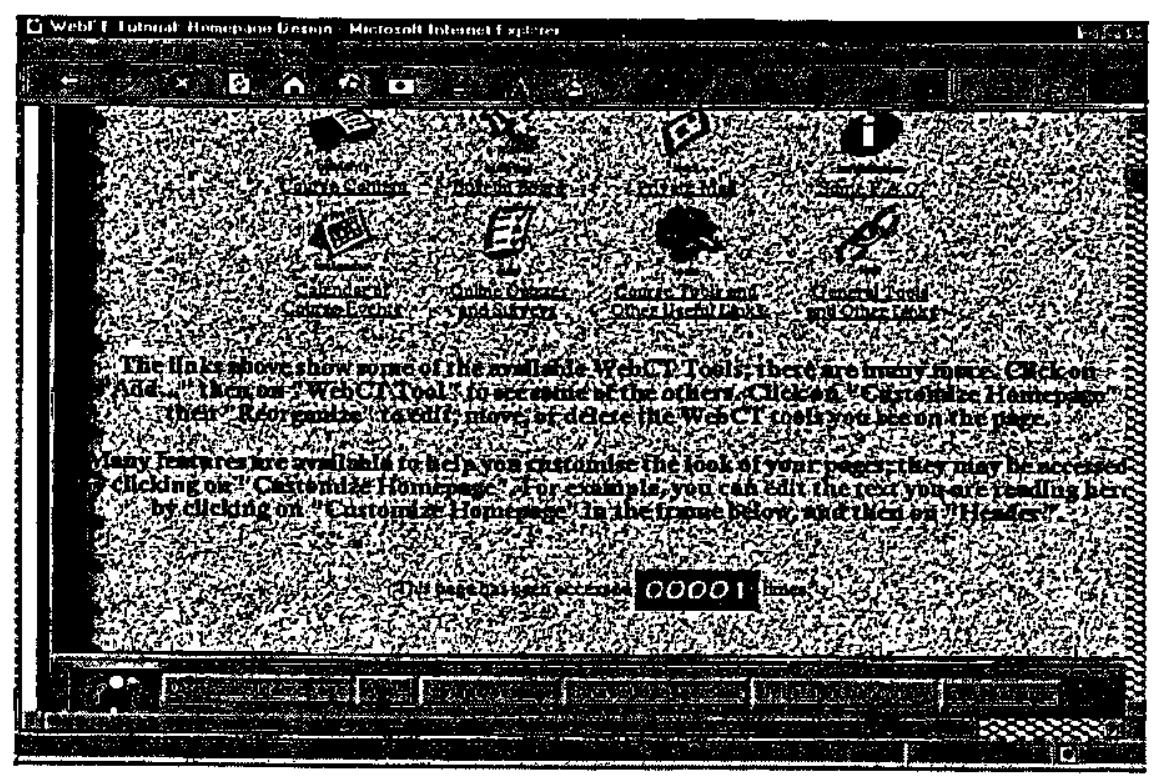

Figura 6.1 - WebCT - Módulo de construção da página de abertura do curso

O módulo File Manager, apresentado na Figura 6.2, permite ao autor o controle dos arquivos utilizados na construção do material didático, tais como arquivos de imagens e ícones (.gif e 
.jpg), documentos HTML gerados durante a autoria, além de possibilitar a compressão dos arquivos e seu envio para o servidor associado ao WebCT.

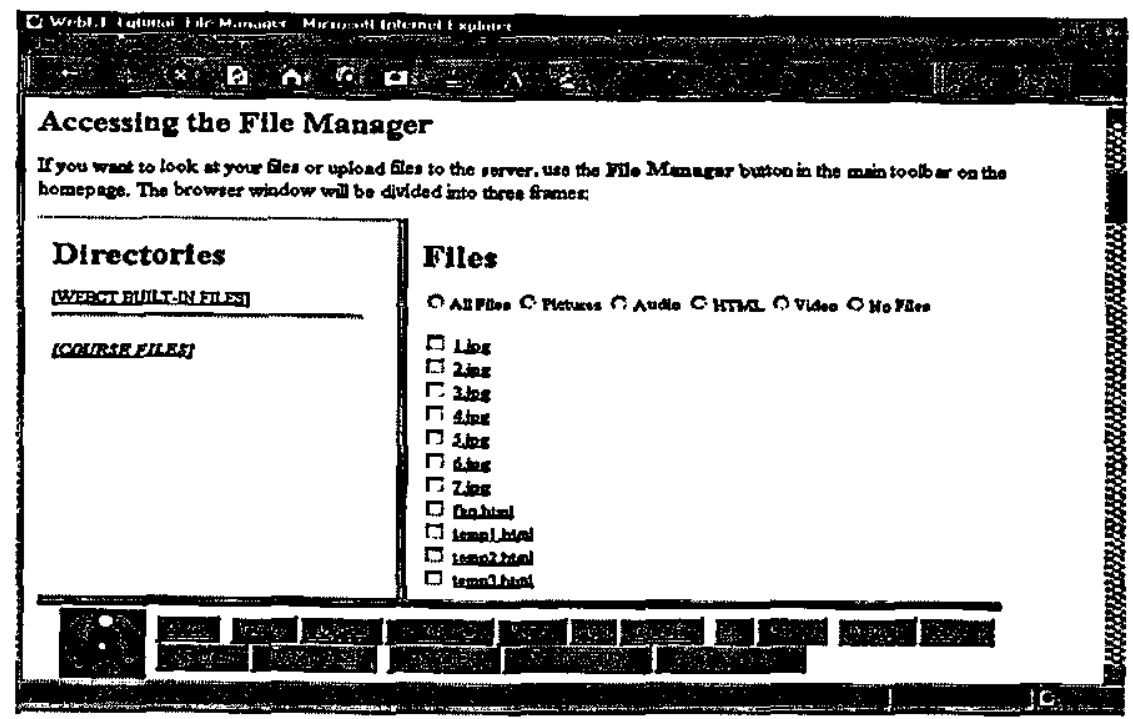

Figura 6.2 - WebCT - Módulo de gerenciamento dos arquivos que compõem o curso

Um outro módulo, denominado Course Content, permite a definição do layout de cada página dos componentes do curso, tais como índice, questionários, referências, entre outros. Neste módulo, o autor seleciona os ícones para identificar cada componente, e escolhe a forma de apresentação dos rótulos que identificam cada componente, conforme ilustra a Figura 6.3.

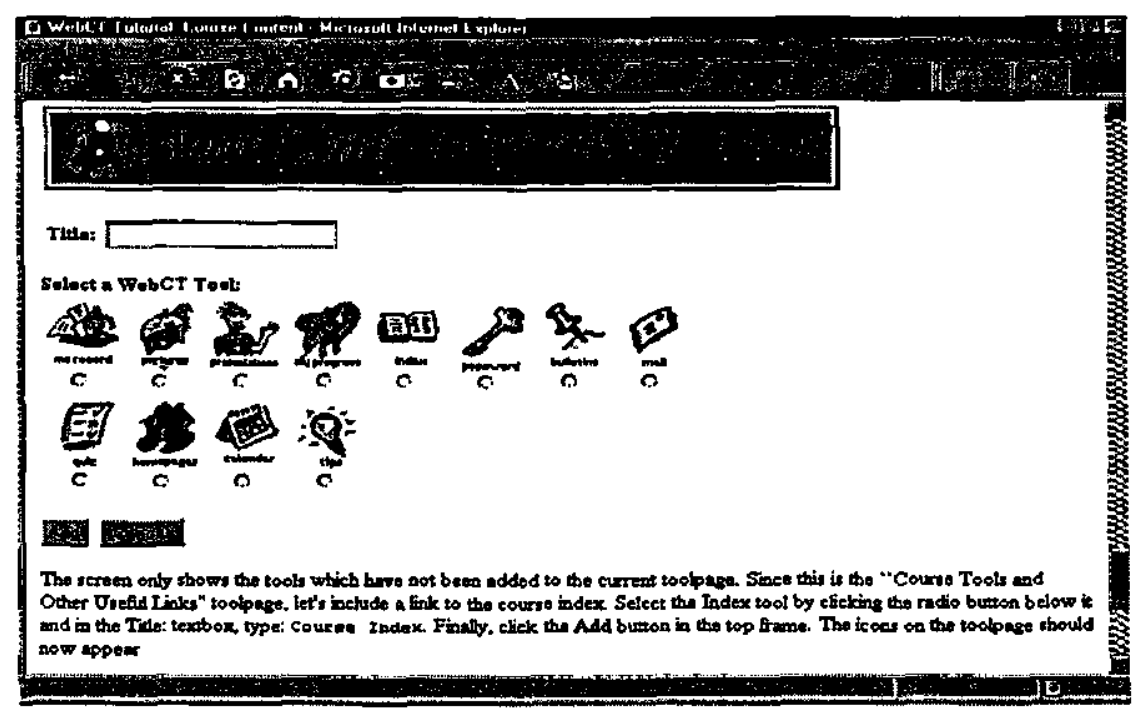

Figura 6.3 - WebCT - Módulo de definição do layout dos componentes do curso

O módulo, denominado Path Editor, permite ao autor a definição da hierarquia dos itens e subitens do conteúdo do curso, conforme ilustra a Figura 6.4. É fornecido um editor e botões de 
controle que orientam a inserção do rótulo do item e qual o seu nível de profundidade na hierarquia de apresentação ao estudante.

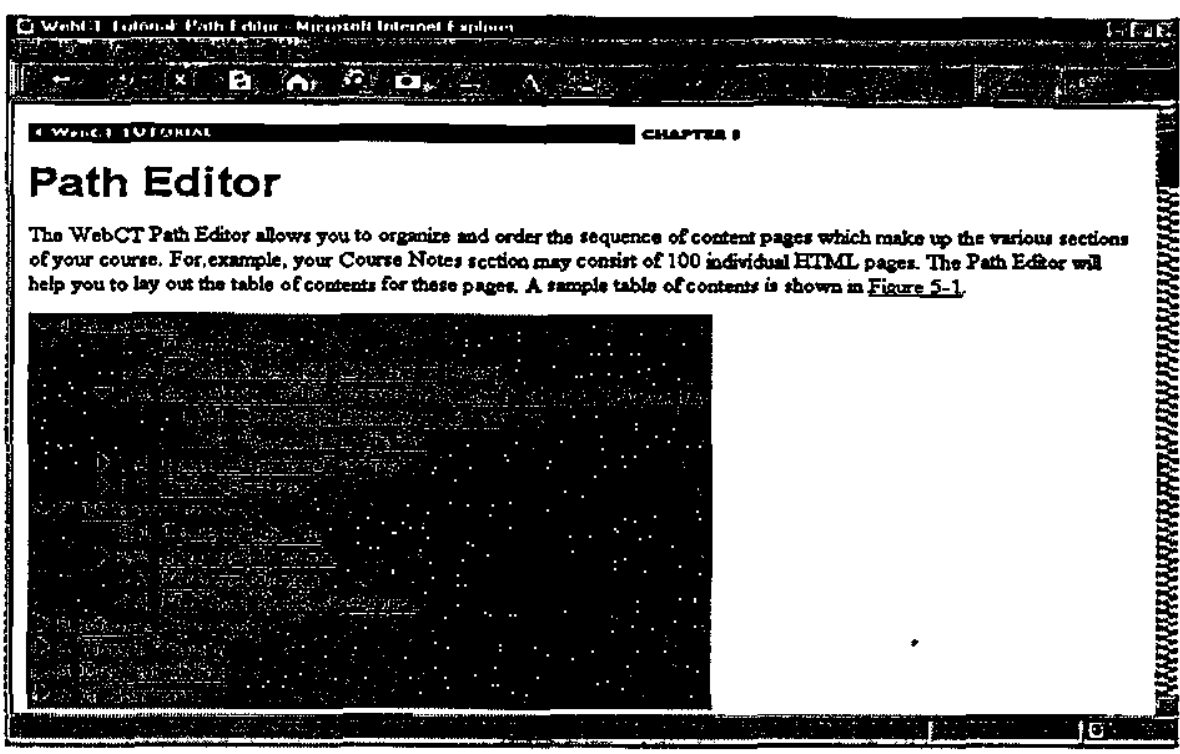

Figura 6.4 - WebCT - Módulo de edição dos itens e subitens do conteúdo do curso

O módulo Page Editor, apresentado na Figura 6.5, permite ao autor a inserção do conteúdo de cada item do cursò, bem como a definição do layout para apresentação ao estudante. Tal layout é definido em termos do local de inserção de imagens e formas de apresentação dos textos.

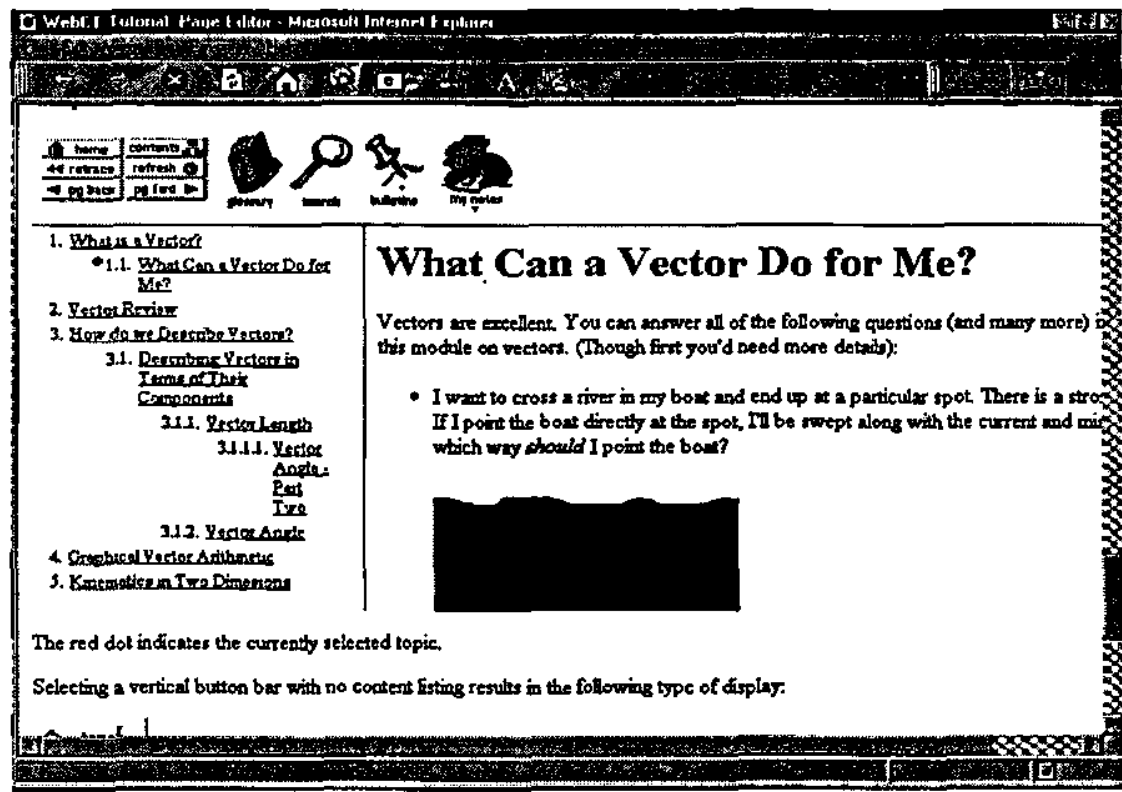

Figura 6.5 - WebCT - Módulo de construção do layout dos itens do conteúdo do curso 
O módulo, denominado Glossary Editor, permite ao autor definir palavras-chaves e seu significado com vistas à inserção em um arquivo-texto que representa o glossário de termos do material didático, conforme ilustra a Figura 6.6. É fornecido um formulário básico no qual o autor indica qual é a palavra-chave e insere um texto correspondente a esta.

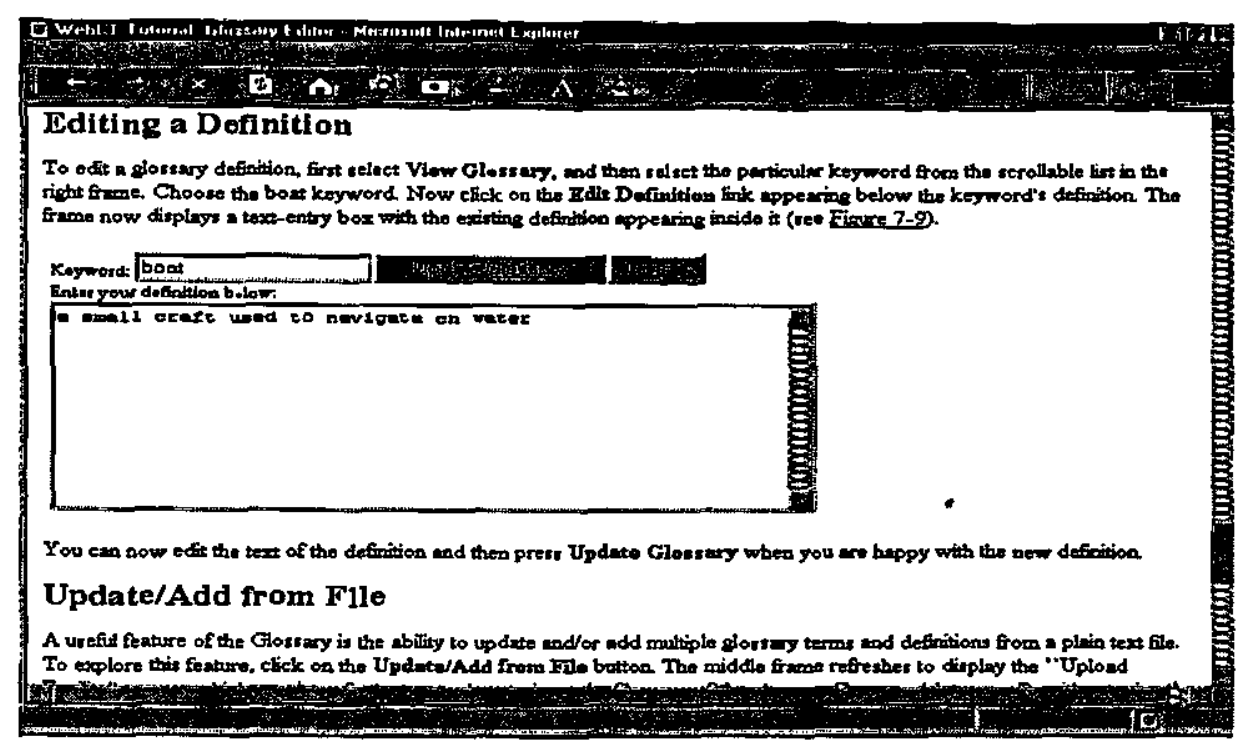

Figura 6.6 - WebCT - Módulo de construção do glossário

Outro módulo, denominado Index Editor, permite ao autor a definição de palavras-chave que podem ser inseridas em meio ao conteúdo do material didático. Neste ponto, quando for permitido ao estudante acionar tais palavras-chave, a navegação será desviada para $o$ índice principal do material didático. A Figura 6.7 ilustra o módulo de criação de índices auxiliares.

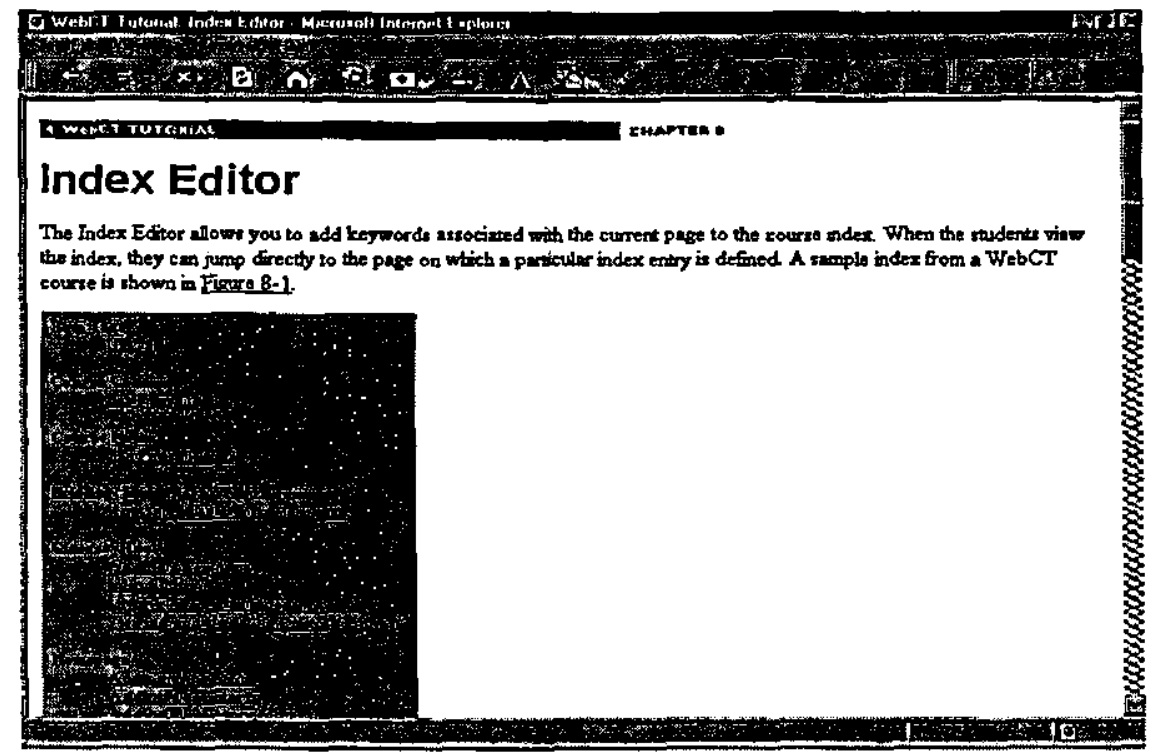

Figura 6.7 - WebCT - Módulo de construção de índices complementares 
O módulo, denominado Reference Editor, permite ao autor inserir referências bibliográficas ao final do material que será disponibilizado ao estudante, conforme mostra Figura 6.8. Um formulário é apresentado ao autor para que este entre com os dados da referência bibliográfica que deseja citar no curso. De modo geral, é permitida a inserção de referências para livros e também uma formatação especial para URL (Uniform Resource Location), para citação de referências que podem ser encontradas na WWW.

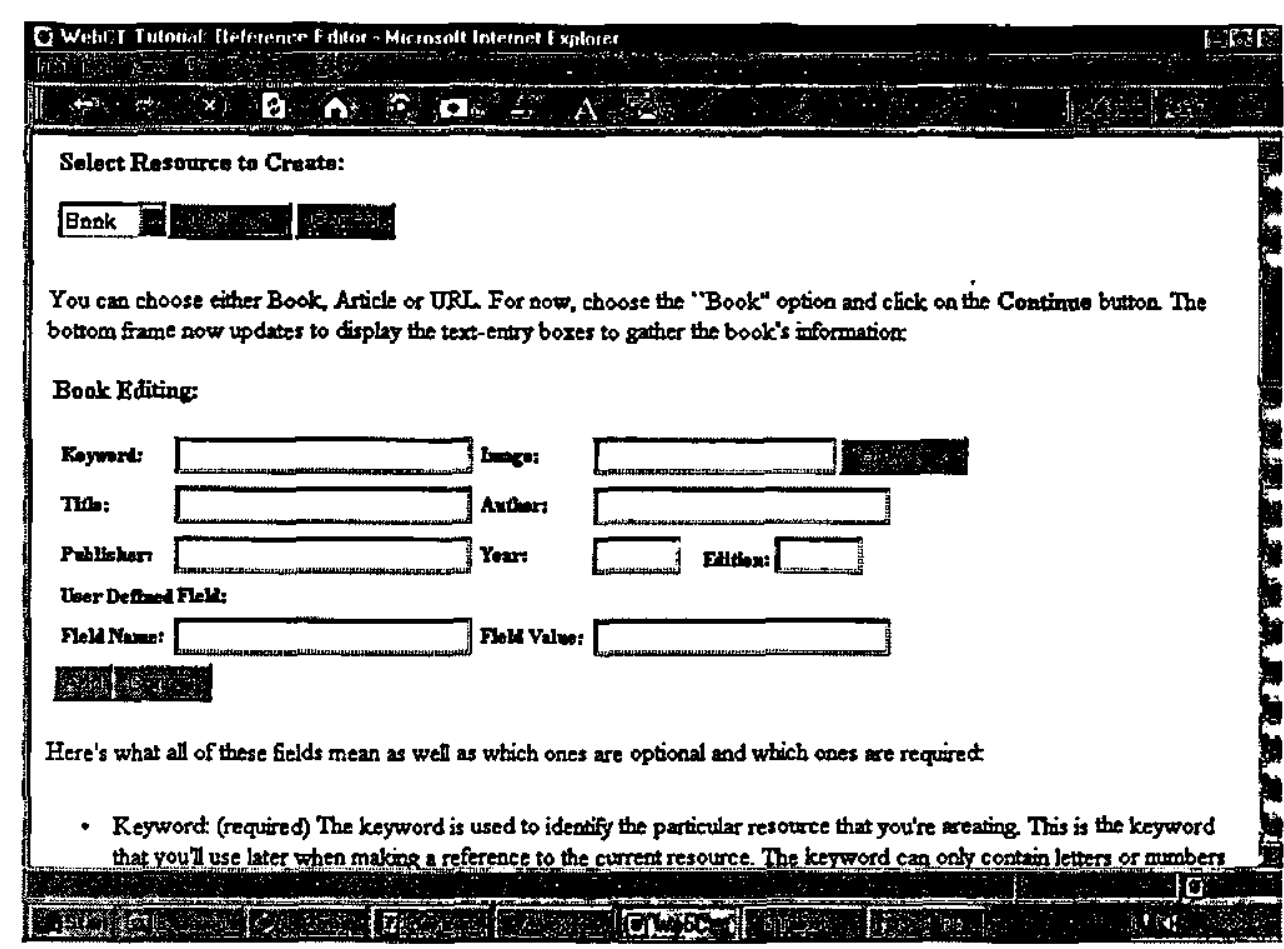

Figura 6.8 - WebCT - Módulo para construção de referências bibliográficas

- O módulo Question Editor, ilustrado na Figura 6.9, permite ao autor a construção de questionários para auto-avaliação do aprendizado pelo estudante. Uma interface baseada em formulários é apresentada ao autor, e este tem à sua disposição campos para informar o enunciado da questão, justificativas para a resposta correta, e uma lista para seleção da resposta correta. É permitida a inserção de questões de múltipla-escolha, falso ou verdadeiro e questões abertas. Para esta última, não são fornecidos mecanismos para correção automática da resposta do estudante. 


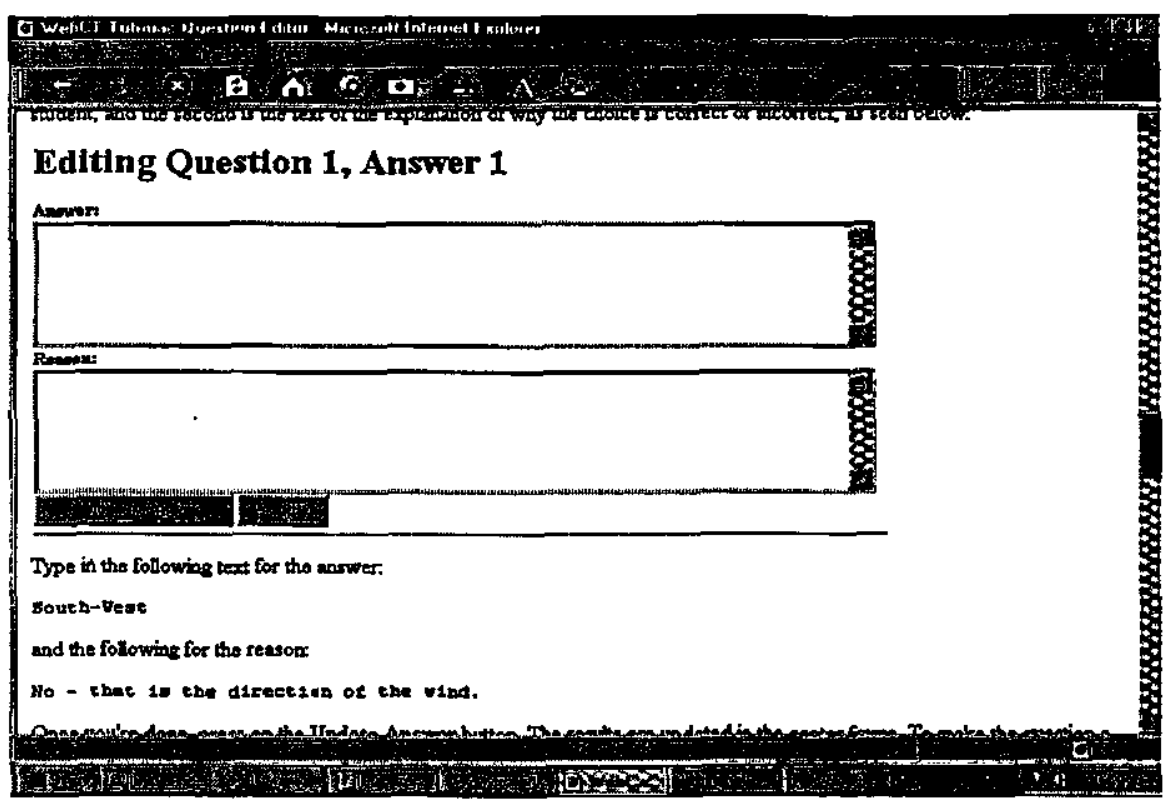

Figura 6.9 - WebCT - Módulo para autoria de questionários

O módulo, denominado Goal Editor, permite ao autor inserir textos sobre objetivos de uma determinada página do conteúdo do curso em construção, conforme ilustrado na Figura 6.10. De modo geral, os objetivos são inseridos na forma de uma lista de tópicos que contém como "o que é a página”, "qual o conteúdo que ela apresenta" e "o que pode ser aprendido com ela".

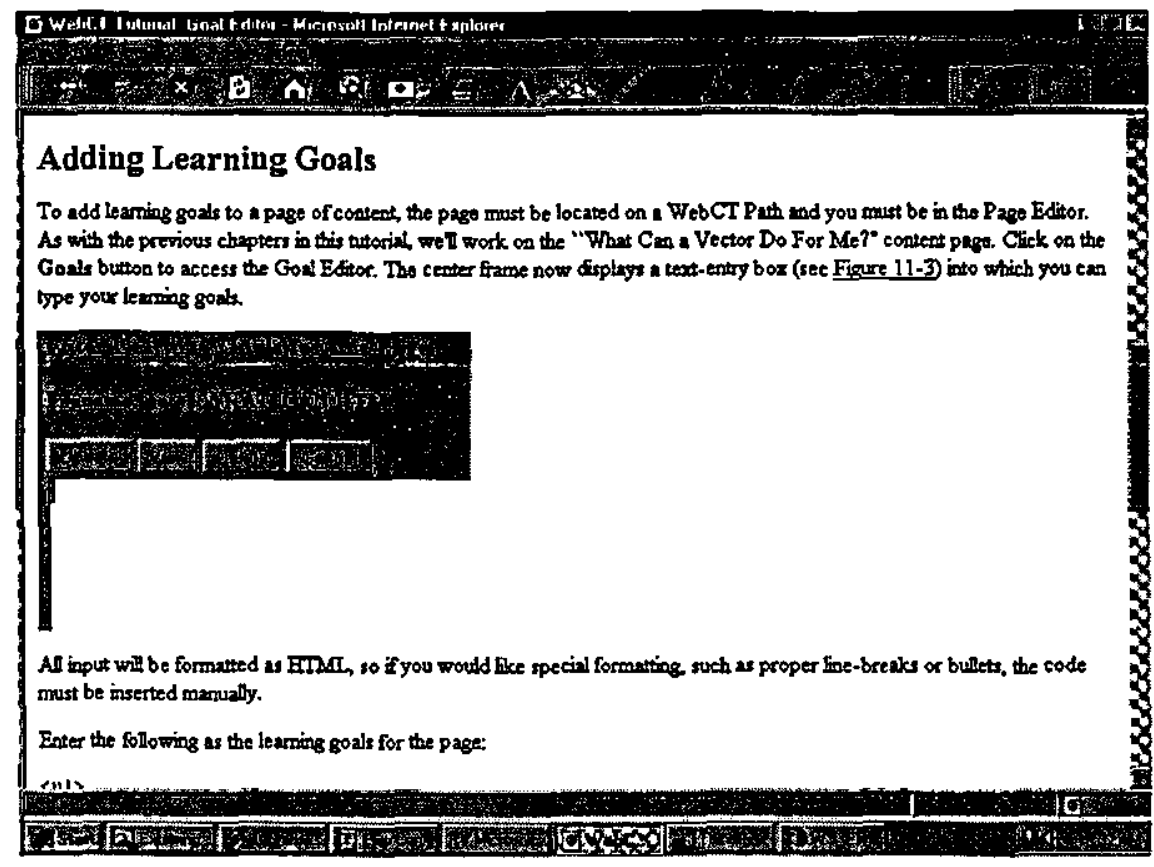

Figura 6.10 - WebCT - Módulo para inserção de objetivos de uma página do curso 
Conforme citado, o resultado do processo de autoria com o WebCT é um conjunto de documentos HTML. O módulo Page Text Editor permite ao autor visualizar os documentos HTML gerados e proceder alteraçōes e/ou ajustes no código-fonte dos mesmos. A Figura 6.11 apresenta o módulo de edição do texto dos documentos.

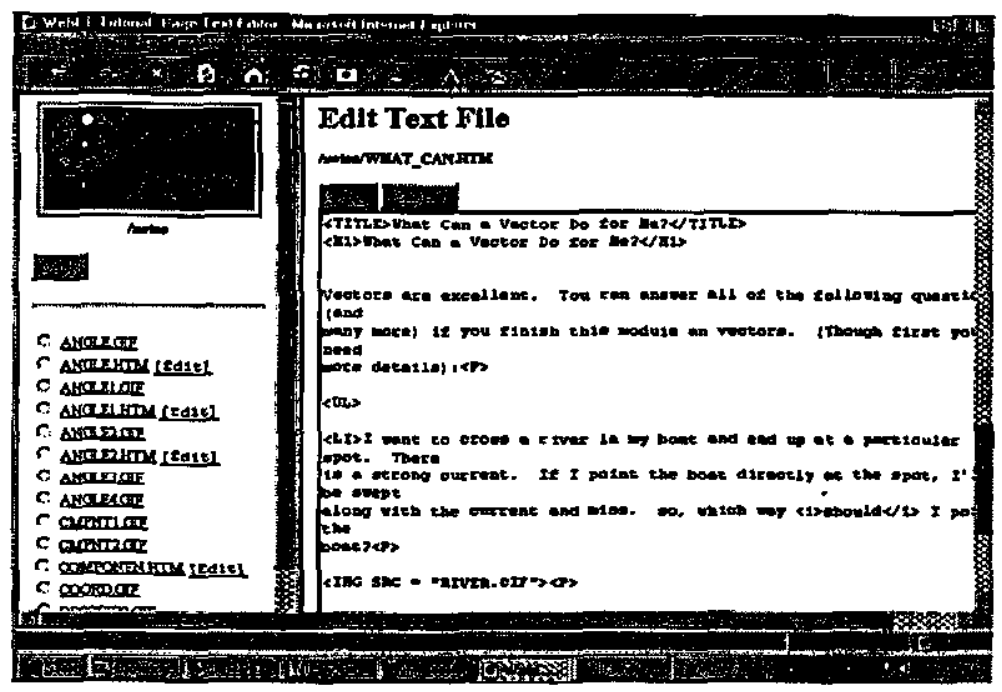

Figura 6.11 - WebCT - Módulo para edição das páginas HTML geradas

O módulo Student Management, apresentado na Figura 6.12, permite ao instrutor o cadastramento e o controle dos estudantes vinculados a um curso. Inicialmente é apresentada uma interface para autenticação do estudante através de um identificador (nome do estudante) e uma senha para acesso. De um modo geral, o módulo, através de tabelas, auxilia o instrutor no controle de quais estudantes estão acessando um determinado curso e, ainda, em que estágio do curso cada estudante está.

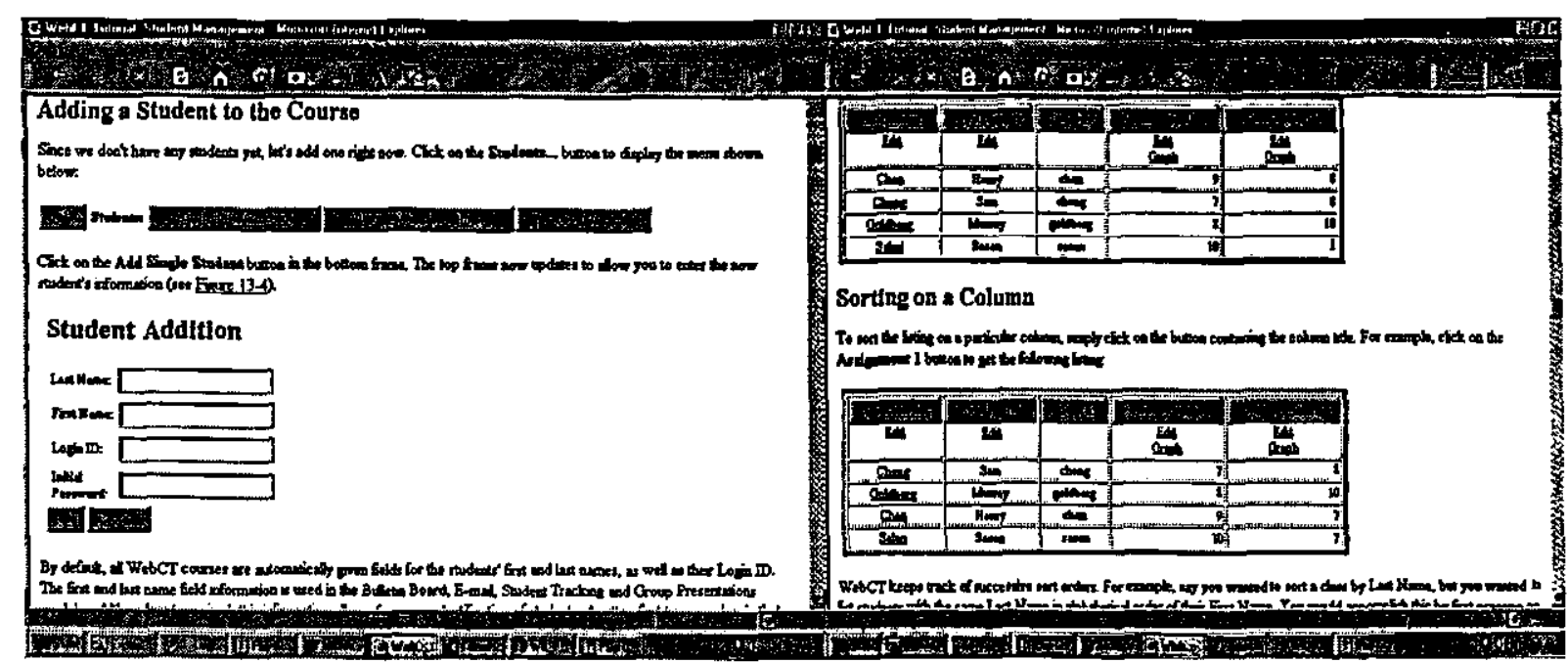

Figura 6.12 - WebCT - Módulo para cadastramento e controle do estudante 
Finalmente, o WebCT fornece um módulo denominado Bulletin Board, que permite a troca de mensagens entre professores e estudantes, conforme ilustra a Figura 6.13. Basicamente é fornecida uma interface que permite a identificação do remetente e destinatário da mensagem, bem como um subject que contenha comentários sobre a mesma. Em adição, é possível a seleção do tipo de mensagem que se deseja enviar, tais como "boas-vindas", "mensagem do instrutor", "avisos" e outras.

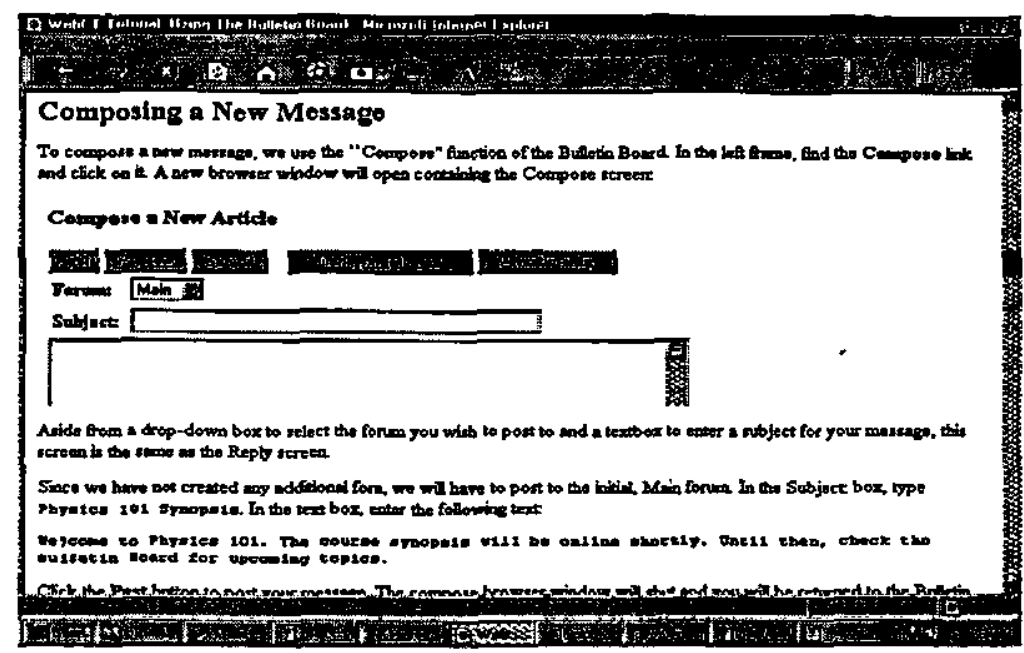

Figura 6.13 - WebCT - Módulo para uso do serviço de troca de mensagens

Em adição ao serviço de troca de mensagens, o WebCT fornece um módulo denominado Bulletin Board Administration, ilustrado na Figura 6.14, que permite ao autor a marcação de reuniōes online com um estudante ou grupo de estudantes. Para tal, uma interface de um chat convencional é apresentada, permitindo a comunicação on-line e bidirecional entre professores e estudantes.

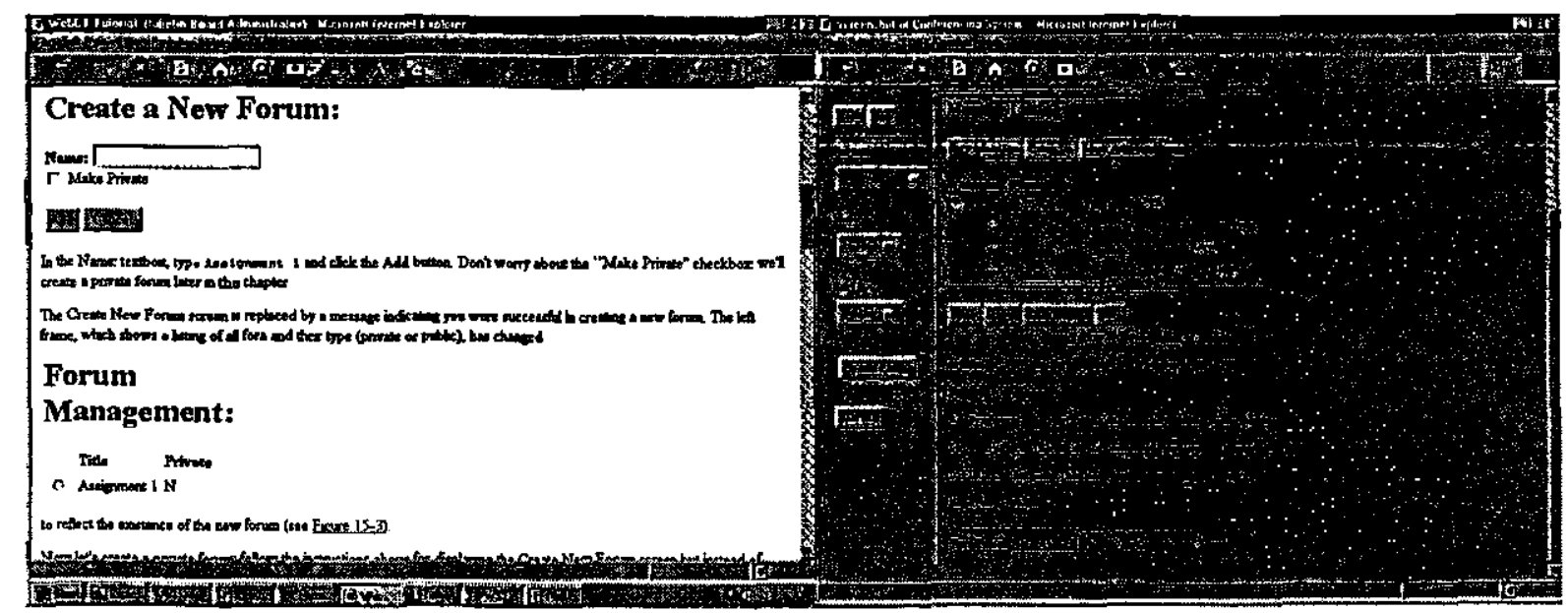

Figura 6.14 - WebCT - Módulo para construção de conferências e reuniões 


\subsection{Comparação do WebCT com as ferramentas do contexto deste trabalho}

As ferramentas HyperBuilder, QuestBuilder e TaskBuilder são componentes de um projeto existente no Grupo de Hipermídia do Instituto de Ciências Matemáticas e de Computação da Universidade de São Paulo, que investiga a aplicação de recursos computacionais em ambientes de ensino, especialmente aqueles suportados pela WWW (Moreira et al., 1995). Neste contexto, torna-se relevante uma.análise comparativa entre as características implementadas nessas ferramentas e as características dos modulos que compõem a ferramenta WebCT que, atualmente, é um dos mais completos toolkits para elaboração e disponibilização de material didático na WWW.

De um modo geral pode-se listar as principais características da ferrạmenta HyperBuilder:

- possui uma estrutura pré-definida pelo DTD DIDTML;

- possui geração automática de contextos de navegação a partir do índice de tópicos construído pelo autor;

- possui dois níveis de profundidade em termos da hierarquia dos itens e subitens do conteúdo do curso;

- gera automaticamente as páginas HTML do hiperdocumento didático estruturado em conformidade com o DIDTML, sendo que a primeira página apresenta o cabeçalho de identificação do curso e o índice de tópicos que pode ser apresentado através de frames ou não;

- gera automaticamente o arquivo contendo a especificação SGML correspondente ao hiperdocumento didático em conformidade com o DIDTML;

- permite a inserção de conteúdos adicionais, denominados exercícios, nos quais podem ser apresentados textos, imagens e testes de múltipla escolha;

- permite a inserção de questionários de avaliação do aprendizado adquirido pelo estudante;

- coleta todos os arquivos envolvidos no material didático e processa o envio destes a um servidor HTTP, promovendo, assim, a disponibilização do material didático de forma transparente ao autor.

Em relação à ferramenta QuestBuilder, pode-se listar as principais características: 
- permite a autoria de questões de falso ou verdadeiro, múltipla escolha, questões abertas (dissertativas) e relacionamento de colunas (matching);

- gera automaticamente um arquivo formatado em conformidade com o DTD QuestML que é interpretado por um applet JAVA quando da apresentação do questionário ao estudante;

- gera automaticamente o arquivo contendo a especificação SGML correspondente ao hiperdocumento didático em conformidade com o QuestML.

Por fim, pode-se listar as principais características da ferramenta TaskBuilder:

- permite a seleção de layout de apresentação de conteúdos em meio aos itens de um material didático;

- permite que o autor especifique imagens a serem inseridas no conteúdo de um item do material didático;

- permite a inserção de textos e testes de múltipla escolha nos itens que formam o conteúdo do material diđático;

- gera automaticamente as páginas HTML correspondentes às especificações feitas pelo autor.

Observa-se que a saída das ferramentas de autoria é um conjunto de documentos HTML correspondente a todo o material didático elaborado pelo autor, além de documentos abertos formatados em SGML. Neste ponto, utiliza-se dos browsers de uso disseminado para prover a apresentação e permitir a navegação pelo estudante. Assim, tanto os testes de múltipla escolha inseridos como exercício em meio ao conteúdo de um item do curso, quanto os questionários de avaliação do aprendizado, são apresentados ao estudante através de applets JAVA, possuindo mecanismos para correção automática das respostas do estudante, exceção feita às questões abertas.

Além das três ferramentas implementadas neste trabalho, outras duas ferramentas encontram-se em desenvolvimento para uma futura integração. Inicialmente, uma ferramenta baseada em recursos de chat está sendo desenvolvida para permitir o suporte ao trabalho cooperativo (CSCW), incluindo todos os recursos de comunicação on-line, marcação de reuniōes e realização 
de texto-conferência (Kutova, 1998). Uma segunda ferramenta está sendo desenvolvida para gerenciar o cadastramento e o acesso de estudantes ao material didático elaborado e disponibilizado pelo autor em um servidor HTTP. Para tal, uma base de dados SQL está sendo construída em paralelo à implementação de applets JAVA responsáveis pela autenticação do estudante e controle do acesso deste aos materiais didáticos correspondentes a um curso (Macedo, 1998).

De modo geral, é relevante uma comparação direta entre as características encontradas no ambiente WebCT e as características das ferramentas implementadas, principalmente para fins de contextualização do potencial de aplicação das ferramentas. Tal comparação é apresentada pelas Tabelas 6.1, 6.2 e 6.3, nas quais os itens indicam características equivalentes em ambas as ferramentas.

\begin{tabular}{|c|c|c|}
\hline & Mote & Hod 16 \\
\hline Usa SGML para formalização da estrutura dos documentos didáticos & Năo & Sim \\
\hline Possui o modo de autoria on-line através do ambiente WWW & Sim & Năo \\
\hline Possui o modo de autoria stand-alone & Nāo & $\operatorname{Sin}$ \\
\hline Permite a inserçăo de questionários de avaliação no material didático & Sim & Sim \\
\hline Gera automaticamente os documentos HTML & Sim & $\operatorname{Sim}$ \\
\hline $\begin{array}{l}\text { Disponibiliza os documentos HTML diretamente em um servidor de } \\
\text { WWW }\end{array}$ & Sim & $\overline{S i m}$ \\
\hline Fornece modelos de estrutura para os documentos didáticos & Sim & Sim \\
\hline Permite a inserção de imagens e fcones no conteúdo do material didático & Sim & Sim \\
\hline Possui modulos de gerenciamento de cursos & Sim & Não \\
\hline Possui módulos para acompanhamento do desempenho dos estudantes & Sim & Não \\
\hline Possui módulos para discussāo entre estudantes & Sim & Nāo \\
\hline
\end{tabular}

Tabela 6.1 - Comparação das características da ferramenta HyperBuilder com o WebCT

\begin{tabular}{|c|c|c|}
\hline Wharactiotica & WobGT & Puegraulder \\
\hline $\begin{array}{l}\text { Usa SGML para formalização da estrutura do documento correspondente } \\
\text { ao questionário }\end{array}$ & Não & $\mathrm{Sim}$ \\
\hline Permite a inserçāo de questões do tipo múltipla-escolha & $\operatorname{Sim}$ & Sim \\
\hline Permite a inserção de questōes do tipo falso ou verdadeiro & Sim & Sim \\
\hline Permite a inserção de questōes de relacionamento de colunas & Năo & Sim \\
\hline Permite a inserção de questōes abertas (dissertativas) & Sim & Sim \\
\hline Gera automaticamente os documentos HTML & Sim & Sim \\
\hline $\begin{array}{l}\text { Possui mecanismos para integraçāo do questionário no material didático } \\
\text { elaborado }\end{array}$ & Sim & Sim \\
\hline Possui módulos para controle da avaliação automática de questionários & $\overline{\text { Sim }}$ & Não \\
\hline
\end{tabular}

Tabela 6.2 - Comparação das características da ferramenta QuestBuilder com o WebCT 


\begin{tabular}{|c|c|c|}
\hline \multicolumn{3}{|l|}{$\mathbf{1}$} \\
\hline $\begin{array}{l}\text { Usa SGML para formalização da estrutura do documento correspondente ao } \\
\text { exercício }\end{array}$ & Nāo & $\overline{\mathrm{Sim}}$ \\
\hline Permite a definição de layouts de apresentação de textos e imagens & $\operatorname{Sim}$ & $\operatorname{Sim}$ \\
\hline Permite a seleção de imagens para inserção no layout do exercício & $\mathrm{Sim}$ & $\operatorname{Sim}$ \\
\hline Gera automaticamente os documentos HTML & Sim & Sim \\
\hline $\begin{array}{l}\text { Possui mecanismos para integração do exercício no material didático } \\
\text { elaborado }\end{array}$ & $\operatorname{Sim}$ & Sim \\
\hline
\end{tabular}

Tabela 6.3 - Comparação das características da ferramenta TaskBuilder com o WebCT

É válido ressaltar que as ferramentas aqui reportadas foram e estão sendo implementadas utilizando-se a tecnologia JAVA, tanto applets quanto aplicações stand-alone, ao passo que a ferramenta WebCT utiliza-se de interfaces baseadas em forms e CGI inseridos em documentos HTML.

O mais importante, em termos de comparação, é que as ferramentas aqui reportadas geram e manipulam documentos estruturados em conformidade com o padrão SGML, o que permite o reuso e intercâmbio com outras ferramentas de autoria e ambientes de apresentação, fato que não observado no conjunto de ferramentas do ambiente WebCT. Em adição, algumas das características das ferramentas do contexto no qual este trabalho se insere, assinaladas com "não" nas tabelas apresentadas, estão sendo investigadas e implementadas (Kutova, 1998; Macedo, 1998; Pires, 1998).

\subsection{Planejamento e execução de um experimento}

O planejamento e a execução de um experimento são importantes no contexto deste trabalho, dada a necessidade de testes de campo com os usuários potenciais das ferramentas implementadas, no caso professores e estudantes.

Neste contexto, a realização de experimentos visa revelar aspectos de usabilidade das ferramentas e também aspectos da eficiência dos processos de autoria e disponibilização de material didático no ambiente WWW. Em linhas gerais, o experimento realizado tem como principal objetivo verificar a validade das ferramentas implementadas em termos do isolamento do autor das complexidades das ferramentas usuais (HTML, JAVA e JAVAScript) para elaboração e publicação de material didático na WWW. Neste contexto, em uma primeira etapa, foram definidos os seguintes passos para o experimento: 
1. propor um material didático composto por textos didáticos, exercícios e questionário de avaliação, a ser elaborado pelos autores;

2. submeter os autores ao uso de HTML, através de um editor de textos qualquer, solicitando-lhes que construam um hiperdocumento referente ao material didático proposto;

3. submeter os autores à utilização das ferramentas de autoria implementadas, solicitandolhes que construam o material didático proposto;

4. observar as ações dos autores em relação às interfaces das ferramentas;

5. monitorar o tempo gasto pelos autores para construir o material didático proposto, utilizando editores HTML de uso genérico e as ferramentas de autoria implementadas.

Expondo os autores ao uso de HTML e das ferramentas implementadas pode-se realizar medições do tempo gasto no processo de autoria, e obter impressões subjetivas do quão fácil é para o autor utilizar ferramentas de autoria, quando comparado ao processo usual de elaboração e disponibilização de material didático. Esta medida é relevante, visto que o ponto forte do trabalho é a construção de uma arquitetura de software que isole o autor das complexidades de desenvolvimento de aplicações para a WWW. Neste ponto, é apresentado a seguir o planejamento básico do experimento realizado.

\subsubsection{O material didático proposto}

Inicialmente, um material didático foi proposto como sendo o objetivo do experimento, o qual os participantes deveriam transformar em um hiperdocumento para disponibilização no ambiente WwW.

O material didático proposto refere-se a alguns tópicos da disciplina Algoritmos e Estruturas de Dados, ministrada nos cursos superiores de Ciência da Computação no Brasil, sendo constituído de textos teóricos, links entre partes do texto e um questionário de avaliação. A Figura 6.15 apresenta o conteúdo com documento inicial do material didático proposto. Já as Figuras 6.16 a 6.18 apresentam os documentos complementares que poderão ser acionados a partir do documento inicial. 


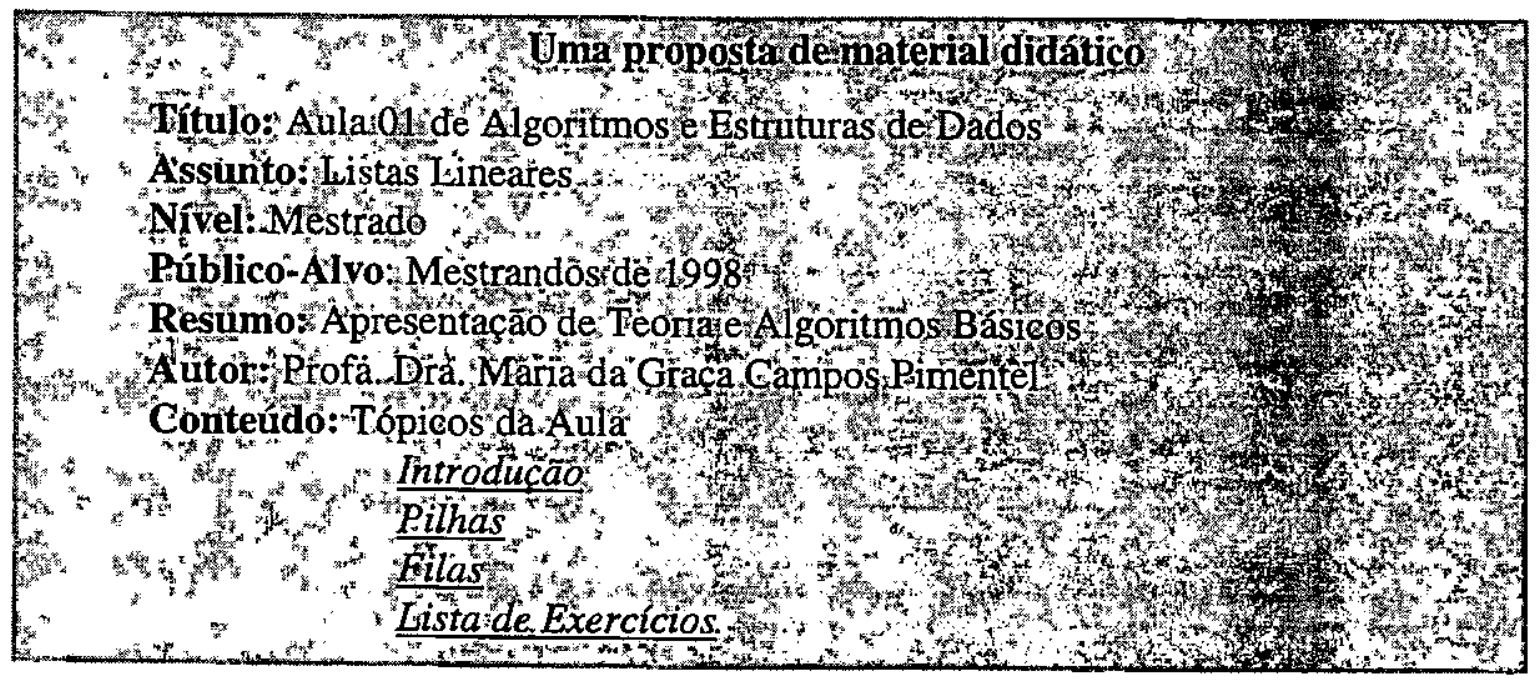

\subsection{5 - Conteúdo do documento inicial do material didático}

Complementando, foram definidas as seguintes tarefas em relação ao documento inicial do material didático:

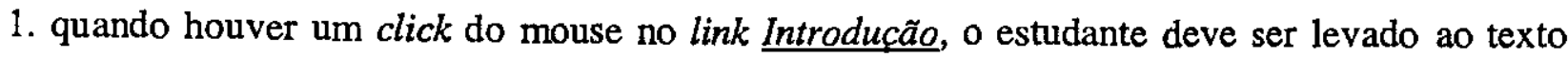
apresentado na Figura 6.16.

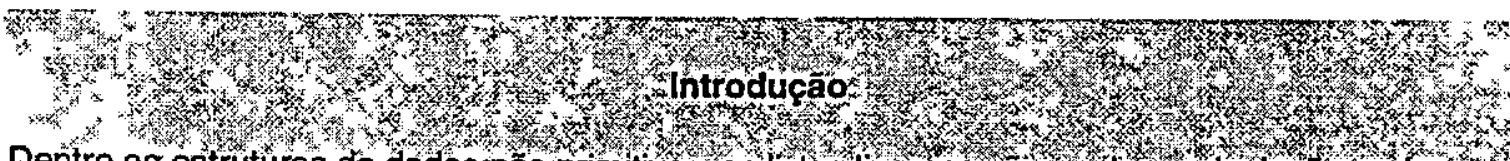

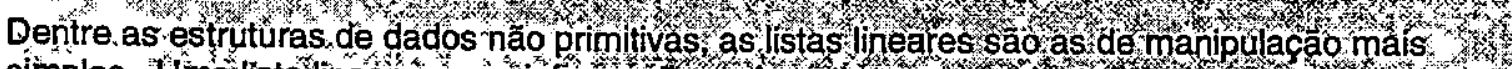

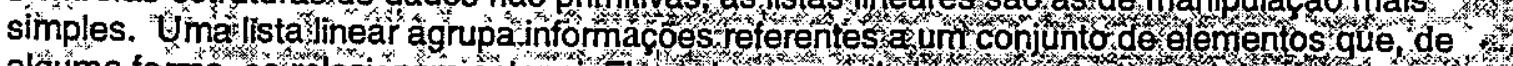

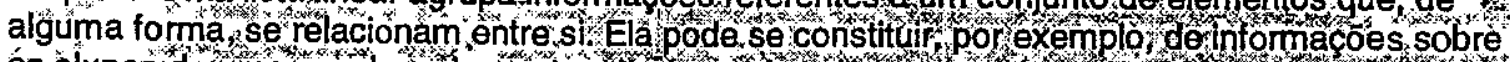
ós alunos de uma escola, sobre notas de un periodo lefivo wetc Na realidade saom numeros os . tipos de dados que podem ser descrítos porristas lineares

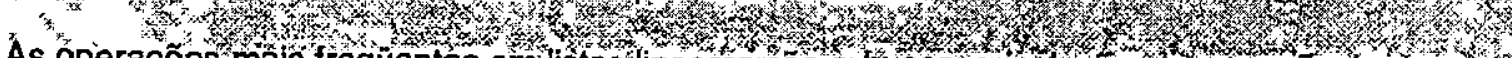
As operaçôes majs frequentes emilistas lineares são a busca, a inclusao e a remoça de um

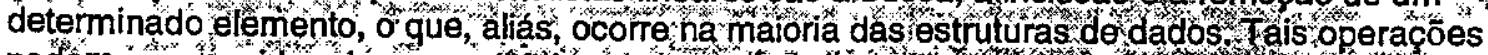

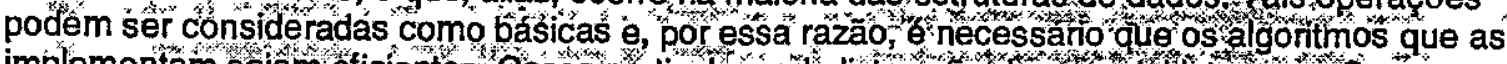

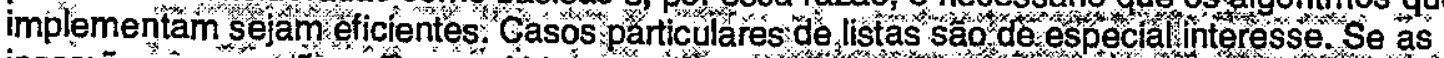

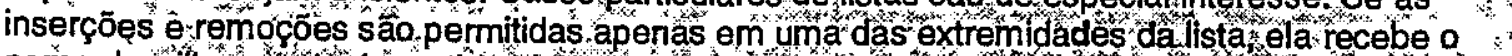

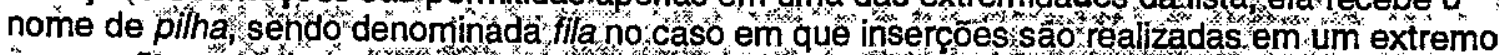
ê remoçöes em oútrô.

$\mathrm{Na}$ alocação seqüencial de listas genéricas, considera-se sempró a primeira pos ição dấ lista no

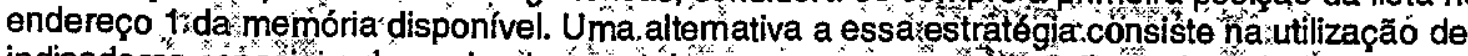

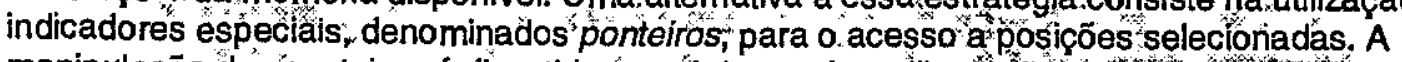
manipulação dos ponteiros é discutida nos tópicos sobre pilhas effilas".

$$
\text { 6.16 - Conteúdo do documento "Introdução" do material didático }
$$

2. quando houver um click do mouse no link Pilhas, o estudante deve ser levado ao texto da Figura 6.17. 


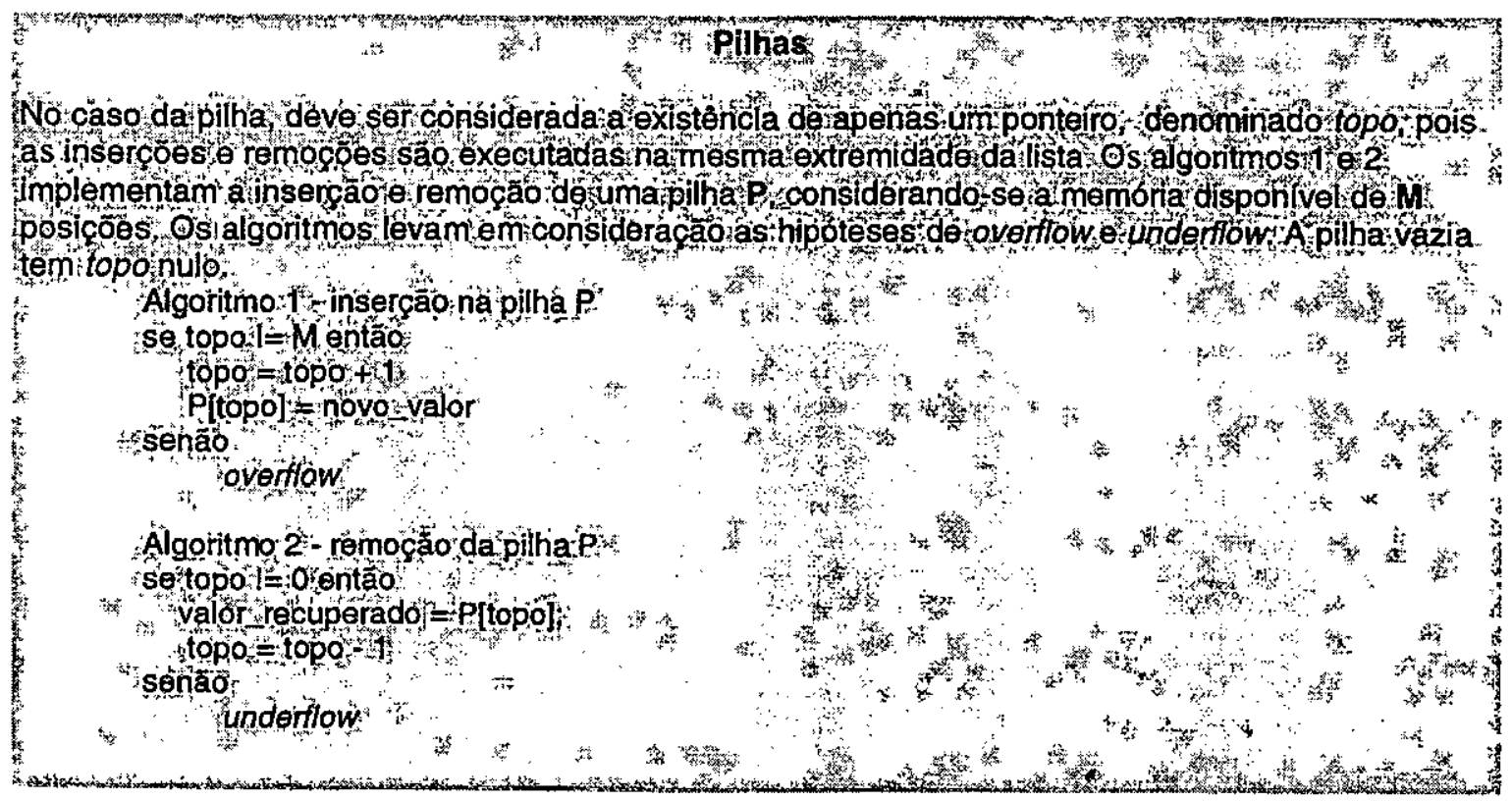

\subsection{7 - Conteúdo do documento "Pilhas" do material didático}

3. quando houver um click do mouse no link Filas, o estudante deve ser levado ao texto da Figura 6.18.

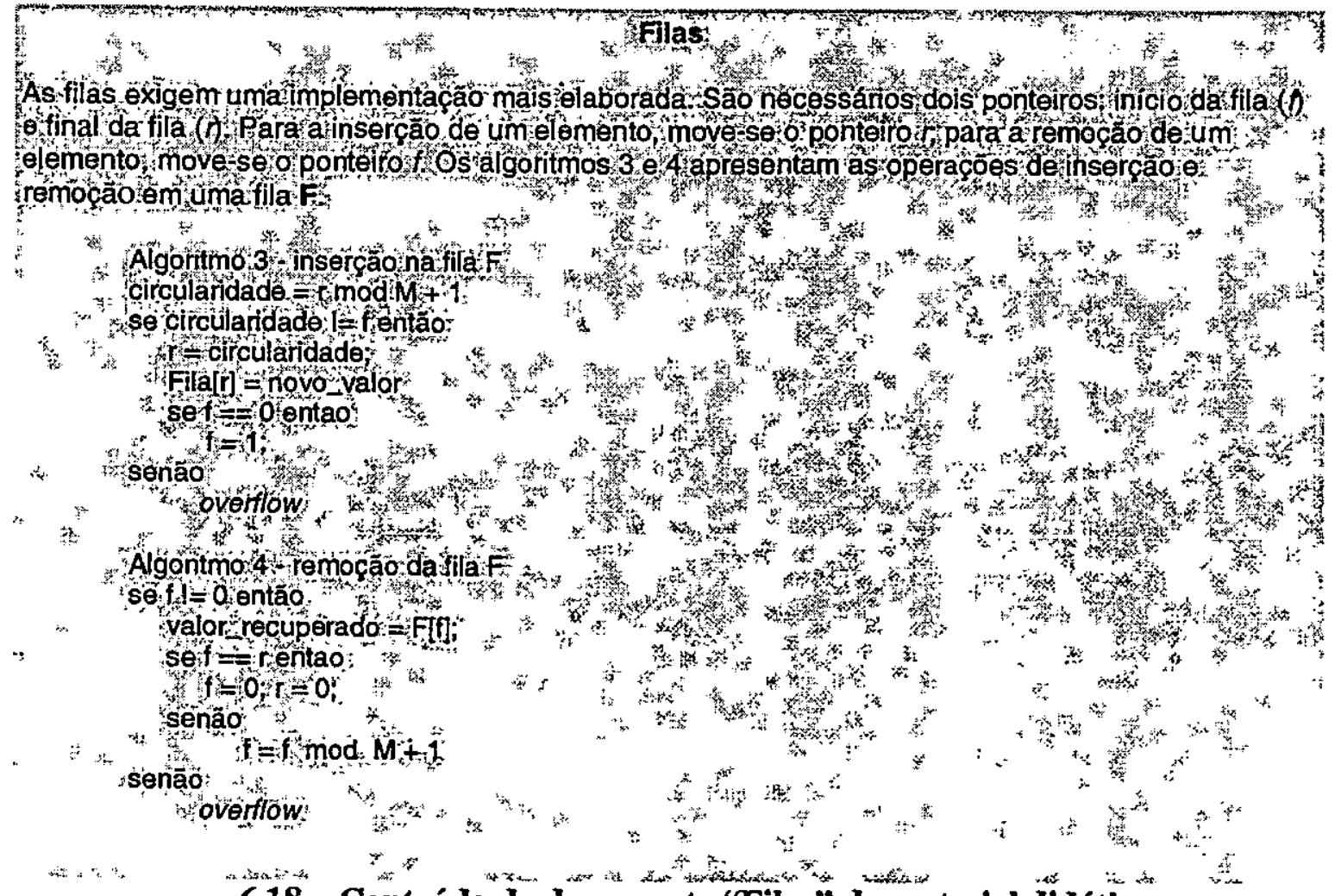

\subsection{8 - Conteúdo do documento "Filas" do material didático}

4. quando houver um click do mouse no link Lista de Exercícios, o estudante deve ser levado ao texto da Figura 6.19. 


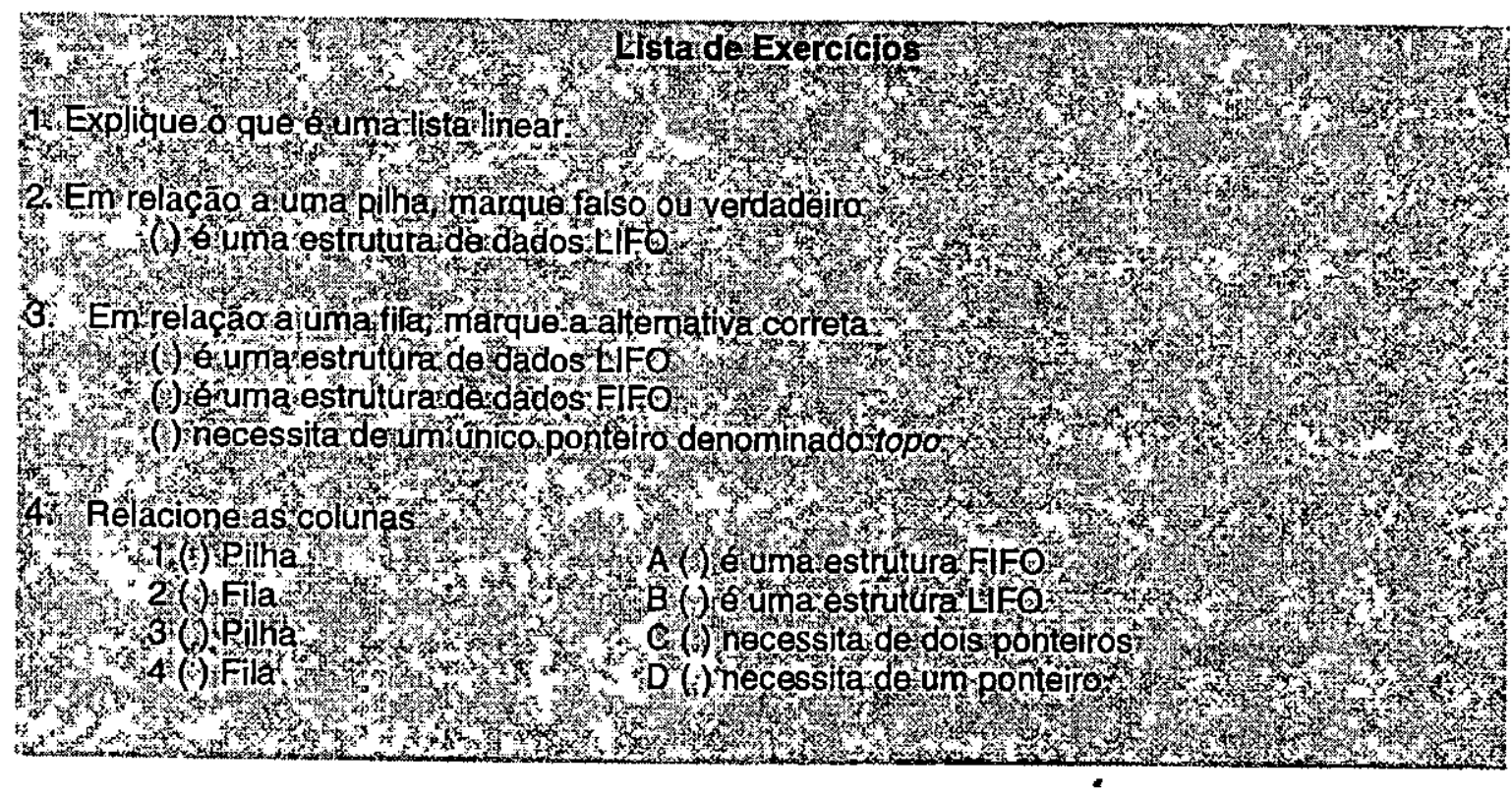

6.19 - Conteúdo do documento "Lista de Exercícios" do material didático

Finalmente, os autores devem responder a um questionário de avaliação contendo questões relativas aos seguintes tópicos:

1. sobre o processo de autoria de textos didáticos com a ferramenta HyperBuilder;

2. sobre o processo de publicação do material didático no servidor HTTP;

3. sobre a autoria de questionários de avaliação;

4. sobre a importância de se ter material didático estruturado.

Complementando, uma hipótese para teste no experimento foi definida como: "o tempo gasto para autoria e disponibilização de material didático com as ferramentas de autoria é menor que utilizando uma ferramenta de edição de documentos HTML genéricos".

\subsubsection{Os colaboradores e suas tarefas}

O experimento foi realizado com a finalidade de verificar e comparar a eficiência das ferramentas de autoria propostas em termos da facilidade de uso tanto por autores com conhecimento especializado em computação, quanto por autores sem quaisquer conhecimentos ou com conhecimentos básicos a nível de operação de um computador. 
Neste contexto, a metodologia utilizada consistiu da utilização de uma amostra de alunos e professores da Universidade de Alfenas - UNIFENAS, no sul do estado de Minas Gerais. Tal amostra foi composta da seguinte forma:

- alunos da $3^{\mathrm{a}}$. série do curso de Bacharelado em Ciência da Computação, com conhecimento avançado da linguagem HTML, inclusive sobre a utilização de forms;

- professores do Departamento de Ciência da Computação, com conhecimento da linguagem HTML e experiência na produção de homepages;

- professores do Departamento de Farmácia, com conhecimento básico em operação de microcomputadores, porém sem conhecimento algum da linguagem HTML, e com interesse pela disponibilização de material didático na WWW com vistas à criação de um curso de extensão em Homeopatia.

O experimento foi executado em três etapas distintas, sendo:

- Primeira etapa - parte 1: os alunos do curso de Bacharelado em Ciência da Computação utilizaram a ferramenta HTMLed para produzir o material didático sobre Estruturas de Dados proposto;

- Primeira etapa - parte 2: os alunos do curso de Bacharelado em Ciência da Computação utilizaram as ferramentas de autoria (HyperBuilder, QuestBuilder e TaskBuilder) para produzir o material didático sobre Estruturas de Dados proposto;

- Segunda etapa - parte 1: os professores do curso de Bacharelado em Ciência da Computação utilizaram a ferramenta HTMLed para produzir o material didático sobre Estruturas de Dados proposto;

- Segunda etapa - parte 2: os professores do curso de Bacharelado em Ciência da Computação utilizaram as ferramentas de autoria (HyperBuilder, QuestBuilder e TaskBuilder) para produzir o material didático sobre Estruturas de Dados proposto;

- Terceira etapa - parte 1: os professores do curso de Farmácia utilizaram as ferramentas de autoria (HyperBuilder, QuestBuilder e TaskBuilder) para produzir um material didático sobre Homeopatia, e que foi planejado para ser equivalente ao material didático sobre Estruturas de Dados proposto, em termos do conteúdo para autoria. 
O experimento foi realizado no Laboratório de Informática I da Universidade de Alfenas UNIFENAS, onde os colaboradores utilizaram microcomputadores com processadores PENTIUM $133 \mathrm{MHz}$, tendo o Windows'95 como sistema operacional.

\subsubsection{Apresentação e discussão dos resultados}

Em cada etapa do experimento foi medido o tempo gasto na autoria do material didático proposto, visando quantificar a eficiência do processo de autoria local e a disponibilização do material didático no ambiente distribuído da WWW. As Tabelas 6.4 a 6.8 apresentam as mediçőes de tempo observadas durante as etapas do experimento.

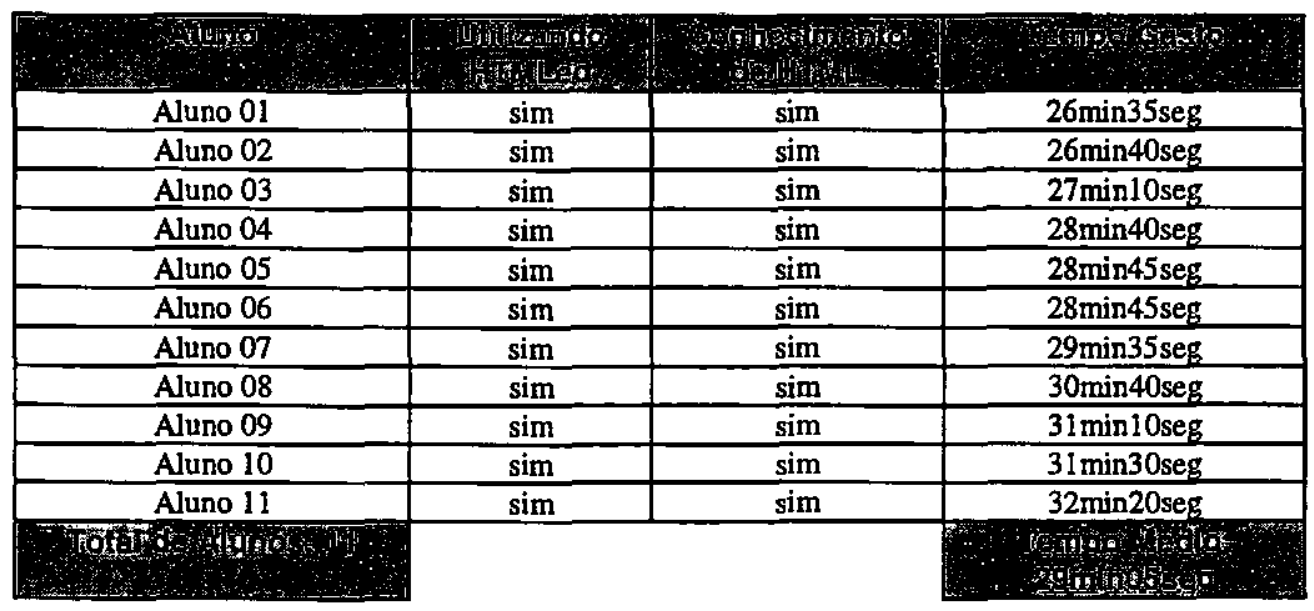

Tabela 6.4 - Tempo dos alunos utilizando a ferramenta HTMLed para autoria

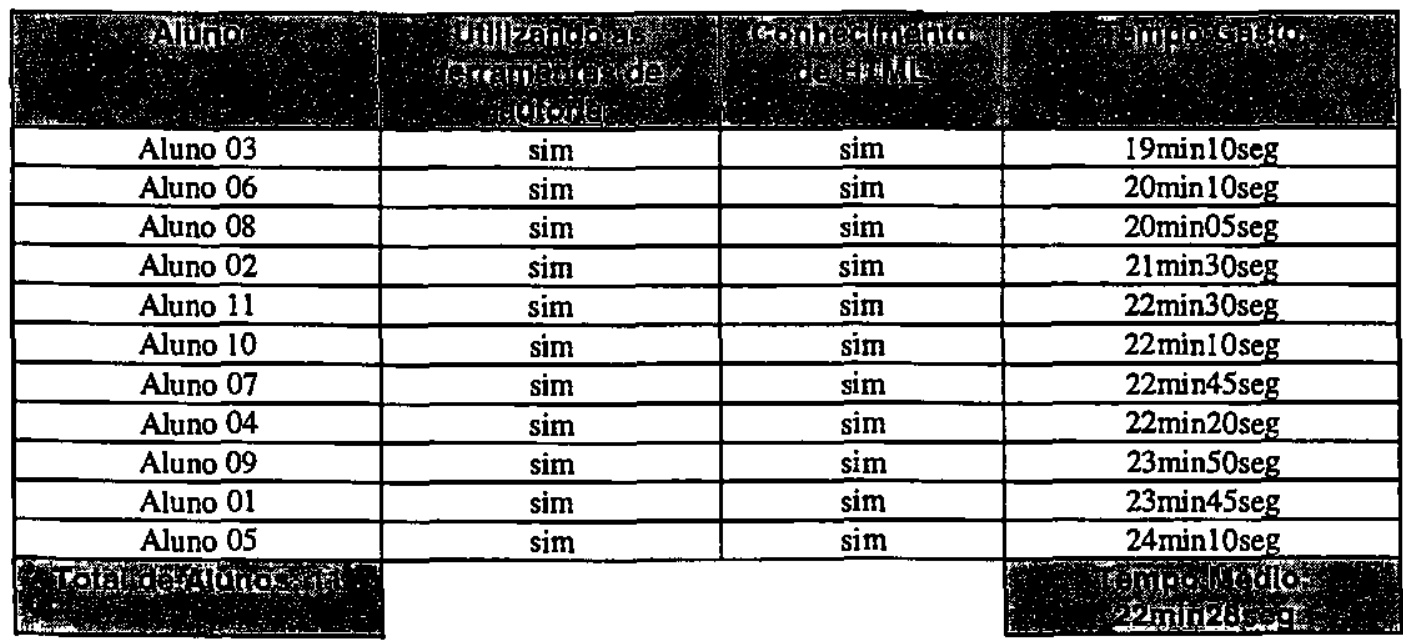

Tabela 6.5 - Tempo dos alunos utilizando as ferramenta de autoria propostas 


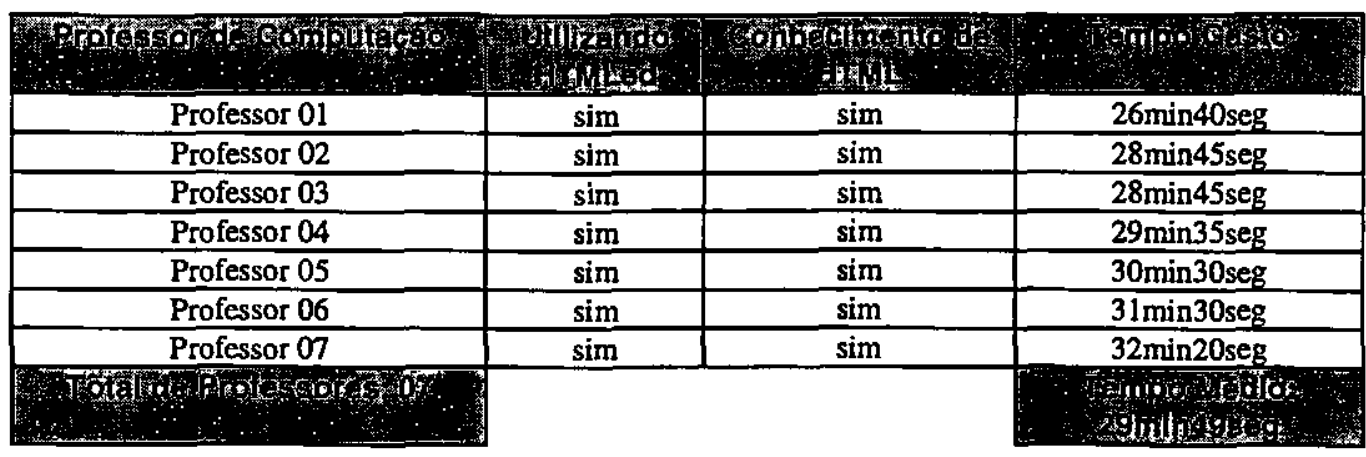

Tabela 6.6 - Tempo dos professores de computação utilizando a ferramenta HTMLed

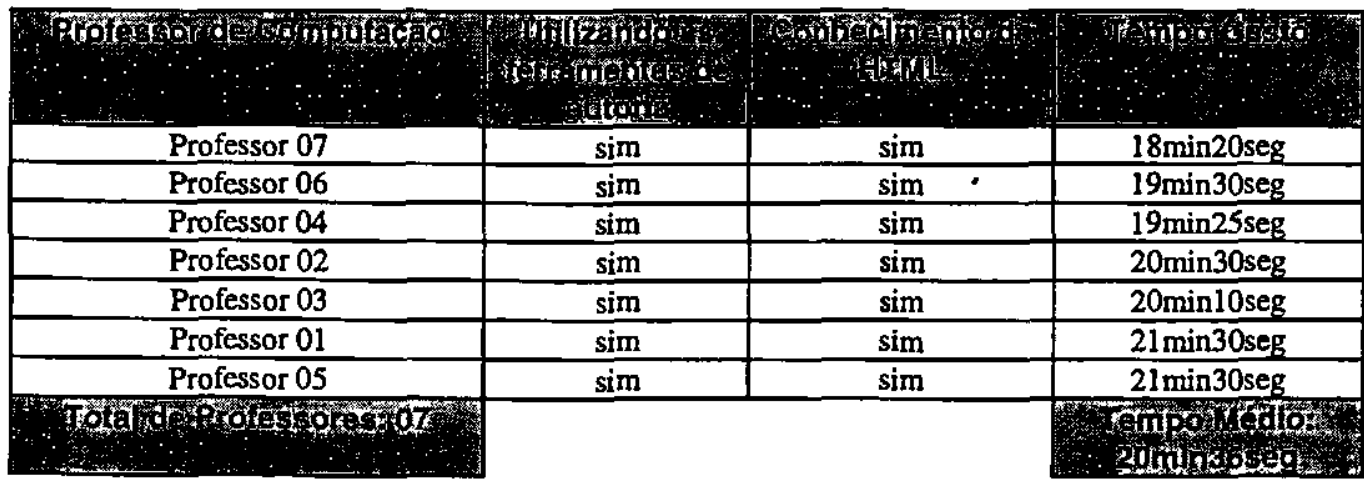

Tabela 6.7 - Tempo dos professores de Computação utilizando as ferramentas de autoria

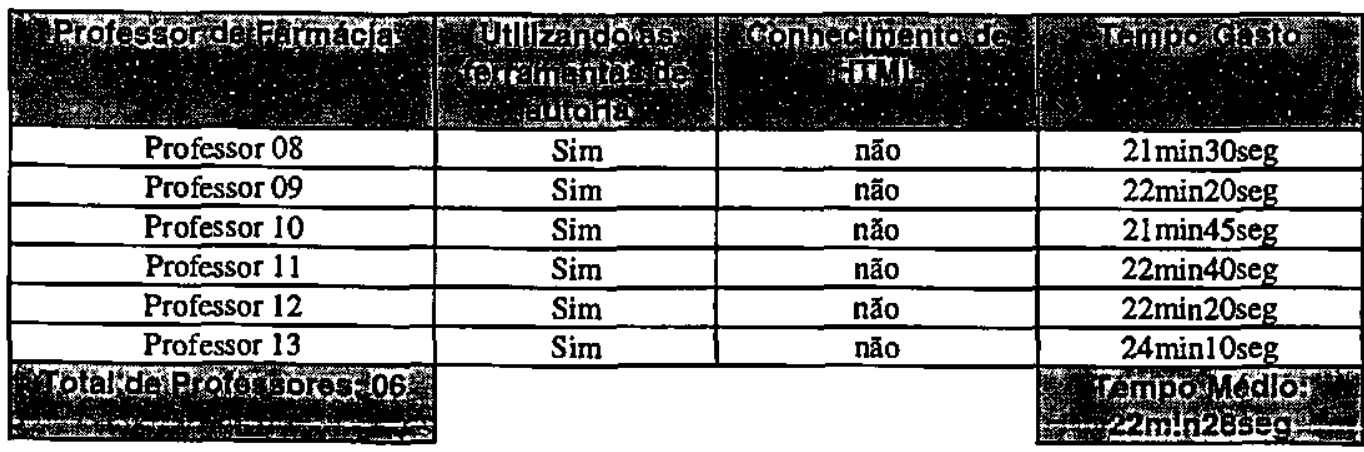

Tabela 6.8 - Tempo dos professores de Farmácia utilizando as ferramentas de autoria

No contexto do experimento, deve-se considerar que todos os colaboradores receberam instruções básicas de uso das ferramentas de autoria (HyperBuilder, QuestBuilder e TaskBuilder), durante um período de 30 (trinta) minutos antes do início do experimento. Ressalta-se, ainda, que os professores e alunos do curso de Computação já possuíam conhecimento da ferramenta HTMLed, motivo pelo qual tal ferramenta foi escolhida para uso comum. 
Em adição, conforme citado no planejamento do experimento, uma hipótese para teste no experimento foi definida como "o tempo gasto para autoria e disponibilização de material didático com as ferramentas de autoria é menor que utilizando uma ferramenta de edição de documentos HTML".

Conforme mostram as tabelas, observa-se, em todos os casos, uma redução no tempo gasto no processo de autoria utilizando-se as ferramentas propostas neste trabalho ao invés do editor HTMLed, o que, de modo geral, era o resultado esperado para comprovação da eficácia das ferramentas de autoria implementadas. Um outro resultado relevante pode ser observado ao se comparar as Tabelas 6.7 e 6.8. Observa-se que os professores do curso de Farmácia não possuíam conhecimentos sobre HTML quando foram submetidoş ao uso das ferramentas de autoria. No entanto, com o treinamento básico, conseguiram assimilar a proposta de cada uma das ferramentas e as utilizaram de maneira satisfatória. Isto pode ser verificado pela proximidade do tempo médio gasto pelos professores de Farmácia em relação aos professores e alunos de Computação.

\subsection{Considerações finais}

Neste capítulo discutiu-se as principais características da ferramenta WebCT, que pode ser considerada uma referência atual em termos de ferramental de suporte à autoria e disponibilização de material didático no ambiente WWW. Em adição, ressaltou-se as características das ferramentas desenvolvidas no contexto no qual este trabalho se insere, relacionando-as com características presentes na ferramenta WebCT. Como resultado final da comparação das ferramentas, tem-se que existe uma equivalência entre as mesmas no que tange às características funcionais, porém, ainda em termos de comparação, as ferramentas aqui reportadas apresentam uma vantagem por utilizarem um padrão aberto, no caso SGML, na formatação dos çonteúdos do material didático utilizando.

Ao final, relatou-se o planejamento de um experimento envolvendo o uso das ferramentas aqui propostas. Apresentou-se a metodologia utilizada na execução do experimento, bem como os resultados coletados em função da medição do tempo gasto para autoria de um material didático proposto. De modo geral, os resultados obtidos apontam que as ferramentas de autoria propostas 
no contexto deste trabalho foram assimiladas com facilidade tanto por autores com conhecimento em computação quanto por autores leigos, o que representa um indício aos aspectos de construção de interfaces orientadas às tarefas dos usuários, bem como o isolamento dos autores das complexidades das ferramentas usuais para autoria e publicação de material didático no ambiente WWW. Certamente, experimentos com aspectos formais mais detalhados devem ser realizados para se alcançar a validação das ferramentas implementadas.

Observa-se que, tanto a análise comparativa com a ferramenta WebCT, quanto o planejamento e execução do experimento, contribuem para a validação das ferramentas implementadas em termos de sua adequação ao domínio de aplicação ensino previamente modelado. 


\section{CONCLUSÕES}

,

\subsection{Considerações iniciais}

A investigação do uso de computadores em ambientes de ensino tornou-se relevante com a evolução dos recursos computacionais, principalmente com o advento da multimídia e, mais recentemente, com o crescente uso dos recursos hipermídia providos pelo ambiente da WWW.

A princípio, o ambiente $\mathrm{WWW}$ é visto como uma fonte potencial de informaçőes e um ponto de referência quando se deseja distribuir e facilitar o acesso a essas informações. No contexto dos ambientes de ensino, tem-se utilizado a WWW como um meio de diponibilização de conteúdos didáticos das mais diversas áreas do conhecimento.

Atualmente, muitas das ferramentas utilizadas para autoria e disponibilização de material didático na WWW foram implementadas para suporte à autoria de documentos de propósito geral, não apresentando recursos específicos para estruturação e apresentação de materiais didáticos. Em adição, para uma melhor exploração dos recursos providos pelo ambiente da WWW, é necessário o conhecimento técnico de algumas linguagens usualmente utilizadas na preparação de documentos, tais como HTML, JAVA e JAVAScript, bem como o conhecimento de alguns conceitos e ferramentas para distribuição de informações, tais como ambientes clienteservidor e serviço de transferência de arquivos entre computadores (FTP). Neste contexto, um autor deve, ainda, possuir conhecimentos especializados em programação para a WWW com vistas à construção de materiais didáticos que não se limitem apenas à apresentação de conteúdos programáticos, mas que orientem a navegação pelo usuário, bem como apresentem mecanismos de avaliação do aprendizado.

A proposta apresentada neste trabalho visou o provimento de uma arquitetura de software composta por um conjunto de ferramentas para autoria e disponibilização de material didático no ambiente da WWW. Essa arquitetura apresenta-se como altemativa, em termos de ferramental de suporte, para o isolamento do autor das complexidades das linguagens e técnicas usuais empregadas no desenvolvimento de aplicações para a WWW. Como passo inicial, uma 
modelagem do domínio de aplicação ensino foi proposta objetivando a formalização do contexto no qual as ferramentas propostas devem ser inseridas. Em adição, a abordagem em termos da estruturação dos documentos didáticos, com o uso de SGML, vem apoiar a elaboração de materiais didáticos, fazendo com que estes não se limitem apenas ao conteúdo, mas possuam relacionamentos entres os elementos que o formam. Entre os benefícios dessa abordagem, destacam-se as facilidades de identificação do material didático pelo estudante, bem como o estabelecimento de mecanismos que controlem o armazenamento, recuperação e apresentação do material para a navegação pelo estudante, além das possibilidades de intercâmbio dos conteưdos com outros ambientes de autoria e/ou apresentação.

\subsection{Contribuições}

Inicialmente, este trabalho contribuiu com a apresentação de uma modelagem do domínio de aplicação ensino, através do uso do RMM, permitindo a formalização do conjunto de ferramentas implementado no sentido de sua aplicação a um domínio definido (Pimentel, Santos Jr. \& Fortes, 1998a). Observa-se que a modelagem é relevante por apresentar a arquitetura de software inserida em um contexto de aplicação prática e não simplesmente a implementação de um conjunto de ferramentas isoladas. Nește ponto, nota-se que existem várias ferramentas para a criação de hiperdocumentos, tais como FrontPage, HTMLed e outras, que se primam por permitir a elaboração do layout e conteúdo dos hiperdocumentos, porém sem apresentar mecanismos que apoiem a inserção dos hiperdocumentos em um domínio de aplicação específico.

. Outra contribuição deste trabalho é a visão apresentada sobre documentos didáticos estruturados, através da modelagem com SGML, no sentido de facilitar o processo de elaboração de cursos e/ou aulas, sobretudo em termos do armazenamento e recuperação dos hiperdocumentos em bases de dados, além da possibilidade de reuso e intercâmbio dos hiperdocumentos com outras ferramentas de autoria e ambientes de apresentação (Pimentel, Santos Jr. \& Fortes, 1998a; Pimentel, Santos Jr. \& Fortes, 1998b; Pimentel, Santos Jr. \& Fortes, 1998c ).

A contribuição prática do trabalho é a arquitetura de software proposta com o objetivo de isolar o autor das complexidades das ferramentas (HTML, JAVA, JAVAScript, Telnet, FTP e outras) 
usualmente utilizadas para a autoria e disponibilização de documentos na WWW, conforme pode-se visualizar na Figura 7.1.

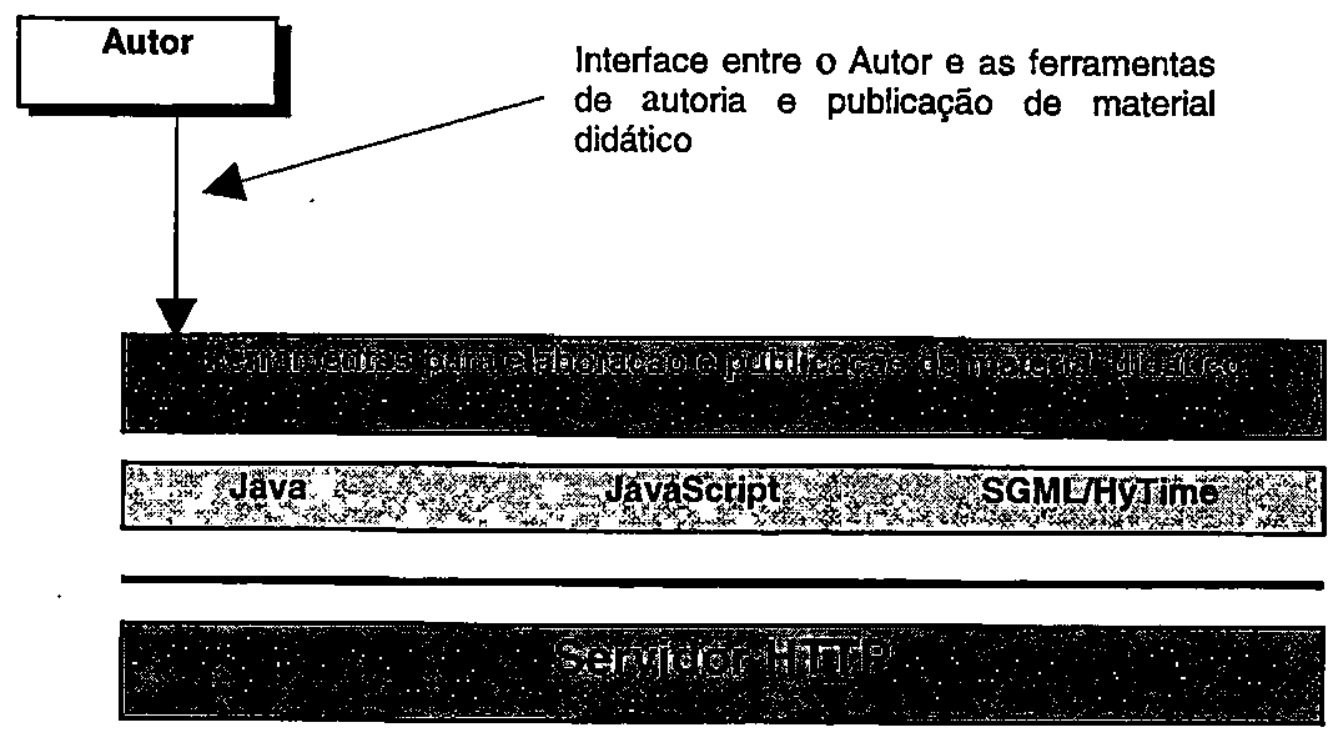

Figura 7.1 - Arquitetura básica proposta para o domínio de aplicação ensino

Considerando a arquitetura proposta, as ferramentas implementadas, através da tecnologia JAVA, correspondem às tarefas de autoria de hiperdocumentos de texto didático (HyperBuilder), autoria de questionários de avaliação do aprendizado (QuestBuilder), e autoria de exercícios baseados em textos, imagens e testes de múltipla escolha (TaskBuilder) (Pimentel, Santos Jr. \& Fortes, 1998b; Pimentel, Santos Jr. \& Fortes, 1998c). Em adição, um mecanismo para publicação do material didático no ambiente WWW foi implementado através do uso de recursos FTP fornecidos pela linguagem JAVA, permitindo assim que através da ferramenta de autoria HyperBuilder o autor faça, de forma transparente, o envio do material didático a um servidor HTTP. Finalmente, ambientes para apresentação de questionários e exercícios ao estudante foram implementados através de applets JAVA e inseridos nos documentos de texto didático formatados em conformidade com a linguagern HTML.

\subsection{Trabalhos futuros}

Considerando as ferramentas implementadas e também a análise apresentada sobre outras ferramentas existentes pode-se discutir a continuidade do trabalho aqui reportado. 
Inicialmente, pode-se realizar extensões no DTD de texto didático, visando a inserção de elementos para suporte a guided-tours e níveis mais complexos de navegação pelo estudante. Em adição, extensões podem ser feitas em termos da inserção de novos componentes estruturais, tais como glossário, bibliografia e índice analítico (Macedo, 1998). Em relação ao DTD QuestML, pode-se realizar extensões para inserção de objetos multimídia nas questões, tais como imagens, áudio e vídeo. Complementando, pode-se especificar e implementar modelos de aula na forma de templates, para que possam ser utilizados como alternativa à edição outline proposta para a ferramenta HyperBuilder (Macedo, 1998).

Num outro ponto de vista, pode-se agregar às ferramentas mecanismos de suporte ao trabalho cooperativo. Neste ponto, ferramentas para prover recursos de chat e marcação de conferências podem ser inseridas (Pimentel et al., 1998).

Mecanismos para armazenamento e recuperação de documentos didáticos em bases de dados podem ser implementados com vistas ao provimento de recursos para controle dos cursos que se deseja disponibilizar na WWW (Pires, 1998). Neste ponto, sugere-se a criação de mecanismos de autenticação do autor quando da criação e disponibilização de materiais didáticos em WebServers, e do estudante quando do acesso ao material didático. Em adição, devem ser providos também mecanismos de armazenamento de resultados dos questionários de avaliação on-line aplicados ao estudante. Neste ponto, sugere-se que o acesso ao material didático seja diretamente condicionado aos resultados de avaliações armazenados em uma base de dados.

Finalmente, processos de avaliação da eficácia das ferramentas implementadas devem ser realizados. Neste contexto, as ferramentas de autoria implementadas devem ser utilizadas na elaboração de cursos, com vistas à obtenção do grau de usabilidade da interface com o usuário, e também em termos de funcionalidade.

\subsection{Considerações finais}

Neste capítulo foram apresentadas as conclusões deste trabalho, ressaltando-se também alguns dos trabalhos que podem ser realizados como continuidade deste. 
De modo geral, o desenvolvimento de pesquisas que investigam a aplicação da informática na educação tem ganho cada vez mais espaço na comunidade científica de ciência da computação. Neste contexto, é válido ressaltar que o crescimento de uso de sistemas computacionais em ambientes de ensino tem sido observado também ao nível mundial, principalmente com o advento da Internet e, especialmente, com a disseminação do ambiente WWW. Neste contexto, o desenvolvimento de ferramentas que, de forma transparente, facilitem a autoria e disponibilização de material didático no ambiente WWW, torna-se relevante, visto que na maioria dos casos o autor não possui conhecimentos especializados em computação.

Em adição, a estruturação dos documentos que compõem o material didático, através do uso de padrőes abertos, facilita o acesso e navegação pelo estudante, bèm como permite o reuso e intercâmbio dos documentos com outras ferramentas de autoria e/ou ambientes de apresentação. No caso da implementação das ferramentas, o uso da linguagem JAVA apresenta-se como um fator importante por permitir a adequação do código a diferentes plataformas. A importância desse trabalho foi reconhecida na comunidade pela aceitação, no Brasil e no exterior, de três trabalhos (Pimentel, Santos Jr. \& Fortes, 1998a; Pimentel, Santos Jr. \& Fortes, 1998b; Pimentel, Santos Jr. \& Fortes, 1998c). 


\section{REFERÊNCIAS BIBLIOGRÁFICAS}

(AulaNet, 1997)

(Barker, 1992)

(Beaumont, 1995)

(Borges \& Lima, 1997)

(Botafogo et al., 1992)

(Castro, 1997)

(Cattani, 1997)

(CGI, 1997)
Projeto AulaNet. Disponível on-line em: URL: http://aulanet.les.inf.puc-rio.br/aulanet/. Visitado em 20 de maio de 1998.

Barker, P.: COMPUTER-BASED TRAINING: AN INSTITUTIONAL APPROACH. Education \& Computing, 1992.

Beaumont, I. et al.: EDUCATIONAL APPLICATIONS OF ADAPTATIVE HYPERMEDIA. Interact'95, 1995.

Borges, R.C. de M. \& Lima, J.V.: INTERFACE DE NAVEGAÇÃO EM HIPERDOCUMENTOS PARA APLICAÇÕES EDUCAIONAIS. Anais do VIII Simpósio Brasileiro de Informática na Educação. São José dos Campos, Brasil, novembro de 1997.

Botafogo, R., Rivlin, E. \& Schneiderman, B.: STRUCTURAL ANALYSIS OF HYPERTEXTS: IDENTIFYING HIERARCHIES AND USEFUL METRICS. The ACM Transactions of Information Systems V.2, N.10, April, 1995.

Castro, M.A.S. et al: INFRA-ESTRUTURA DE SUPORTE A EDITORAÇÃO DE MATERIAL DIDÁTICO UTILIZANDO MULTIMÍDIA. Revista Brasileira de Informática na Educaçăo, ISSN 1414-5685, No. 01, setembro de 1997.

Cattani, A.: PROJETO E IMPLEMENTAÇÃO DE UM SITE INTERATIVO PARA ALUNOS DE $5^{\mathrm{a}}$. SÉRIE. Anais do VIII Simpósio Brasileiro de Informática na Educação. São José dos Campos, Brasil, novembro de 1997.

CGI Specification. Disponível on-line em URL:http://www.w3.org/CGI. Visitado em 10 de julho de 1997. 
(Cláudio et al., 1997)

(Conklin, 1987)

(CUQuiz, 1995)

(eWeb, 1996)

(Fortes, 1996)

(Gaines, 1996)

(Garzotto, 1993)

(Greenfield, 1987)

(Halasz \& Schwartz, 1994)

(Halasz, 1988)

(Herwijnen, 1994)
Cláudio, D.M.: USANDO RECURSOS COMPUTACIONAIS NO ENSINO DE MATEMÁTICA. Anais do VIII Simpósio Brasileiro de Informática na Educação. São José dos Campos, Brasil, novembro de 1997.

Conklin, J.: A SURVEY ON HYPERTEXT. Computer, January, 1987.

CUQuiz Homepage. Disponível on-line em: URL: http://kcox.cs.cityu.edu.hk/quiztest. Visitado em 05 de março de 1998.

eWeb Homepage. Disponível on-line em: URL: http://ewebsite.com. Visitado em 20 de dezembro de 1997.

Fortes, R.P.M.: ANÁLISE E AVALIAÇÃO DE HIPERDOCUMENTOS: UMA ABORDAGEM BASEADA NA REPRESENTAÇÃO ESTRUTURAL. Tese de Doutorado, Instituto de Física de São Carlos IFSC-USP, 1996.

Gaines, Brian R. et al.: UTLITY, USABILITY AND LIKEABILITY: DIMENSIONS OF THE NET AND WEB. Proceedings of WebNet'96, 1996.

Garzotto, F. et al.: HDM: A MODEL-BASED APPROACH TO HYPERTEXT APPLICATION DESIGN. The ACM Transactions of Information Systems. V.11, N.2, January, 1993.

Greenfield, P. M.: ELETRONIC TECHNOLOGIES, EDUCATION, AND COGNITIVE DEVELOPMENT. Lawrence Erlbaum Associates, 1987.

Halasz, F.G. \& Schwartz, M.: THE DEXTER HYPERTEXT REFERENCE MODEL. Communications of the ACM V.37, N.2, February, 1994.

Halasz, F.: SEVEN ISSUES FOR NEXT GENERATION HYPERMEDIA. Communications of the ACM, 1998.

Herwijnen, E. van: PRATICAL SGML. Kluwer Academic Pub, $2^{\mathrm{a} e d .,} 1994$. 
(HTML, 1992)

(HTML, 1997)

(HTTP, 1992)

(Isakowitz, 1995)

(ISO, 1986)

(Kidlink, 1996)

(Kutova, 1998)

(Lima et al., 1997)

(Lucena, 1997)

(Macedo, 1998)
HTML Specification. Disponível on-line em URL:http://www.w3.org/MarkUp. Visitado em 10 de julho de 1997.

HTML Tutorial. Disponível on-line em URL: http://www.icmc.sc.usp.br/manuals/HTML/intro.html. Visitado em 10 de julho de 1997.

HTTP Specification. Disponível on-line em URL: http://www.w3.org/Protocols/HTTP/HTTP2.html.

Visitado em 20 de julho de 1997.

Isakowitz, T. et al.: RMM: A METHODOLOGY FOR STRUCTURED HYPERMEDIA DESIGN. Communications of the ACM V.38, N.8, August, 1995.

ISO/IEC IS 8879. Information Processing - Text and Office Systems - Standards Generalized Markup Language (SGML), 1986.

Projeto Kidlink no Brasil. Disponível on-line em: URL: http://www.venus.puc-rio.br/kids. Visitado em 20 de maio de 1998 .

Kutova, M.A.S.: FERRAMENTAS PARA SUPORTE AO TRABALHO COOPERATIVO EM AMBIENTES DE ENSINO. Monografia de Qualificação. ICMC-USP, abril de 1998.

Lima, J.V. et al.: EXPERIÊNCIA DO USO DE UMA FERRAMENTA WWW PARA O ENSINO INTERATIVO DE LÍNGUA PORTUGUESA. Anais do VIII Simpósio Brasileiro de Informática na Educação. São José dos Campos, Brasil, novembro de 1997.

Lucena, C.J.P. de: Curso sobre Sociedade da Informação. Disponível on-line em: URL: http://www.les.inf.pucrio.br/socinfo. Visitado em 10 de maio de 1998.

Macedo, A. A.: DOCUMENTOS DIDÁTICOS ESTRUTURADOS. Monografia de Qualificação. ICMCUSP, abril de 1998.

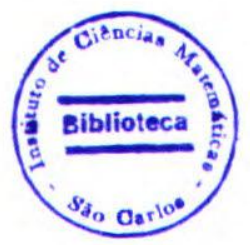


(Menezes et al., 1997)

(Microsoft, 1995)

(Moreira et al., 1995)

(Morelli, 1997)

(Nielsen, 1995)

(Nunes \& Fortes, 1997)

(Nunes et al., 1997)

(Pimentel \& Buford, 1996)

(Pimentel \& Hagui, 1996)
Menezes, C.S. et al.: QSabe - TROCANDO EXPERIENCIAS SOBRE INFORMÁTICA EDUCATIVA EM UMA REDE DE EDUCADORES. Anais do VIII Simpósio Brasileiro de Informática na Educação. São José dos Campos, Brasil, novembro de 1997.

Microsoft Corporation. THE MICROSOFT OFFICE, MICROSOFT POWER POINT GUIDE. Microsoft Press, 1995.

Moreira, E.S.; Nunes, M.G.V. \& Pimentel, M.G.C.: DESIGN ISSUES FOR A DISTRIBUTED HYPERMEDIA-BASED TUTORING SYSTEMS (HyDTS). Proceedings of the International Conference on Computer Application in Industry, dezembro, 1995.

Morelli, A.F.: PROJETO NetAULA COMPLEMENTAÇÃO DE AULAS PELA INTERNET. Anais do VIII Simpósio Brasileiro de Informática na Educação. São José dos Campos, Brasil, novembro de 1997.

Nielsen, J.: MUTIMEDIA AND HYPERTEXT THE INTERNET AND BEYOUND. Academic Press, 1995.

Nunes, M.G.V. \& Fortes, R.P.M.: ROTEIROS EM APLICAÇÕES NO ENSINO: A QUESTÃO DO CONTROLE DO LEITOR. Anais do III Workshop em Sistemas Multimídia e Hipermídia, São Carlos, 1997.

Nunes, M.G.V.: SASHE: AUTORIA DE APLICAÇÕES HIPERMÍDIA PARA O ENSINO. Anais do VIII Simpósio Brasileiro de Informática na Educação. São José dos Campos, Brasil, novembro de 1997.

Pimentel, M. G. C. \& Buford, J.: NON-INVASIVE IMPROVEMENTS TO HYPERLINKING WITH HTML. Proceedings of WebNet'96, 1996.

Pimentel, M.G.C. \& Hagui, S. H.: USANDO A WWW COMO FERRAMENTA DE APOIO AO ENSINO. Anais do VII Simpósio Brasileiro de Informática na Educação, Belo Horizonte, 1996. 
(Pimentel et al., 1998)

(Pimentel, 1997)
Pimentel, M.G.C.: HIPERDOCUMENTOS ESTRUTURADOS NO SUPORTE AO TRABALHO COOPERATIVO EM SISTEMAS ABERTOS DISTRIBÚIDOS. Anais do XXV Seminário Integrado de Software e Hardware. Belo Horizonte, Brasil, agosto de 1998.

Pimentel, M.Gomes: MAPHE: METODOLOGIA DE APOIO A PROJETOS DE HIPERTEXTOS EDUCACIONAIS. Anais do VIII Simpósio Brasileiro de Informática na Educação. São José dos Campos, Brasil, novembro de 1997.

(Pimentel, Santos Jr \& Fortes, Pimentel, M.G.C.; Santos Jr, J.B. dos; Fortes, R.P.M.: 1998a)

MODELAGEM, AUTORIA E APRESENTAÇÃO DE DOCUMENTOS DIDÁTICOS ESTRUTURADOS. Anais do IV Simpósio Brasileiro de Sistemas Multimídia e Hipermídia. Rio de Janeiro, Brasil, maio de 1998.

(Pimentel, Santos Jr \& Fortes, Pimentel, M.G.C.; Santos Jr, J.B. dos; Fortes, R.P.M.: 1998b)

TOOLS FOR AUTHORING AND PRESENTING STRUCTURED TEACHING MATERIAL IN THE WWW. Proceedings of the WebNet 98 Conference. Orlando, USA, 1998-november.

(Pimentel, Santos Jr \& Fortes, Pimentel, M.G.C.; Santos Jr, J.B. dos; Fortes, R.P.M.: 1998c) TOOLS FOR AUTHORING AND PRESENTING STRUCTURED TEACHING MATERIAL IN THE WWW. Extended version to appear in Journal of Universal Computer Science, USA, 1998.

(Pires, 1998)

Pires, D.F.: MODELAGEM E ARMAZENAMENTO DE DOCUMENTOS DIDÁTICOS ESTRUTURADOS EM NA WWW. Plano de Pesquisa FAPESP, março de 1998.

(Preece, 1994)

(Pressman, 1995)

(qForm, 1995)

Preece, J. et al.: HUMAN-COMPUTER INTERACTION. Addisson-Wesley, 1994.

Pressman, R. S.: ENGENHARIA DE SOFTWARE. Makron Books, 1995.

QForm HOMEPAGE. Disponível on-line em: URL: http://www.satlab.hawaii.edu/space/hawaii/qform.html. Visitado em 20 de fevereiro de 1998. 